University of Louisville

ThinkIR: The University of Louisville's Institutional Repository

Electronic Theses and Dissertations

8-2017

\title{
The role of HIF-1 $\alpha$ in intestinal epithelial barrier function in alcoholic liver disease.
}

Tuo Shao

University of Louisville

Follow this and additional works at: https://ir.library.louisville.edu/etd

Part of the Medical Pharmacology Commons

\section{Recommended Citation}

Shao, Tuo, "The role of HIF-1 $\alpha$ in intestinal epithelial barrier function in alcoholic liver disease." (2017). Electronic Theses and Dissertations. Paper 2742.

https://doi.org/10.18297/etd/2742

This Doctoral Dissertation is brought to you for free and open access by ThinkIR: The University of Louisville's Institutional Repository. It has been accepted for inclusion in Electronic Theses and Dissertations by an authorized administrator of ThinkIR: The University of Louisville's Institutional Repository. This title appears here courtesy of the author, who has retained all other copyrights. For more information, please contact thinkir@louisville.edu. 


\title{
THE ROLE OF HIF-1a IN INTESTINAL EPITHELIAL BARRIER FUNCTION IN ALCOHOLIC LIVER DISEASE
}

\author{
BY \\ TXR SKDR \\ M.S. in Wenzhou Medical University, 2014
}

\begin{abstract}
A Dissertation
Submitted to the Faculty of the

School of Medicine of the University of Louisville

for the Degree of
\end{abstract}

Doctor of Philosophy in Pharmacology and Toxicology

Department of Pharmacology and Toxicology

University of Louisville

Louisville, Kentucky

August 2017 

THE ROLE OF HIF-1 $\alpha$ IN INTESTINAL EPITHELIAL BARRIER FUNCTION IN ALCOHOLIC LIVER DISEASE

BY

TXR SKDR

A ' IMHUVURQRSSSIRYHG

JULY $7 \square 2017$

by the following Dissertation Committee:

\begin{tabular}{l}
\hline Dr. Wenke Feng \\
\hline Dr. Craig J. McClain \\
\hline Dr. Zhao-Hui Song Lu Cai \\
\hline Dr. Zhao-Hui Song \\
\hline Dr. G. Rafel Fernandez-Botran
\end{tabular}




\section{ACKNOWLEDGEMENTS}

The entire PhD study is a fulfilling yet challenging journey, and I could never finish it without the support of a number of people. I would like to take this opportunity to thank my thesis mentor, Dr. Wenke Feng, who has always been supportive and encouraging during my three-year graduate life. The thesis committee members, Dr. Lu Cai, Dr. Zhao-Hui Song, Dr. Craig J. McClain and Dr. G. Rafael Fernandez-Botran, have also provided tremendous help on my graduate research and thesis writing. I especially want to thank Dr. Xiaokun Li, who introduced Dr. Feng to me, and built up the partnership in Pharmacology \& Toxicology between Wenzhou Medical University and University of Louisville. It has been an unforgettable experience to work with all the people in the Feng lab and I have learned a lot from all of them.

Most importantly, I want to thank my parents--without their encouragement and great love, I could never have finished my Ph.D. I also need to thank all of my friends in Louisville, I will miss you and I cannot thank you enough for all of your help. Finally, none of this would have been possible without the unconditional love and support from my wife, Rui Wang, who has always been here for me. And many thanks to Marion McClain for the manuscript proofreading. 


\begin{abstract}
THE ROLE OF HIF-1a IN INTESTINAL EPITHELIAL BARRIER FUNCTION IN ALCOHOLIC LIVER DISEASE
\end{abstract}

Tuo Shao

JULY 7, 2017

Hypoxia inducible factor $1 \alpha$ (HIF1 $\alpha)$ is an oxygen-responsive subunit. HIF-1 $\alpha$ plays a pivotal role in many pathophysiological processes. In addition to oxygen availability, HIF-1 $\alpha$ can be regulated by multiple other factors in response to various pathophysiological processes. Previous studies showed that hepatic HIF-1 $\alpha$ could be beneficial or harmful in experimental alcoholic liver disease (ALD). However, the role of intestinal HIF-1 $\alpha$ in ALD has not yet been studied. Given the critical role of the gut-liver axis in ALD, it is important to elucidate the role of intestinal epithelial HIF-1 $\alpha$ in ALD.

In the first chapter, we used wide type (WT) and intestinal epithelial-specific HIF-1a knockout (IEhif-1 $\alpha^{-/ /}$) mice to build chronic ALD model. Alcohol feeding significantly increased serum levels of ALT and LPS, hepatic triglyceride concentration, and liver injury in the IEhif-1 $\alpha^{-/-}$mice compare with WT mice. Alcohol exposure resulted in greater reduction of the expression of intestinal 
epithelial tight junction proteins and antimicrobial substance in IEhif-1 $1{ }^{-/-}$mice. Bacterial analysis of the fecal samples showed an increased dysbiosis with a significantly decreased firmicutes/bacteroidetes ratio in IEhif-1 $\alpha^{-/-}$mice compared to the WT mice exposed to alcohol.

In the second chapter, we used a more severe intestinal damage modeldextran sodium sulfate (DSS) induced colitis with binge ALD model in the same mice. DSS treatment alone did not affect liver function in both WT and IEhif-1 $1 \alpha^{-/-}$ mice. However, serum ALT, AST and LPS levels were significantly elevated in DSS + alcohol treatment groups, and these elevations were more pronounced in IEhif-1 $1 \alpha^{-/-}$mice. DSS induced a marked increase in CRAMP expression in WT mice. However, this elevation was impaired in the IEhif-1 $\alpha^{-/ /}$mice. EtOH exposure eliminated the increased of CRAMP both in WT and IEhif-1 $\alpha^{-/ /}$mice. Therefore, we used global CAMP ${ }^{\sim-}$ mice to identify our hypothesis. As we expected, binge alcohol on colitis enhance liver injury in $\mathrm{CAMP}^{-/-}$mice compared with WT mice. In summary, our results demonstrate that intestinal HIF1a is required for the adaptation response to alcohol exposure-induced changes in intestinal microbiota and barrier function associated with elevated endotoxemia and hepatic steatosis and injury. 


\section{TABLE OF CONTENTS}

PAGE

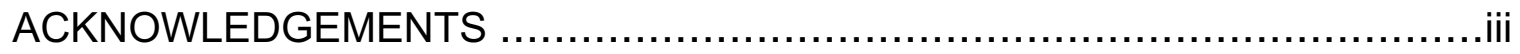

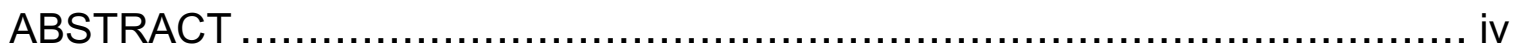

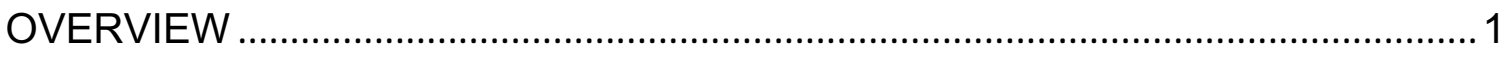

\section{CHAPTER I}

1. Title: Intestinal HIF-1a Deletion Exacerbates Alcoholic Liver Disease through Inducing Intestinal Dysbiosis and Barrier Dysfunction

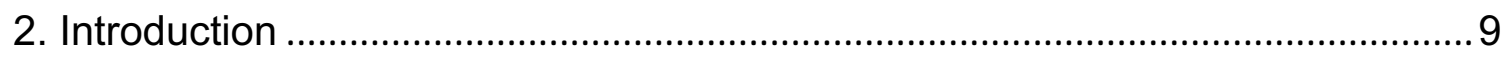

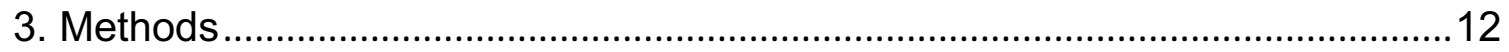

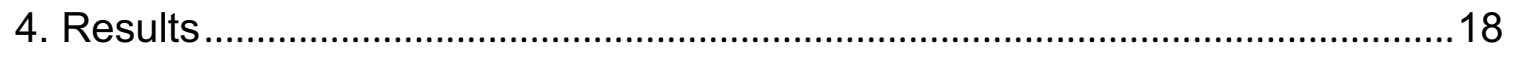

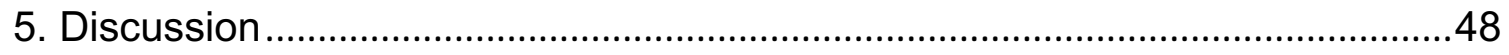

\section{CHAPTER II}

1. Title: DSS-induced Intestinal Damage Exacerbates Liver Injury by Acute Alcohol Exposure in Mice: Role of Intestinal Hypoxia-inducible Factor 1a

2. Introduction 


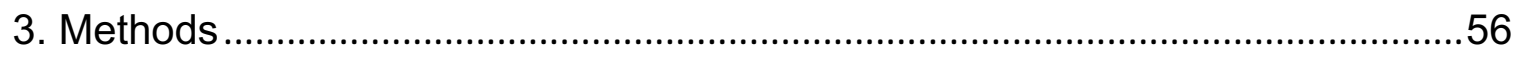

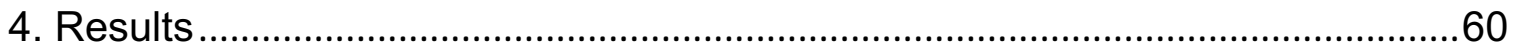

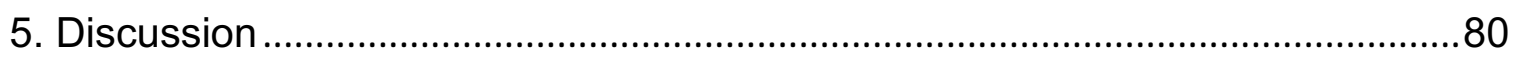

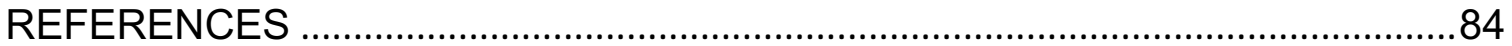

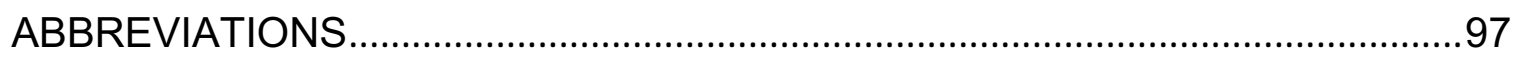

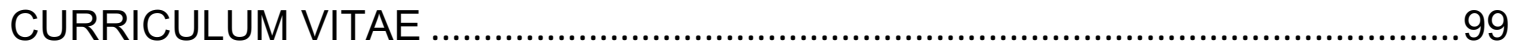




\section{OVERVIEW}

Alcohol intake remains one of the most important cause of liver cirrhosis in the Western world. The causal association between alcohol intake and the development of ALD has been well demonstrated. Alcohol is commonly consumed worldwide and is associated with a spectrum of liver injury including simple steatosis or fatty liver, alcoholic hepatitis, fibrosis, and cirrhosis $[1,2]$. Hepatic steatosis is present in more than $90 \%$ of heavy drinkers, is reversible with abstinence. However, with continued alcohol intake, alcoholic hepatitis (AH) can be occurred. The prognosis of $\mathrm{AH}$ is variable, with nearly $100 \%$ survival in mild cases as compared to high short-term mortality among the most severe cases. With continued excessive alcohol consumption, patients are at risk for the development of fibrosis and cirrhosis. Twenty to $40 \%$ of patients with steatosis will develop to fibrosis, of which $8-20 \%$ will progress cirrhosis. As in other liver diseases, patients with cirrhosis are at risk for hepatocellular carcinoma (HCC) $[3,4]$. Despite the profound impact of ALD on public health, relatively few advances have been made in this field. The disease pathogenesis remains incompletely understood, and medical treatment for ALD has not changed significantly in 40 years.

Oxygen delivery to the liver and small intestine is significantly decreased following alcohol ingestion, while the oxygen extraction and consumption are 
significantly enhanced in both organs $[5,6]$. Hypoxia plays a role in pathophysiological conditions such as inflammation, oxidative stress, apoptosis, and dysregulated barrier function and innate immunity [7-9]. The hypoxia inducible transcription factors (HIFs) are key elements in the response to hypoxia in virtually all cells and tissues. HIF consists of an $\alpha$ subunit and a $\beta$ subunit. Three $\alpha$ subunits, termed HIF1 $\alpha$, HIF2 $\alpha$, and HIF3 $\alpha$, have been described in humans, mice, and rats; all bind to a common $\beta$ subunit named, alternatively, HIF1 $\beta$, or the aryl-hydrocarbon-nuclear receptor translocator [ARNT] [10]. HIF-1, the major transcriptional factor activated during hypoxia, is known to regulate hypoxia-associated responses [11]. Under normoxic conditions, HIF-1a is rapidly degraded in a ubiquitin-dependent manner, whereas it escapes degradation under conditions of hypoxia. Accumulated HIF-1 $\alpha$ dimerizes with HIF-1 $\beta$, translocates to the nucleus, and regulates numerous gene transcription programs $[8,9,12,13]$.

HIF stabilization has been reported in acute and chronic alcoholics and in a murine model of ALD [14-20]. Alcohol-induced fatty liver shares similar clinical features and underlying pathogenesis with Non-alcoholic fatty liver disease (NAFLD). Therefore, it is likely that HIF-1 $\alpha$ contributes to the development of hepatic steatosis in ALD as well as in NAFLD. However, the role of HIF-1 $\alpha$ in the pathogenesis of ALD has not clear. To date, there are only six reports describing the involvement of HIF-1 $\alpha$ in alcohol-associated hepatic steatosis, and some results are contradictory. 


\section{Hypoxia Inducible Factor 1a regulation: A Common Mechanism of Lipid}

\section{Accumulation in ALD?}

Multiple lines of evidence show that hypoxia and/or HIF may play a role in hepatic lipid accumulation. Two studies have implied a role for hypoxia in altering lipid storage in ALD, but their finding are contradictory [14,15]. Both studies used

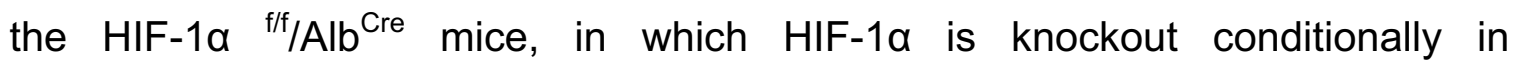
hepatocytes. The earlier study demonstrated that compared with WT mice, deficiency of HIF-1a produced less hepatic steatosis [15]. This study demonstrated that HIF-1 $\alpha$ protein expression and its DNA-binding activity was increased by monocyte chemotactic protein (MCP)-1 which was an upstream activator. In contrast, the later study demonstrated that alcohol feeding increased hepatic steatosis and serum triglyceride concentration in hepatic HIF-1a KO mice [14]. The data showed that lipogenic genes, such as acyl-CoA carboxylase (ACC)-1, fatty acid synthase (FAS), and stearoyl-CoA desaturase (SCD)-1 were enhanced in HIF1a KO than in WT mice [14]. These lipogenic genes are regulated by sterol regulatory element-binding protein (SREBP)-1c, which is repressed by differentiated embryo chondrocyte 1 (DEC1). DEC1 is one of transcriptional targets of HIF-1 $\alpha$. The result demonstrated that DEC1 was increased in alcohol-fed WT but not HIF1a KO mice. Furthermore, prolyl hydroxylase (PHD) inhibitor dimethyloxaloylglycine (DMOG), were able to decrease steatosis in HIF-1a KO mice [14].

The discrepant results obtained from the two studies may be due to differences in the experimental details, for example, intestinal microbiome 
differences of animals, the different dose of ethanol, and the different control mice. Furthermore, these two studies only focused on determine the role of HIF in alcohol-induced steatosis, which is an early manifestation of ALD. The role of HIF signaling in other forms of ALD has not been studied. It is important to elucidate whether and how HIFs may play a role in the disease progression in future studies.

\section{Hepatic Hypoxia Inducible Factor 1 $\alpha$ and Cytochrome P450 2E1 in ALD}

Ethanol is metabolized to acetaldehyde by alcohol dehydrogenase (ADH), ethanol-inducible cytochrome P450 2E1 (CYP2E1), and catalase (CAT); acetaldehyde is further oxidized to acetate by mitochondrial aldehyde dehydrogenase (ALDH2) [21,22]. CYP2E1 potentiates ethanol-induced oxidative stress and fatty liver, and at high levels, plays a role in ethanol-induced liver damage as shown by experiments using CYP2E1 inhibitors [23,24]. CYP2E1 has been examined in ethanol-induced hypoxia in the liver [13]. Studies also showed that activation of HIF1 $\alpha$ could either protect against or promote CYP2E1dependent toxicity.

The study by Wang, XD et al. demonstrated that CYP2E1 knock-in (KI) potentiates ethanol-induced oxidative stress, fatty liver and liver injury [13]. This study showed that protein levels of HIF1a and downstream targets of HIF-1a activation were elevated in the ethanol-fed CYP2E1 KI mice compared to the WT and CYP2E1 KO mice. Levels of HIF prolyl hydroxylase 2 were reduced in the ethanol-fed CYP2E1 KI mice, along with the increases in HIF-1 $\alpha$. In situ double 
staining showed that pimonidazole and CYP2E1 were co-localized to the same area of injury in the hepatic centrilobular tissue. Increased protein levels of HIF$1 \alpha$ were also found after acute ethanol treatment of the $\mathrm{KI}$ mice. Treatment of HepG2 E47 cells (which express CYP2E1) with ethanol plus arachidonic acid (AA) caused loss of cell viability to a greater extent than in HepG2 C34 cells, which do not express CYP2E1 [13]. These treatments elevated protein levels of HIF-1 $\alpha$ to a greater extent in E47 cells than in C34 cells. The HIF-1 $\alpha$ inhibitor (2Methoxyestradiol) also blocked the elevated oxidative stress produced by ethanol/AA in the E47 cells. These results suggest that blocking HIF-1a activation and actions may have therapeutic application for protection against ethanol/CYP2E1-induced hepatic oxidative stress, steatosis, and liver injury [13]. These regulatory mechanisms of CYP2E1 and HIF-1 $\alpha$ in chronic ALD were also demonstrated in acute binge alcohol model [18]. The authors concluded that binge alcohol promotes acute hypoxic liver injury in mice and humans at least partly by activating the CYP2E1-HIF1a-dependent apoptosis pathway.

\section{Hepatic Hypoxia Inducible Factor 1 $\alpha$ and MicroRNA-1222 in ALD}

MicroRNAs (miRNAs) are small non-coding RNA molecules that regulate post transcriptional gene expression via RNA silencing. MicroRNAs have been reported to control the liver tumor development and aggressiveness [25]. One of the most abundant miRNAs in the liver is miR-122. Decreases of miR-122 in liver tissue have been correlated with gain of metastatic properties of liver cancer and increased mortality [26]. Acute ethanol ingestion leads to a significant rise in miR122 [27]. Recent study shown that miR-122 regulates HIF-1 $\alpha$ in hepatocytes in a 
diet-induced steatohepatitis animal model [28]. More recently, it was demonstrated that alcoholic steatohepatitis accelerates hepatobiliary tumors by loss of miR-122 expression with a significant up-regulation of the miR-122 target, HIF-1a [20]. The study showed that chronic alcohol feeding in adult mice accelerated diethyl-nitrosamine (DEN) induced liver tumor development with molecular characteristics of HCC. Increased progenitor cell activation was triggered in the alcoholic liver tissue microenvironment and was characterized by high levels of pro-inflammatory signals of both innate (TNFa and MCP-1) and adaptive immunity, and activation of HIF-1 $\alpha$.

\section{Intestinal Hypoxia Inducible Factor 1a regulation: A Common Mechanism in} Gut-Liver Axis in ALD?

The attenuation of alcohol-induced endotoxemia and liver damage by antibiotics indicates that endotoxin plays an important role in alcoholic liver damage [29]. Endotoxins are lipopolysaccharides (LPSs) derived from the cell walls of gram-negative bacteria. Both dead bacteria and the LPS shed from the cell walls contribute to the circulating endotoxins. Cellular targets of LPS in the liver include Kupffer cells, sinusoidal endothelial cells, stellate cells, neutrophils, and hepatocytes [30]. Normally, Kupffer cells in the liver detoxify endotoxins by phagocytosis. In Kupffer cells, lipopolysaccharide binding protein (LBP) presents LPS to CD14, a 55-kDa glycoprotein [31], and activates the MyD88-independent and dependent signaling pathway through TLR4. TLR4 activation results in the 
production of proinflammatory cytokines such as tumor necrosis factor (TNF)- $\alpha$ and reactive oxygen species (ROS) that contribute to hepatocellular damage [32].

Alcohol induced intestinal barrier dysfunction increases circulating endotoxin levels. Endotoxin absorption and leak is impeded by normal mucosal barrier function, and loss of normal barrier function may play an important role in causing endotoxemia in alcoholics. The intestines rely on an extensive underlying vasculature, and therefore are major targets for conditions of attenuated blood flow and result tissue hypoxia [33]. Both adaptive and proinflammatory responses have been attributed to conditions of hypoxia $[34,35]$, and it is now clear that responses to hypoxia include transcriptionally regulated gene expression coordinated by HIF $[36,37]$. As important regulators of oxygen homeostasis, HIF-1 $\alpha$ and HIF-2 $\alpha$ have been implicated in transcriptional regulation of anti-inflammatory or tissue-protective-signaling pathways $[38,39]$. For example, a number of barrier-protective genes are critically regulated by HIF$\alpha$, including intestinal trefoil factor (ITF), CD73, and multidrug resistance gene-1 (MDR1). Among these, ITF, Muc3, defensins, CRAMP, Claudin-1 and CD73 appear to serve as barrier-protective factors during hypoxia in vivo. There are also a number of factors other than hypoxia, such as lipopolysaccharide (LPS) that regulate HIF-1 expression and accumulation. A recent study demonstrates that long time exposure to LPS impairs HIF-1 $\alpha$ induction that, in turn, reduces the ability of cells to survive and function under hypoxia conditions [40].

A recent study in our lab showed that chronic alcohol feeding decreased HIF-2 $\alpha$ protein levels in the intestines of mice [41]. However, the role of intestinal 
HIF1a has not been studied in ALD. We proposed that HIF-1a plays a critical role in the intestine by regulating gut microbiota homeostasis and barrier function in ALD. HIF-1 $\alpha$ upregulation in the intestine serves as a compensatory mechanism to increase factors that reduce gut dysbiosis leading to reduced LPS production and enhanced barrier function that inhibits the translocation of bacteria and their products in ALD. We expect that deficiency of intestinal HIF-1 $\alpha$ exacerbates gut dysbiosis, intestinal barrier dysfunction, increased LPS and bacterial translocation into the liver, and eventually, liver damage. We also expect that upregulation of HIF-1 $\alpha$ by intestinal pathogenesis, such as inflammatory bowel disease, provides a feed-back mechanism to limit the intestinal barrier dysfunction, and deficiency of intestinal HIF-1a leads to further exacerbation of ALD when the intestine is damaged by inflammatory bowel disease. 


\author{
CHAPTER I \\ INTESTINAL HIF-1a DELETION EXACERBATES ALCOHOLIC \\ LIVER DISEASE THROUGH INDUCING INTESTINAL DYSBIOSIS AND \\ BARRIER DYSFUNCTION
}

\title{
INTRODUCTION
}

Alcoholic liver disease (ALD) ranges from hepatic steatosis to steatohepatitis, cirrhosis, and, potentially, hepatocellular carcinoma [1]. While alcohol induces deleterious effects in the liver, it also disrupts the gut microbiota homeostasis and intestinal epithelial integrity resulting in an increased permeability, bacterial translocation and release of bacteria-derived endotoxin into the circulation [2-4]. Clinical and experimental studies have demonstrated that serum levels of lipopolysaccharide (LPS) are, indeed, increased in alcoholic subjects [5, 6]. LPS binding to Toll-like receptors (TLRs) on the surface of Kupffer cells leads to an elevated pro-inflammatory cytokine production, which, in turn, damages hepatocyte function $[7,8]$.

Intestinal barrier function is key to preventing the increased bacterial translocation by alcohol $[6,9,10]$. Goblet cells in the intestinal epithelium produce protective trefoil factors and mucins, which are abundantly core glycosylated and either localized to the cell membrane or secreted into the lumen 
to form the mucus layer $[11,12]$. The mucus is the first barrier that intestinal bacteria meet, and pathogens must penetrate it to reach the epithelial cells [13, 14]. Additionally, trefoil factors stimulate expression and secretion of mucins and play a role in building/modifying the mucus layer and promoting epithelial tight junction integrity [15]. Intestinal Paneth cells produce antimicrobial peptides that are retained in the mucus layer, thereby concentrating their bactericidal activity close to the epithelium. Together, Paneth and Goblet cells prevent bacterial invasion to some extent, and thereby play a prominent role in the innate immune surveillance of the gut [12]. A single layer of epithelial cells forms the main physical barrier between the lumen and mucosal tissues. The paracellular space is sealed by tight junctions (TJ), which regulate the flow of small molecules through the composition of claudins and other proteins in the junctional complex [16]. IgA production and other intestinal immune-regulators provide protection against bacterial transcytosis [17]. Recent studies demonstrate that targeting intestinal barrier function may be an effective strategy in the prevention/treatment of ALD [18].

The intestines are supported by an extensive underlying vasculature, and are therefore susceptible to conditions related diminished blood flow and concomitant tissue hypoxia $[19,20]$. It is now clear that the responses to hypoxia include transcriptionally regulated gene expression coordinated by the transcription factor hypoxia-inducible factor (HIF) [21]. HIF-1 $\alpha$ and HIF-2a have been implicated in transcriptional regulation of anti-inflammatory or tissueprotective-signaling pathways [22-24]. A number of barrier-protective genes are 
critically regulated by HIF-1a, including intestinal trefoil factor (ITF), CD73, Pglycoprotein (P-gp), cathelicidin, claudin-1, muc3 and $\beta$-defensin-1(DEFB1) [19, 25-30]. While hypoxia is an important factor for HIF-1a protein stabilization, there are also a number of factors other than hypoxia, such as LPS, that regulate HIF$1 \alpha$ expression and accumulation [31]. A recent study demonstrates that long time exposure to LPS impairs HIF-1a induction, which then reduces cell viability and function under hypoxia conditions [32].

Disruption of epithelial HIF-1 $\alpha$ resulted in an increased epithelial permeability, as shown in murine colitis models [33-36]. Our previous study showed that long-term exposure to alcohol decreased epithelial HIF-2 $\alpha$ protein expression in mice [37]. We also demonstrated that knockdown of HIF1/2a resulted in an increased permeability and a decreased trans-epithelial electrical resistance (TEER) in Caco-2 cells $[37,38]$. However, it is unknown whether intestinal epithelial HIF-1 $\alpha$ is critical in maintaining intestinal barrier function in response to alcohol exposure in mice.

In the present study, we discovered that intestinal epithelial specific HIF-1 $\alpha$ knockout (IEhif1 $\left.\alpha^{-/-}\right)$worsens alcohol-induced liver injury. We showed that alcohol exposure in IEhif1 $\alpha^{-/-}$mice resulted in a more severe dysbiosis, bacterial translocation and liver injury. IEhif1 $1 \alpha^{-/-}$mice had decreased levels of antimicrobial peptide in the intestine and an increased intestinal inflammation. Probiotic administration decreased alcohol-induced liver injury in wild type (WT) mice but not in IEhif1 $1 \alpha^{--}$mice. Sterilizing the gut using non-absorbable antibiotics 
attenuated liver-injury in IEhif1 $\alpha^{-/}$mice. Our results suggest that targeting intestinal HIF-1 $\alpha$ may be a strategy for preventing ALD.

\section{MATERIALS AND METHODS}

\section{Animal Models of Alcohol Feeding and Drug Administration}

C57BL/6J, hif1 ${ }^{f}{ }^{f / f f}$, and Villin-Cre mice were purchased from Jackson Laboratory (Bar Harbor, ME). IEhif1 $\alpha^{-/-}$mice were generated by crossing hif1 $\alpha_{-}^{\mathrm{fl} / \mathrm{fl}}$ and Villin-Cre mice as previous described [39]. The Cre mice were used as controls in this study (WT). Eight to ten-week old male mice (WT and IEhif1 $\alpha^{-/}$) were pair-fed a Lieber-DeCarli liquid diet containing alcohol (AF) or isocaloric maltose dextrin (PF). In the first week, all groups of mice were given modified Lieber-DeCarli liquid diet without alcohol to acclimate the mice to the liquid diet. Starting at week 2, alcohol was gradually introduced and increased to $5 \%(\mathrm{w} / \mathrm{v})$ at the end of the week and was continued at $5 \%$ for 24 days. This modified Lieber-DeCarli diet contained $17 \%$ of energy as protein, $40 \%$ as fat, $7 \%$ as carbohydrate, and $35 \%$ as either alcohol $(5 \% \mathrm{w} / \mathrm{v})$ or isocaloric maltose dextrin (Research Diets, New Brunswick, NJ). A group of mice was treated with nonabsorbable antibiotics (Polymyxin B, $150 \mathrm{mg} / \mathrm{kg} \mathrm{BW/day} \mathrm{and} \mathrm{Neomycin,} 200$ $\mathrm{mg} / \mathrm{kg} \mathrm{BW} /$ day) at day 12 of the $5 \%$ alcohol-feeding period. Control mice were gavaged daily with an equal volume of vehicle (water). Lactobacillus rhamnosus GG was supplemented to one group of mice at a dose of $10^{9} \mathrm{CFU} /$ day. A group of mice was administered $8 \mathrm{mg}$ of dimethyloxalylglycine (DMOG, Cayman 
Chemical, Ann Arbor, MI) intraperitoneally every other day for the last 2 weeks of ethanol diet feeding. Intestinal tissues of mice treated with alcohol using same protocol described above for 48 days (from another study) were used for HIF-1 $\alpha$ analysis. All animal protocols were approved by the Institutional Animal Care and Use Committee of the University of Louisville.

\section{Histological analysis}

The liver and small intestine tissues were collected in $4 \%$ paraformaldehyde and then imbedded in paraffin. Tissues were cut into $5 \mu \mathrm{m}$ sections and stained with hematoxylin and eosin (H\&E) and analyzed by light microscopy. For hepatic lipid accumulation analysis, frozen liver sections were stained with Oil Red O to visualize neutral lipids. Nuclei were counterstained with hematoxylin. Neutrophil accumulation in the livers was assessed by chloroacetate esterase (CAE) (Sigma, St. Louis, MO) staining. Intestine and liver macrophages were evaluated by F4/80 immunofluorescent staining.

\section{Tissue triglyceride}

Liver tissues were homogenized in distilled water and the homogenate was collected for lipid extraction. Triglyceride content was determined using commercially available colorimetric kits (Thermo Scientific, Waltham, MA).

\section{Serum ALT assay}


Mouse serum was collected by orbital vein bleeding at time of euthanasia. Serum alanine aminotransferase (ALT) levels were analyzed by Piccolo Xpress system (ABAXIS, Union City, CA).

\section{Endotoxin assay}

All material used for harvesting blood and measuring endotoxin was pyrogen free. An endpoint chromogenic Limulus amebocyte lysate (LAL) endotoxin kit was used to determine plasma LPS levels according to the manufacturer's protocol (Lonza, Basel, Switzerland).

\section{Immunofluorescent staining of FFPE tissue.}

Formalin-fixed paraffin embedded (FFPE) tissue was processed for staining as described previously with certain modifications [34]. Following deparaffinization, antigen retrieval was performed in unmasking solution (Vector Laboratories, Burlingame, CA) for $20 \mathrm{~min}$ at $125^{\circ} \mathrm{C}$ in a Decloaking chamber (Biocare Medical, Pacheco, CA). Unreacted aldehydes were quenched for 10 min with $1 \% \mathrm{NaBH}_{4}$. Prior to blocking, ImagelT enhancer (Invitrogen, Carlsbad, CA) was applied to each section. Non-specific antibody binding was blocked with either $1 \% \lg$-free BSA or $5 \%$ Normal donkey serum (Jackson Immuno, West Grove, PA) in TBS (Tris-buffered saline), depending on the antibodies used. Primary antibodies were incubated overnight at $4^{\circ} \mathrm{C}$. Sections were washed with TBS, and AlexaFluor-conjugated secondary antibodies (Invitrogen) were applied for $30 \mathrm{~min}$ at room temperature. DAPI counterstain (Invitrogen) was used to 
image nuclei and slides were mounted with ProLong gold (Invitrogen). Primary antibodies used were: E. coli (Abcam, Cambridge, MA), F4/80 (Abcam), Claudin1 (Santa Cruz, Dallas, TX), and Occludin (Santa Cruz).

\section{Quantitative PCR (qPCR)}

Total RNA from liver and ileal tissues was isolated with TRIzol according to manufacturer's protocol (Invitrogen), and total RNA was reverse transcribed (RT) using Sensiscript Reverse Transcriptase and oligo(dT) (Applied Biosystems, Foster City, CA) to yield the cDNA. The cDNA was amplified in 96-well reaction plates with a SYBR green PCR Master Mix (Applied Biosystems) on an ABI 7500 real-time PCR thermo cycler. The primers used in this study are listed in the Supplementary Table 1. Data were expressed as relative mRNA levels using the $\Delta \Delta$ CT method. 
Table 1. Primers used for $\mathrm{qPCR}$

\begin{tabular}{|c|c|c|}
\hline $\begin{array}{l}\text { Gene } \\
\text { name }\end{array}$ & Forward sequence $5^{\prime}$-> 3' & Reverse sequence 5' -> 3' \\
\hline SERBP-1 & CCA CCT CGT GAA CGA AGA TT & ACC ACC ACG ACC TCG AAT AG \\
\hline TNF- $\alpha$ & ATCTACCTGGGAGGCGTCTT & GAGTGGCACAAGGAACTGGT \\
\hline IL-6 & TGGAAATGAGAAAAGAGTTGTGC & CCAGTTTGGTAGCATCCATCA \\
\hline $\mathrm{IL}-1 \beta$ & TTCATCTTTGAAGAAGAGCCCAT & TCGGAGCCTGTAGTGCAGTT \\
\hline MCP-1 & ACCACAGTCCATGCCATCAC & TTGAGGTGGTTGTGGAAAAG \\
\hline $\begin{array}{c}\text { Universal } \\
\text { bacteria }\end{array}$ & AAACTCAAAKGAATTGACGG & TCACRRCACGAGCTGAC \\
\hline $\begin{array}{r}\text { Akkermans } \\
\text { ia }\end{array}$ & CAG CAC GTG AAG GTG GGG AC & CCT TGC GGT TGG CTT CAG AT \\
\hline $\begin{array}{r}\text { Lactobacill } \\
\text { us }\end{array}$ & CCT TGC GGT TGG CTT CAG AT & CACCGCTACACATGGAG \\
\hline $\begin{array}{r}\beta- \\
\text { Defensin-1 }\end{array}$ & ATACTTCAAAAGCAATTTTCCTTTAT & TTGTCTGAGATGGCCTCAGGTGGTAAC \\
\hline $\begin{array}{r}\beta- \\
\text { Defensin-2 }\end{array}$ & CATGAGGGTCTTGTATCTCCTCT & CCTCCTCATGGCTTTTTGCAGC \\
\hline CRAMP & TCTCTACCGTCTCCTGGACCTG & CCACATACAGTCTCCTTCACTCG \\
\hline LL-37 & AGGATTGTGACTTCAAGAAGGACG & GTTTATTTCTCAGAGCCCAGAAGC \\
\hline hBD-1 & ATACTTCAAAAGCAATTTTCCTTTAT & TTGTCTGAGATGGCCTCAGGTGGTAAC \\
\hline hBD-2 & CATGAGGGTCTTGTATCTCCTCT & СCTCCTCATGGCTTTTTGCAGC \\
\hline P-gP & CCCATCATTGCAATAGCACC & GTTCAACTTCTGCTCCTGA \\
\hline CYP2E1 & AAC TGT CCC CGG GAC CTC & GCG CTC TGC ACT GTG CTT T \\
\hline HIF-1 $1 \alpha$ & ATCTCGGCGAAGCAAAGAGTC & TGGGGAAGTGGCAACTGAT \\
\hline $18 S$ & GTAACCCGTTGAACCCCATT & CCATCCAATCGGTAGTAGCG \\
\hline
\end{tabular}




\section{Western blot analysis}

Liver and ileal tissues were lysed on ice for $30 \mathrm{~min}$ in IPB $(50 \mathrm{mM}$ Tris $\cdot \mathrm{HCl}$, pH 7.4, $150 \mathrm{mM} \mathrm{NaCl}, 2 \mathrm{mM}$ EDTA, $4 \mathrm{mM} \mathrm{Na}_{3} \mathrm{VO}_{4}, 40 \mathrm{mM} \mathrm{NaF}, 1 \%$ Triton X-100, $1 \mathrm{mM}$ PMSF, $1 \%$ protease inhibitor cocktail) and centrifuged at $14,000 \times \mathrm{g}$ for 10 min. The supernatants were collected. An appropriate amount of protein in total tissue lysates was resolved by SDS-polyacrylamide gel electrophoresis and transferred onto a polyvinylidene difluoride membrane (Whatman, Sanford, ME). Membranes were blocked for $1 \mathrm{~h}$ in Tris-buffered saline/Tween 20 (10 mM Tris$\mathrm{HCl}, \mathrm{pH} 8.0,150 \mathrm{mM} \mathrm{NaCl}$, and $0.05 \%$ Tween 20) containing $5 \%$ nonfat dry milk and incubated overnight at $4^{\circ} \mathrm{C}$ with the different primary antibodies diluted in blocking buffer. Subsequently, membranes were incubated with peroxidaseconjugated second antibodies. Following treatment with supersignal west HRP substrate (MilliporeSigma, Billerica, MA), protein bands were detected by a ChemiDoc Molecular Imager (Bio-Rad, Hercules, CA). Data were normalized to $\beta$-actin.

\section{Bacterial cultures}

Mouse fecal pellets were collected and processed as described previously [45]. Briefly, fecal pellets were suspended in PBS at a concentration of $1 \mathrm{~g}$ feces/15 ml PBS and vortexed vigorously for 5 minutes. Serial dilutions of fecal homogenates were prepared in sterile Lysogeny Broth (LB) medium (BD Biosciences, San Jose, CA) in 15-ml tubes. The tubes were shaken for 24-48 $\mathrm{h}$ 
at $37^{\circ} \mathrm{C}$ under aerobic conditions. Bacterial growth was monitored by measuring $\mathrm{OD}_{600}$

\section{Statistical analysis}

Statistical analyses were performed using the statistical computer package, GraphPad Prism version 6, (GraphPad Software Inc., San Diego, CA, USA). Results are expressed as means \pm SEM. Statistical comparisons were made using one-way analysis of variance (ANOVA) with Tukey's post hoc test, or Student's $t$-test where appropriate. Differences were considered to be significant at $P<0.05$.

\section{RESULTS}

\section{IEhif1 $a^{-/-}$Mice Have Exacerbated Alcohol-Induced Hepatic Steatosis}

To examine the role of the intestinal HIF-1 $\alpha$ in experimental alcoholic liver disease, we generated intestinal epithelial specific knockout mice (IEhif1 $\alpha^{-/}$) by crossing hif- $1 d^{\mathrm{fl} / \mathrm{fl}}$ mice with Villin-Cre mice. To confirm the deletion effectiveness, the chemical hypoxia inducer, $\mathrm{CoCl}_{2}$, was administered to mice via intraperitoneal injection, and liver and intestine HIF-1a protein was immunoblotted. $\mathrm{CoCl}_{2}$ induced a prominent increase in HIF-1 $\alpha$ protein in the liver, but the changes were minimal in the intestine, indicating the effectiveness of the epithelial specific HIF-1a deletion (Fig.1). Chronic alcohol feeding for 24 days 
increased hepatic micro- and macro-steatosis in both WT and IEhif1 $1 \alpha^{-/-}$mice. This effect was more pronounced in IEhif1 $\alpha^{-/-}$mice, as shown in Fig. 2A and 2B. Liver to body weight ratio was not changed in WT mice, but was significantly increased in IEhif1 $\alpha^{-/}$mice (Fig. 2C). Confirming the histological findings, liver triglyceride level was increased by alcohol feeding in WT mice (not statistically significant), but it was markedly increased in the IEhif1 $a^{-/-}$mice (Fig. 2D). Alcohol feeding significantly increased hepatic SREBP-1 mRNA level in both WT and IEhif1 $\alpha^{-/-}$mice, but the effect was much greater in IEhif1 $1 \alpha^{-/}$mice compared to WT mice, indicating an increased lipogenesis in IEhif1 $\alpha^{-/-}$mice exposed to alcohol (Fig. 2E). Fasting serum glucose level was slightly decreased by alcohol feeding. However, the KO mice had significantly higher glucose levels compared to WT mice fed alcohol (Fig. 3A). Serum triglyceride (Fig. 3B) and total cholesterol levels (Fig. 3C) in IEhif1 $a^{-/-}$mice were slightly lower under pair-fed conditions compared to WT mice. WT mice had decreased total cholesterol and triglyceride levels, which were significantly increased in IEhif1 $\alpha^{-/-}$mice after alcohol feeding. Alcohol feeding did not affect serum levels of LDL (Fig. 3D) in either WT or IEhif1 $\alpha^{-/-}$mice, but serum HDL (Fig. 3E) and VLDL levels (Fig. 3F) were significantly increased in IEhif1 $\alpha^{-/-}$mice in response to alcohol feeding. 
A

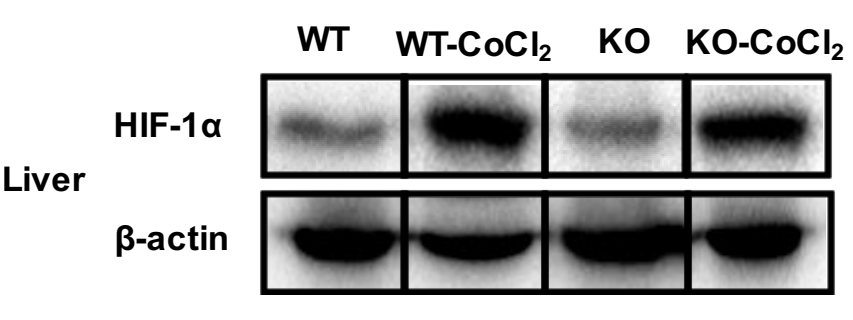

B

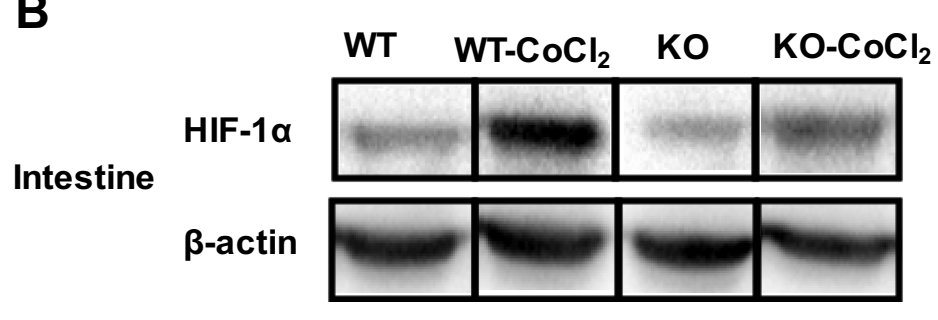

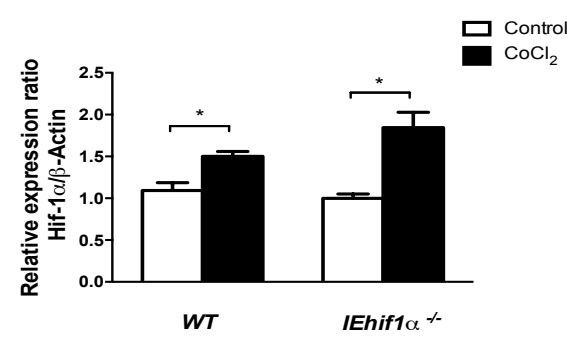

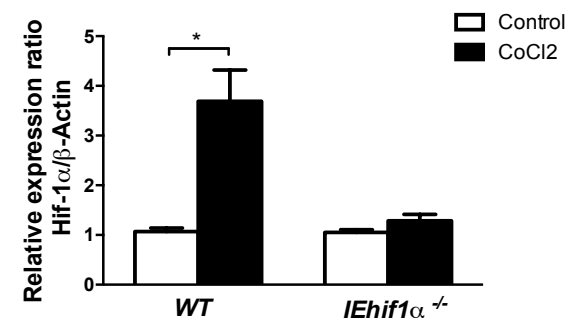

Figure1. Expression of HIF-1a in different organs with or without the hypoxia inducer. $\mathrm{CoCl}_{2}$ (intraperitoneally injected with $60 \mathrm{mg} / \mathrm{kg}$, mice were sacrificed at $3 \mathrm{~h}$ after $\mathrm{CoCl}_{2}$ injection) is used as a chemical hypoxia treatment, HIF-1a protein levels in liver $(A)$ and intestinal $(B)$ tissues. $\left({ }^{*} P<0.05\right)$. 




C
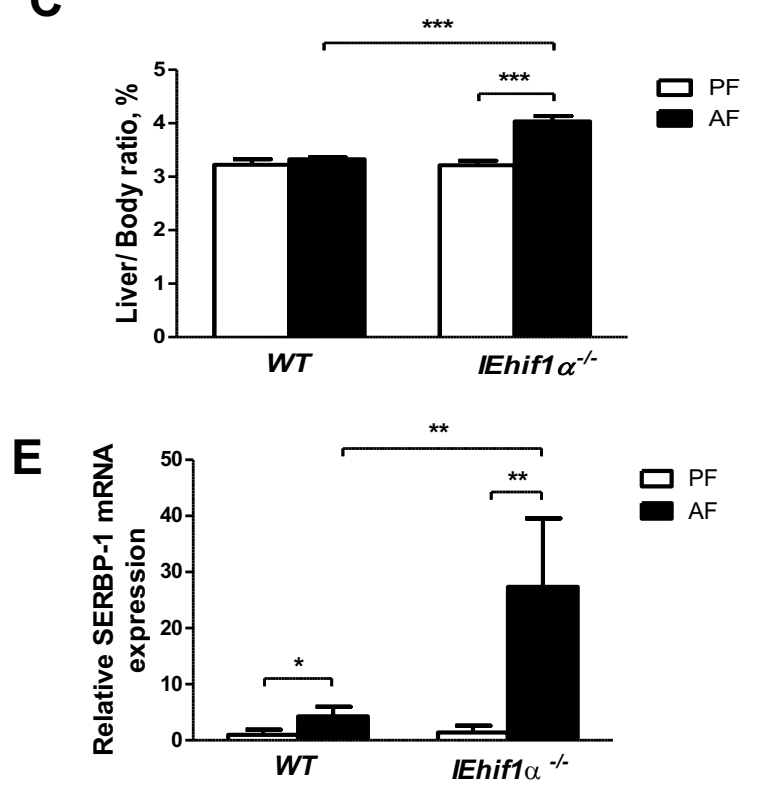

D

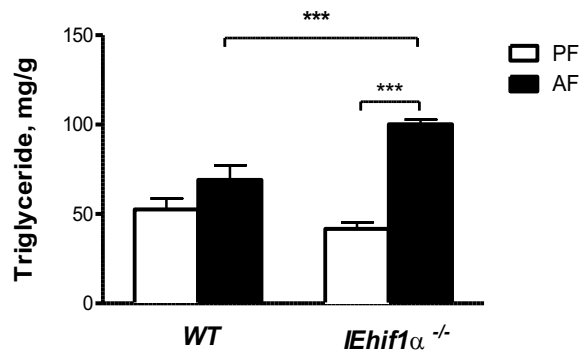




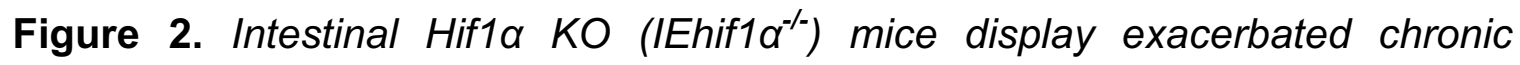
alcoholic liver injury and steatosis. WT and IEhif1 $\alpha^{-/-}$mice were fed pair-fed liquid diet (Lieber DeCarli) containing either 5\% alcohol (alcohol-fed, AF) or isocaloric maltose-dextrin (pair-fed, PF) for 24 days. (A) Hematoxylin and eosin staining of the liver sections of PF and AF WT and IEhif1 $1 \alpha^{-/-}$mice. Original magnification, $\times 10$. (B) Oil red O staining of the liver neutral lipids of PF and AF WT and IEhif1 $\alpha^{-/-}$mice. (C) Liver weight to body weight ratio of WT and IEhif1 $\alpha^{-/-}$mice fed PF or AF diets. (D) Quantification of hepatic triglyceride content. (E) Gene expression of SREBP-1 in liver tissues. ${ }^{*} P<0.05,{ }^{* *} P<0.01,{ }^{* *} P<0.001$. 
A

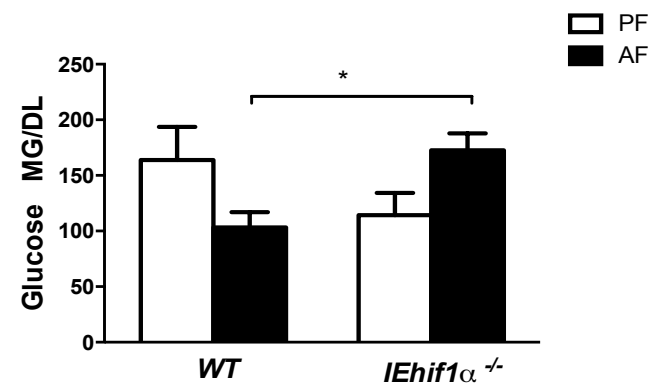

C

E
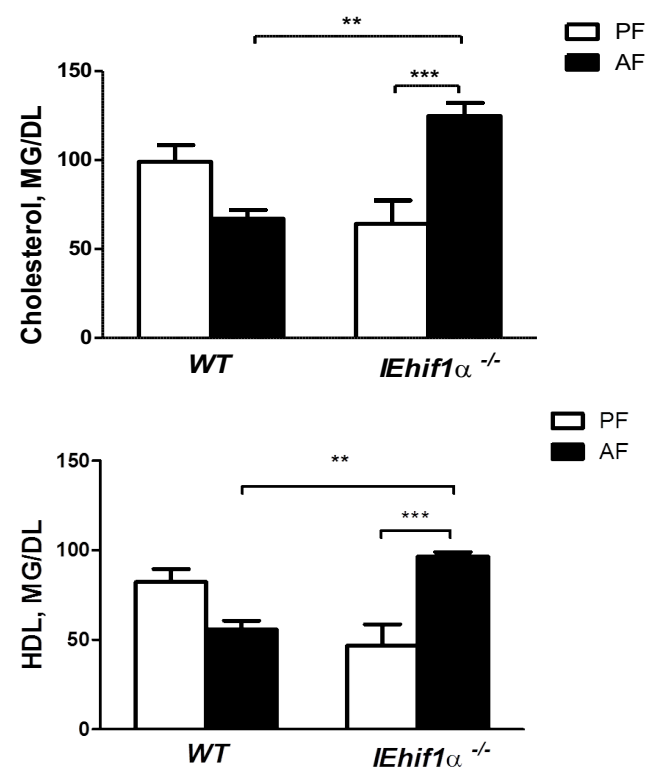

B

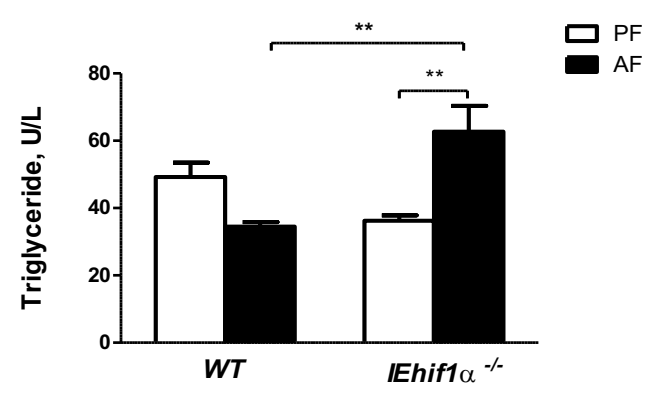

D

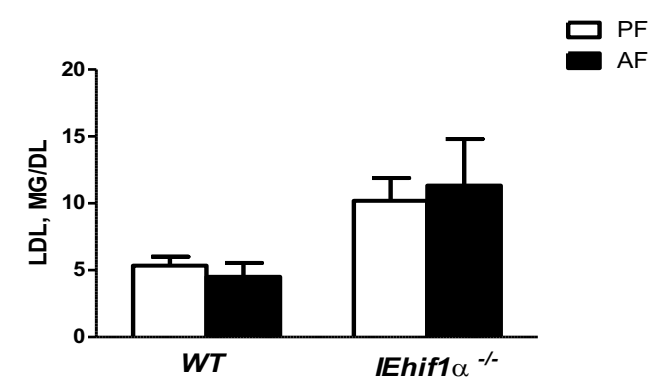

$\mathbf{F}$

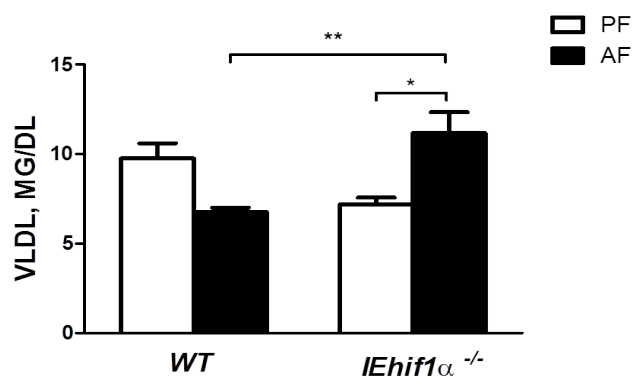

Figure 3. Effect of alcohol on lipid metabolism. Mice were fed alcohol-containing Lieber DeCarli diet for 24 days as described in the Material and Methods. The serum level of glucose (A), triglyceride (B), total cholesterol (C), low-density lipoprotein cholesterol (D), high-density lipoprotein cholesterol $(E)$, and very lowdensity lipoprotein cholesterol (F) were detected in WT (PF, AF) and the KO (PF, AF) groups. $\left({ }^{\star} P<0.05,{ }^{* *} P<0.01,{ }^{* * *} P<0.001\right)$. 


\section{Alcohol Increases Hepatic Inflammatory Response in IEhif1 $\alpha^{-/-}$mice}

Next, we analyzed alcohol exposure-induced inflammation in IEhif1 $\alpha^{-/-}$mice. Alcohol feeding increased hepatic inflammation in IEhif $1 \alpha^{-/-}$mice as evidenced by increased inflammatory foci (Fig. 2A arrows). As shown in Fig. 4A, IEhif1 $1 \alpha^{-/-}$mice had an increased infiltration of cytotoxic neutrophils (CAE staining) in the liver compared to WT mice in response to alcohol feeding. Additionally, immunohistochemical staining using $\mathrm{F} 4 / 80$ revealed more inflammatory macrophages in the livers of IEhif1 $\alpha^{-/-}$mice (Fig. 4B). More intense neutrophil infiltration and macrophage activation in livers of IEhif $1 a^{-/-}$mice were associated with elevated gene expression of the pro-inflammatory cytokines, tumor necrosis factor alpha (TNF- $\alpha$ ) and IL-6, and the chemokine MCP-1 (Fig. 4C, 4D and 4E). Hepatic TLR4 protein level increased in IEhif1 $\alpha^{-/}$mice after alcohol exposure (Fig. 5). Serum levels of ALT were increased in both WT and IEhif1 $1 \alpha^{-/-}$mice (Fig. 4F). Taken together, these results demonstrate that IEhif $1 \alpha^{-/-}$mice have enhanced hepatic steatosis and inflammation upon chronic alcohol exposure. 

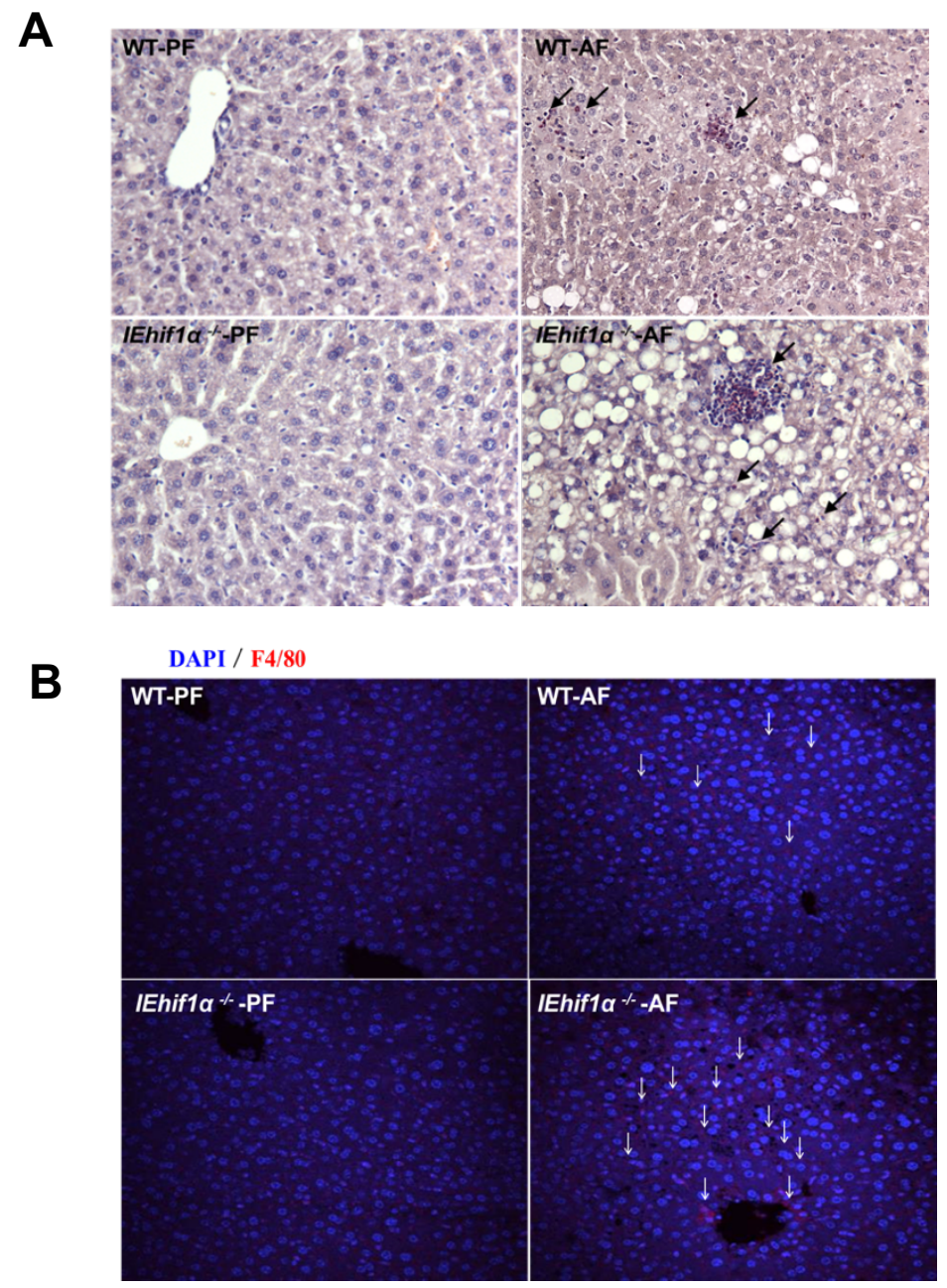

C

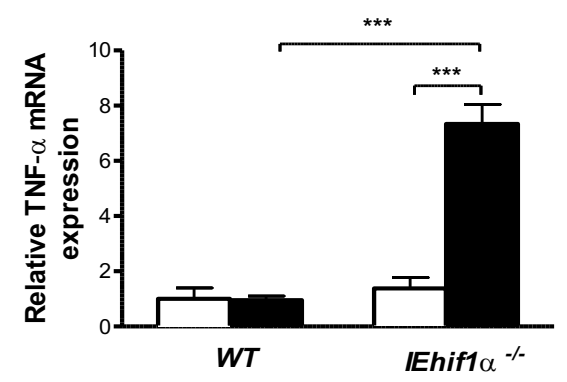

D

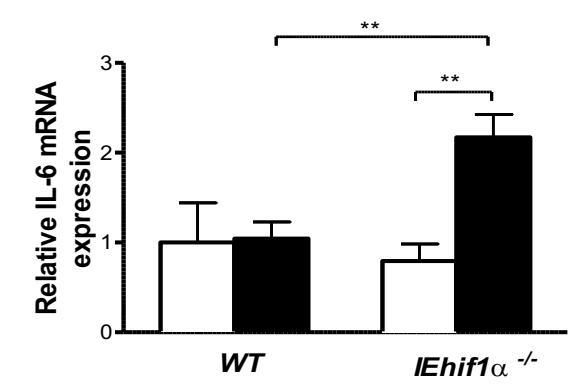

E

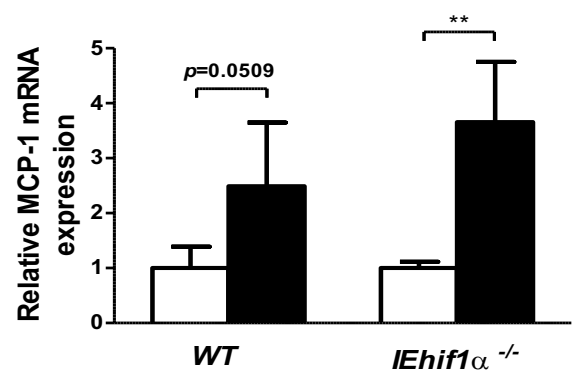

F

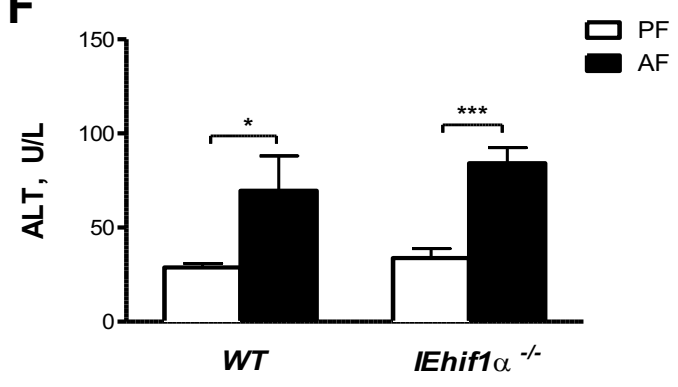


Figure 4. Inflammatory responses in EtOH-induced liver injury. (A) Chloroacetate esterase (CAE) localization (cell-localized fuchsia staining) in livers of WT and IEhif1 $\alpha^{-/-}$mice fed PF and AF diets for 24 days. Original magnification, $\times 10$. Arrows indicates neutrophil infiltration. (B) F4/80 staining of the liver tissues of PF and AF WT and IEhif1 $1 \alpha^{-/}$mice. Arrows indicate positive staining. DAPI (blue) was used to counterstain nuclei. Original magnification, $\times 10$. (C, D, E) Hepatic gene expression of proinflammatory cytokines TNF- $\alpha, I L-6$ and the chemokine MCP-1, respectively. (F) Serum alanine aminotransferase (ALT) activities of PF and AF WT and IEhif1 $\alpha^{-/-}$mice. ${ }^{*} P<0.05,{ }^{* *} P<0.01,{ }^{* * *} P<0.001$. 


\section{A}
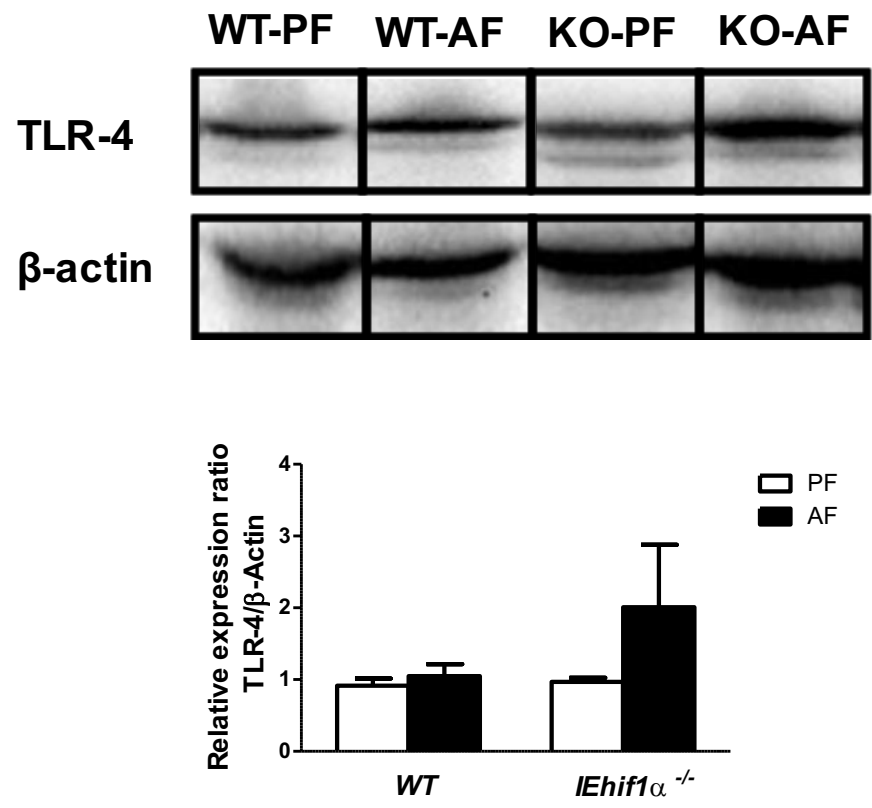

Figure 5. Effect of alcohol on hepatic Toll-like receptor 4 protein expression. Mice were fed alcohol-containing Lieber DeCarli diet for 24 days as described in the Material and Methods. 


\section{Alcohol Increases Hepatic Fibrosis in IEhif1 $a^{-/-}$mice}

Sirius Red staining of the liver sections showed a marginal increase of fibrosis in WT mice by alcohol feeding. IEhif1 $\alpha^{-/-}$mice had a significant increase in Sirius Red positive area compared to WT mice (Fig. 6A). The gene expression of fibrogenic factors, collagen $\alpha 1$ and aSMA, were marginally increased in the WT mice, but significantly increased in IEhif1 $\alpha^{-/}$mice, by alcohol feeding (Fig. 6B and $6 \mathrm{C})$. This suggests that intestinal epithelial HIF-1a depletion exacerbates hepatic fibrosis by alcohol exposure. 
A
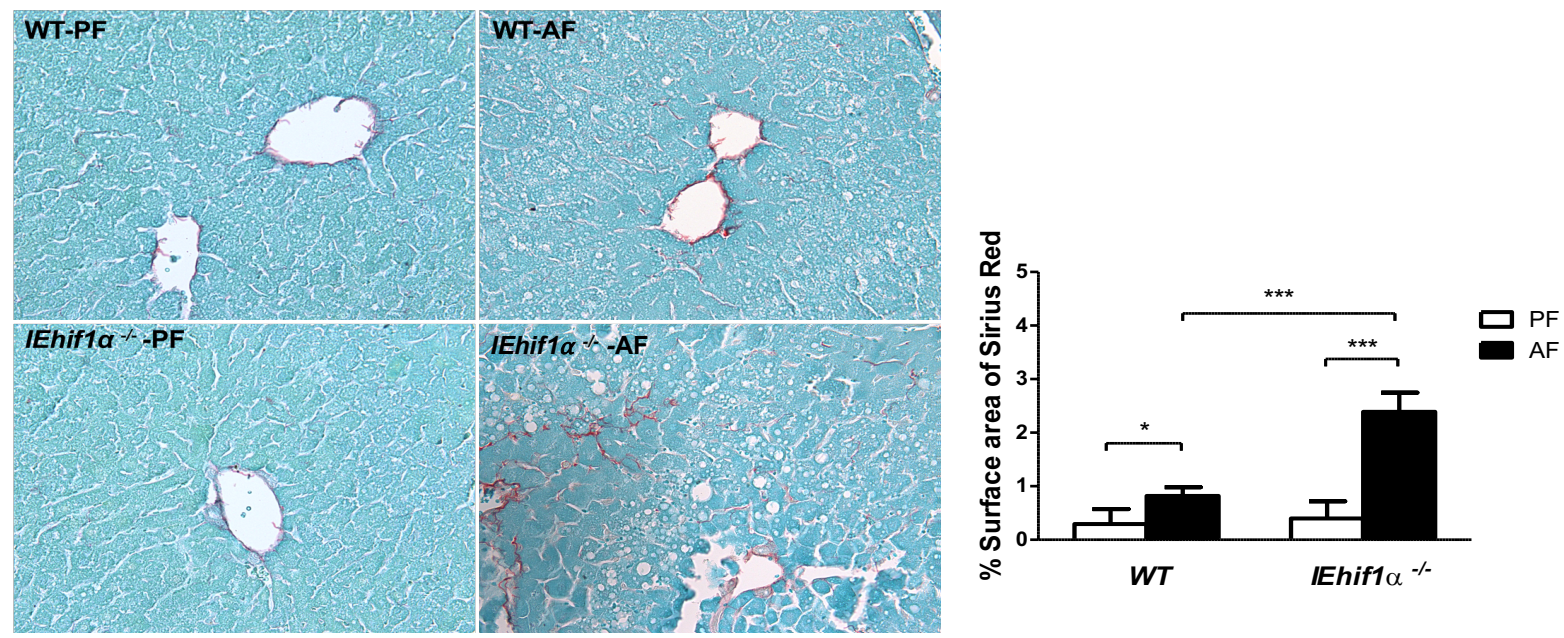

B
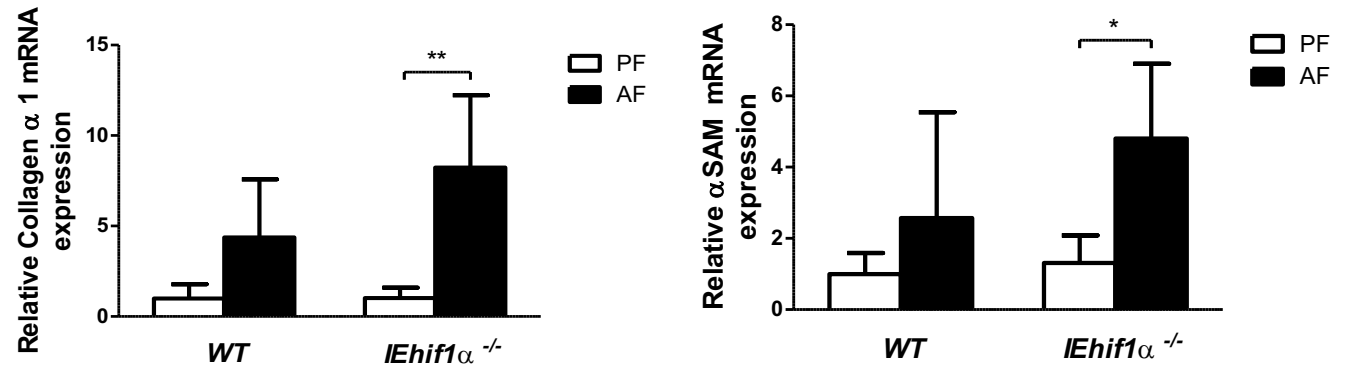

Figure 6: IEhif1 ${ }^{-/-}$mice have exacerbated liver fibrosis following alcohol treatment. (A) Sirius Red staining of the liver sections. The degree of fibrosis was evaluated by semi-quantification of Sirius Red positive area. (B) gene expression of Collagen $\alpha 1$ and $\alpha$ SMA in the liver tissues. ${ }^{*} P<0.05,{ }^{* *} P<0.01,{ }^{* * *} P<0.001$. 


\section{IEhif1 $\alpha^{-/-}$Mice Exhibit Gut Dysbiosis and Hepatic Bacterial Translocation}

Previous studies showed that ALD is associated with gut dysbiosis and endotoxin release. We next determined whether gut bacterial homeostasis and the translocation of bacteria and bacterial products from the intestine into the circulation are affected by the absence of intestinal Hif1a. Fecal samples were analyzed by $16 \mathrm{~S}$ ribosomal RNA bacterial primer sets to evaluate the effect of alcohol on bacterial overgrowth. As shown in Fig.7A, total bacterial load was unchanged in the WT mice, but significantly increased in the IEhif1 $\alpha^{-/-}$mice after 24 days of chronic alcohol feeding, indicating a bacterial overgrowth. Metagenomic analysis showed that alcohol feeding markedly increased phylum levels of Bacteroidetes and decreased Firmicutes in IEhif1 ${ }^{-/-}$mice (Fig. 7B). Further, 16S PCR analysis showed that Akkermansia spp. was increased in IEhif1 $\alpha^{-/-}$mice but not in the WT mice (Fig. 7C). Interestingly, Lactobacillus spp. was decreased by alcohol in WT mice, and was almost undetectable in IEhif1 ${ }^{-/-}$ mice (Fig. 7D). These data indicated that IEhif1 $\alpha^{-/-}$mice had an exacerbated gut dysbiosis following 24-day alcohol exposure. Intestinal antimicrobial peptides, secreted by epithelial cells such as enterocytes, Goblet and Paneth cells, play a critical role in gut microbiota homeostasis. Interestingly, alcohol exposure decreased the numbers of Goblet cells in the mucosal tissues of both WT and IEhif1 $\alpha^{-/-}$mice, but the effect was exacerbated in IEhif1 $\alpha^{-/-}$mice (Fig. 7E). $\beta$ defensins are the dominant classes of antimicrobial peptide secreted by the epithelium. The gene expression of $\beta$-Defensin-1 and -2 was increased by alcohol exposure in the ileal tissue of WT mice, while it remained unchanged in 
the IEhif1 $\alpha^{-/-}$mice, following alcohol exposure (Fig. 7F and 7G). Cathelicidin related antimicrobial peptide (CRAMP) is the only member of cathelicidin antimicrobial peptide family in mice. Alcohol exposure significantly reduced CRAMP expression in both WT and IEhif1 $1{ }^{-/-}$mice (Fig. $\left.7 \mathrm{H}\right)$. 
A

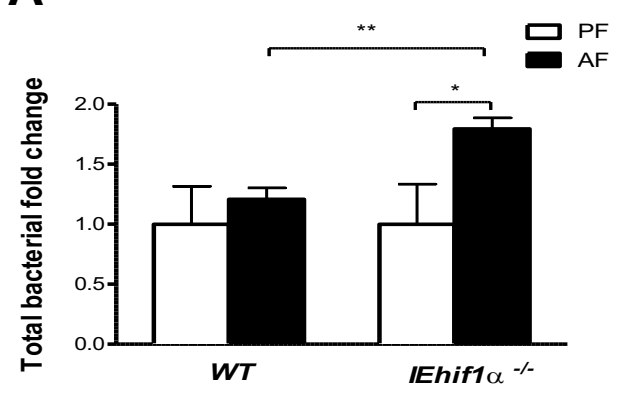

C

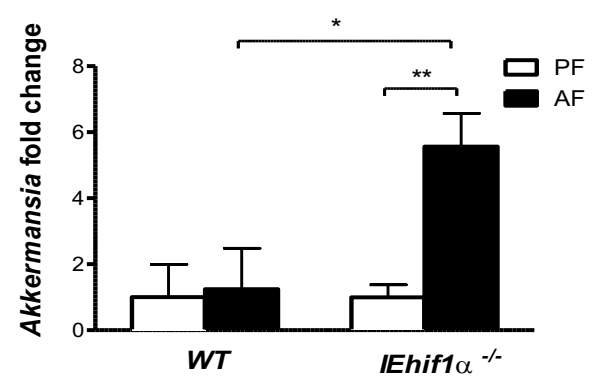

E
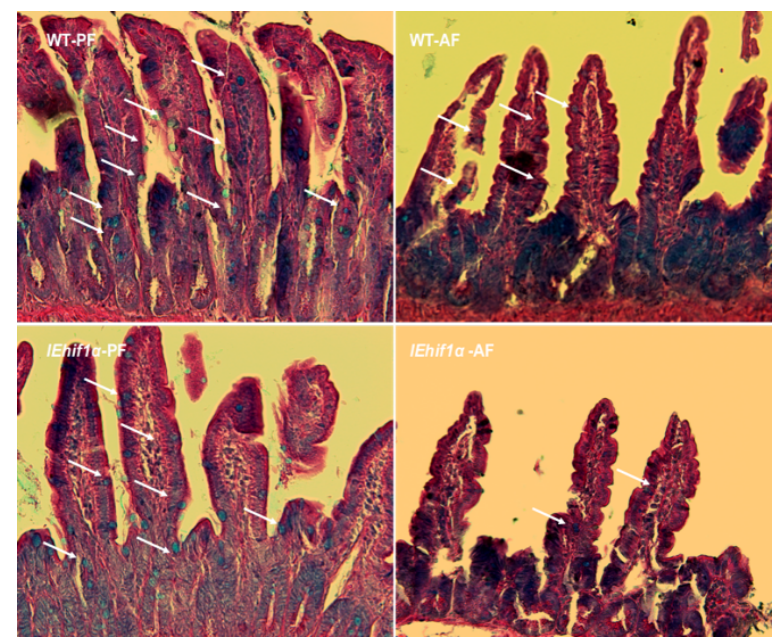

D
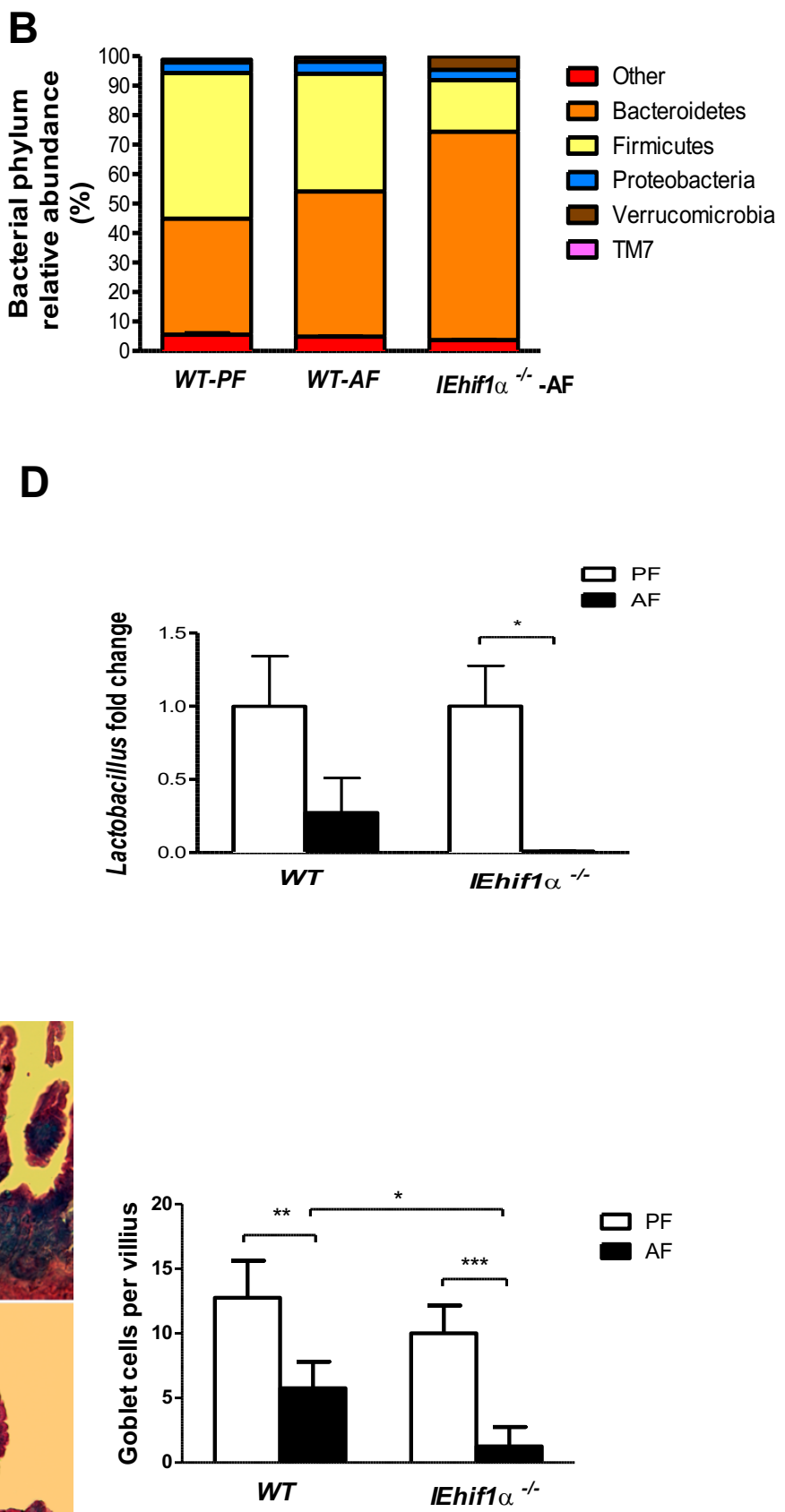
$\mathbf{F}$

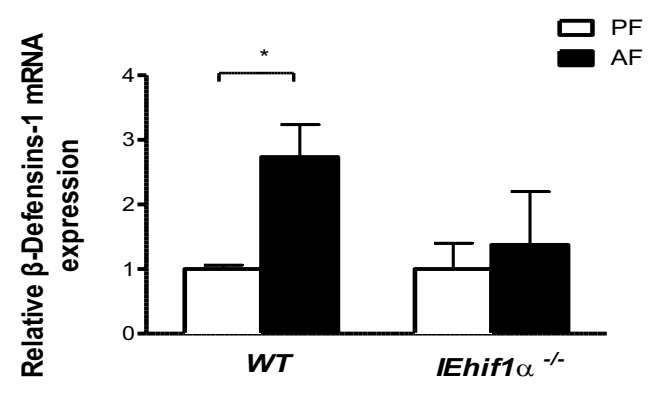

H

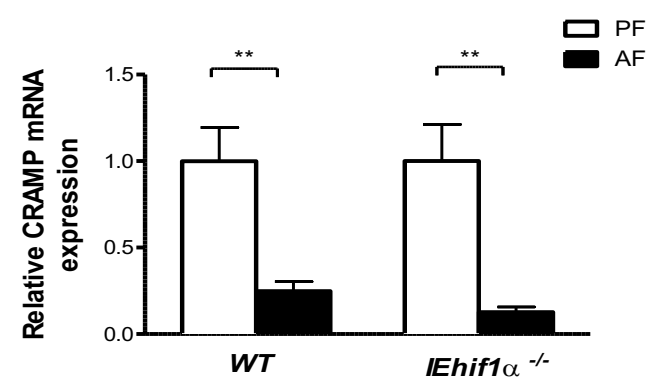

G

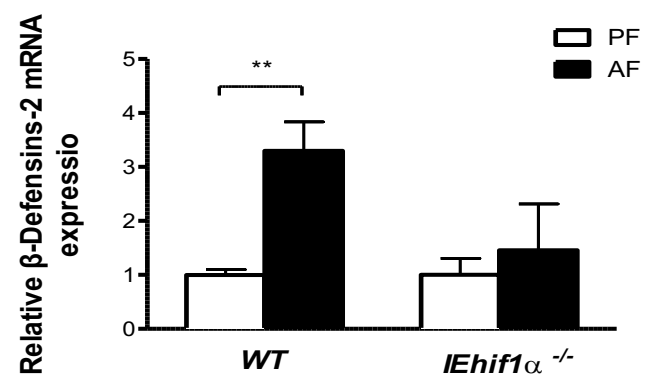

Figure 7. Effect of Hif1a on alcohol-induced dysbiosis. (A) The total bacterial load in the cecum of PF and AF WT and IEhif1 $\alpha^{-/-}$mice. (B) Phylum levels of microbiota in fecal samples of PF and AF WT and IEhif1 $\alpha^{-/-}$mice. (C, D) Akkermansia (Verrucomicrobia phylum) and Lactobacillus (Firmicutes phylum) levels of PF and AF WT and IEhif1 $\alpha^{-/-}$mice. (E) Goblet cell staining and quantification of the ileal tissues of PF and AF WT and IEhif1 $\alpha^{-/-}$mice. $(F, G, H)$ $\beta$-Defensins ( $\beta$-Defensins-1, 2) and cathelicidin-related antimicrobial peptide (CRAMP) gene expression in the ileal tissues of PF and AF WT and IEhif1 ${ }^{-/-}$ mice. ${ }^{*} P<0.05,{ }^{* *} P<0.01,{ }^{* *} P<0.001$ 


\section{Induction of HIF in the Intestinal Epithelial Cells Inhibits Mouse Fecal Bacterial Growth}

The role of intestinal HIF-1a in gut lumen bacterial growth was further analyzed in an in vitro assay. T84 intestinal epithelial cells were incubated with DMOG (Dimethyloxaloylglycine), a HIF-1 $\alpha$ activator. The conditioned medium was added to the mouse fecal bacterial culture in LB media, and bacterial growth rate was determined. As shown in Fig. 8A, DMOG itself did not change the fecal bacterial growth over the period of 6 hours. However, DMOG-conditioned medium significantly inhibited bacterial growth at the 5- and 6-hour time points, indicating HIF-1a-mediated secreted factors from epithelial cells likely possess anti-microbial capacity. To further confirm whether HIF-1 $\alpha$ activation can increase anti-microbial capabilities, we determined anti-microbial peptide expression in T84 cells after treatment with DMOG. The gene expression of human $\beta$ Defensin-1, -2 (hBD-1, 2) and human cathelicidin related antimicrobial peptide (LL-37) was increased significantly by DMOG in T84 cells (Fig. 8B-D), indicating HIF-1 $\alpha$ activation increases antimicrobial peptide expression in epithelia cells. 


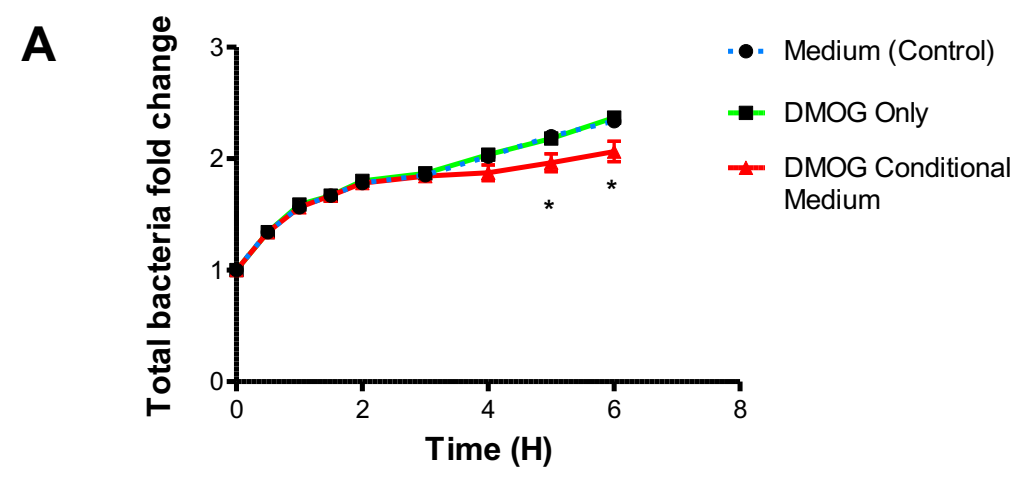

B

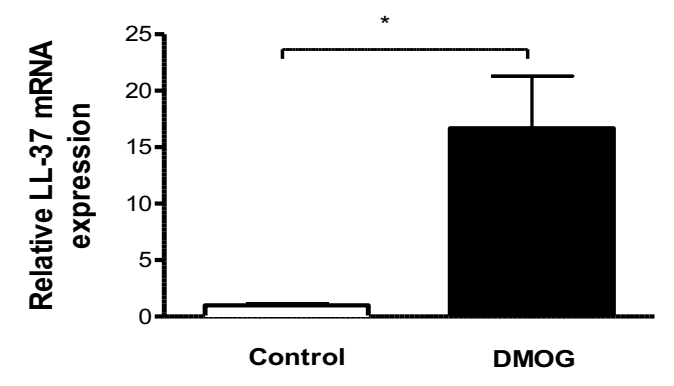

D

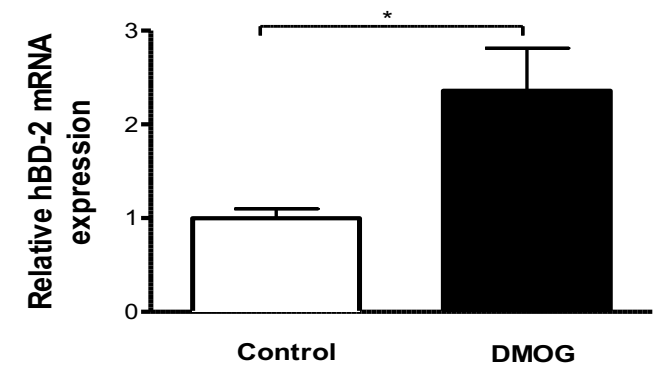

C

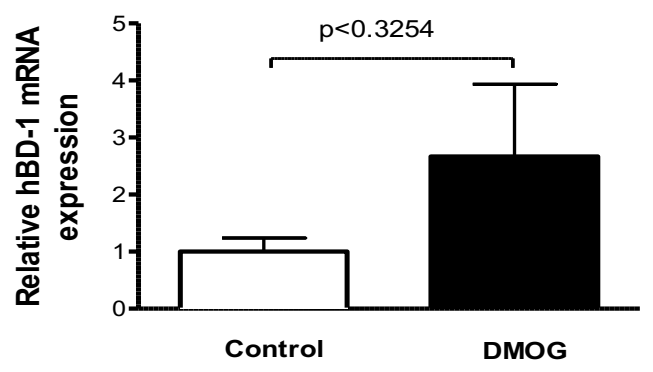

Figure 8. Effect of HIF activation on the bacterial growth and antimicrobial peptide gene expression. (A) Mouse fecal bacterial growth in response to DMOG and DMOG-conditioned medium in T84 cells. (B, $C, D)$ Gene expression of LL-37 and human $\beta$-Defensins $(h B D-1,2)$ in the $T-84$ cells treated with DMOG. ${ }^{*} P<0.05$ 


\section{HIF1a-deficiency Induces Intestinal Barrier Dysfunction After Chronic}

\section{Alcohol Exposure}

Increased bacterial translocation indicates intestinal barrier dysfunction. Immunofluorescent staining showed a decreased expression of the TJ proteins, occludin and claudin-1, in the ileal tissues of WT mice after alcohol exposure. Importantly, these decreases were more severe in IEhif1 ${ }^{-/-}$mice (Fig. 9A and 9B). The decreased TJ protein expression was associated with the disruption of intestinal protective factors, such as ITF and P-gp. ITF plays an important role in intestinal mucus layer protection. Protein level of ITF was significantly lower in the IEhif1 $\alpha^{-/-}$mice compared to the WT mice (Fig. 9C). Furthermore, P-gp (also known as multidrug resistance protein 1, MDR1) plays an important role in overall intestinal barrier integrity, and it was upregulated by alcohol in WT mice. This adaptive increase was, however, eliminated in the IEhif1 $\alpha^{-/-}$mice (Fig. 9D). 

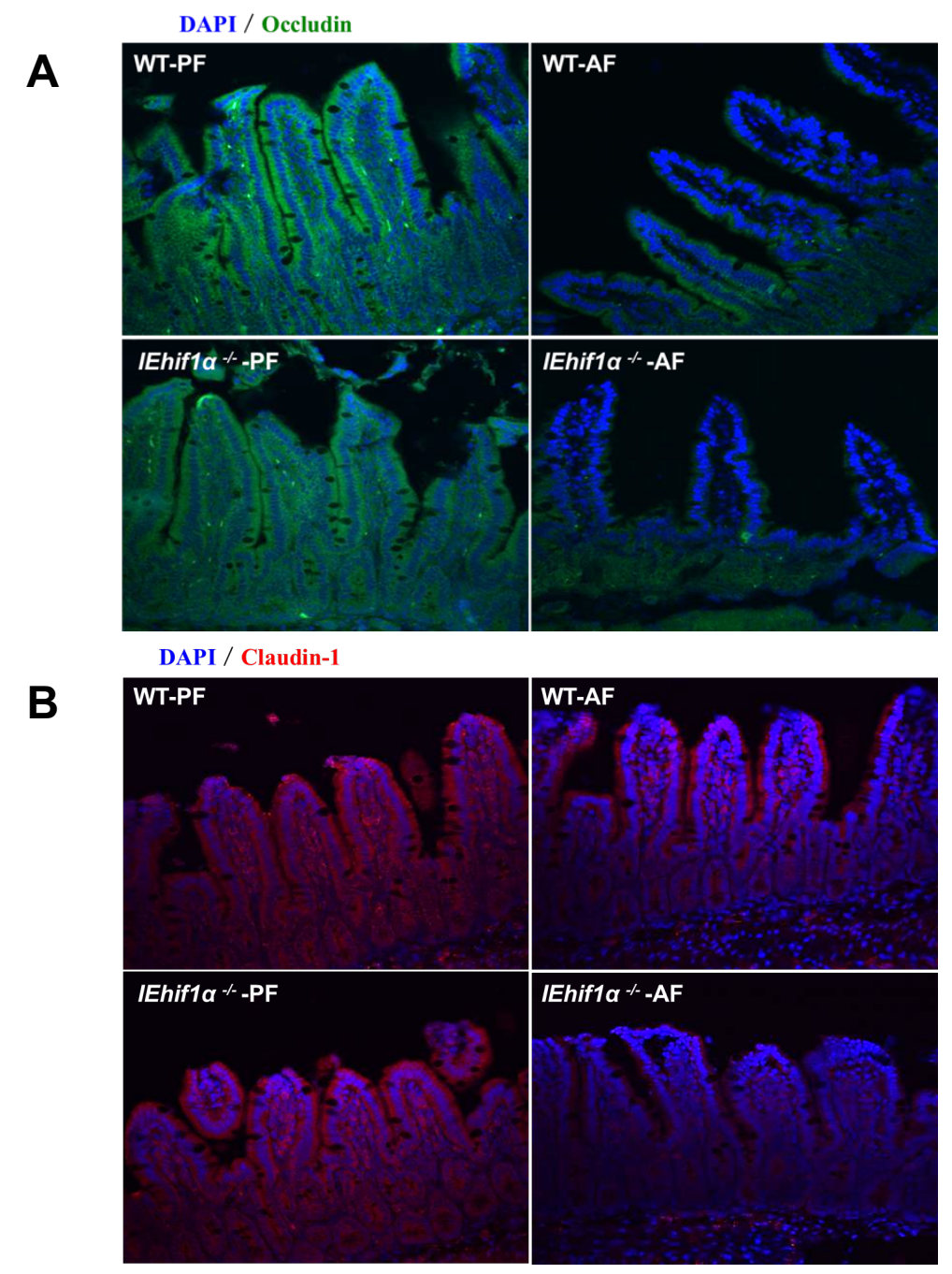

C
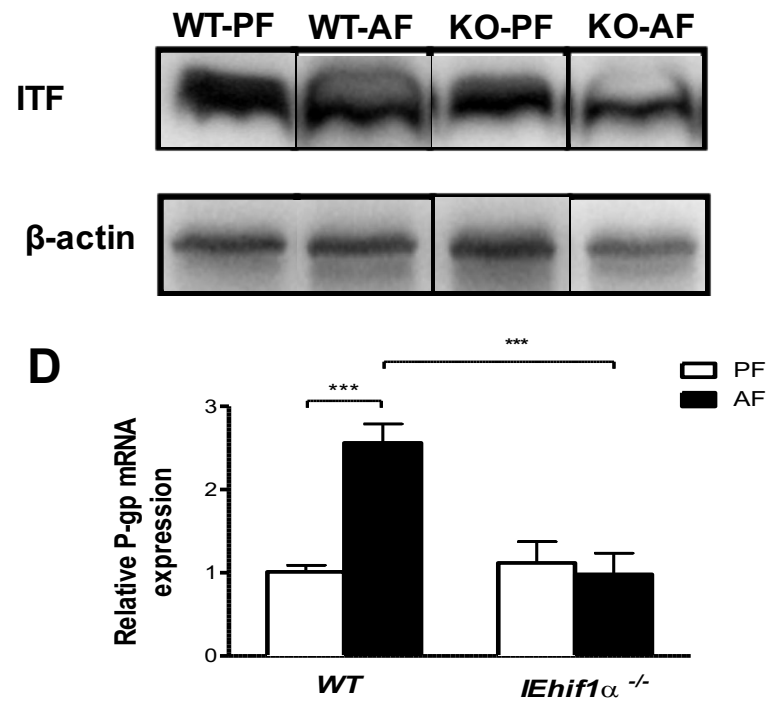

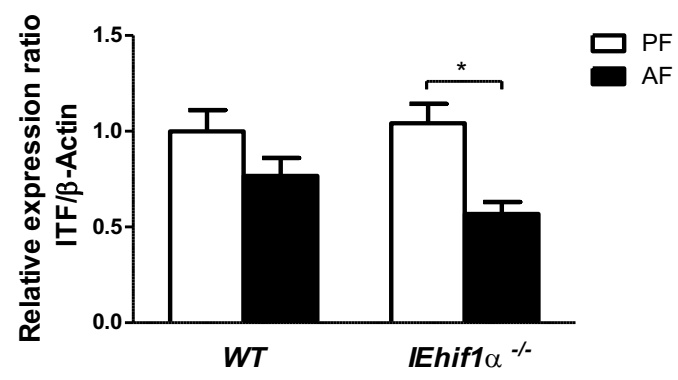


Figure 9. Effect of Hif-1a on intestinal barrier integrity. In $(A, B)$ Immunoflorescent staining of occludin (green) and claudin-1 (blue) in the ileal tissues of PF and AF WT and IEhif1 ${ }^{-/-}$mice. DAPI (blue) was used to counterstain nuclei. Original magnification, $\times 10$. (C) ITF protein Western blotting and quantification of ileal tissues of PF and AF WT and IEhif1a-/- mice normalized by $\beta$-actin. (D) P-gp gene expression in ileal tissues of PF and AF WT and IEhif1 $\alpha^{-/}$mice. ${ }^{*} P<0.05,{ }^{* *} P<0.01,{ }^{* * *} P<0.001$. 


\section{Alcohol Increases Intestinal Inflammatory Response in IEhif1 $a^{-/-}$Mice}

Histologic examination revealed a prominent inflammatory response in the ileum of IEhif1 $\alpha^{-/-}$mice exposed to alcohol (Fig. 10A). Alcohol feeding significantly increased macrophage-like appearance in Peyer's patches (PPs), a major component of the gut-associated lymphoid tissue which serve as important antigen entry sites in mucosal immunity. The PP domes were irregular, and the surrounding villi were sparse and atrophic (Fig. 10A), indicating an increased intestinal inflammatory response in the small intestines of IEhif $1 \alpha^{-/-}$mice exposed to alcohol. We further analyzed alcohol-induced intestinal inflammation in the IEhif1 $\alpha^{-/-}$mice. Immunofluorescent analysis revealed an increased number of cells expressing F4/80 in alcohol-treated-IEhif1 $\alpha^{-/-}$mice compared with WT mice (Fig. 10B). Intestinal inflammation in the IEhif1 $\alpha^{-/}$mice by alcohol exposure was further confirmed by the increased mRNA levels of pro-inflammatory cytokines, IL-6, IL-1 $\beta$ and TNF- $\alpha$ (Fig. 10C-E). 

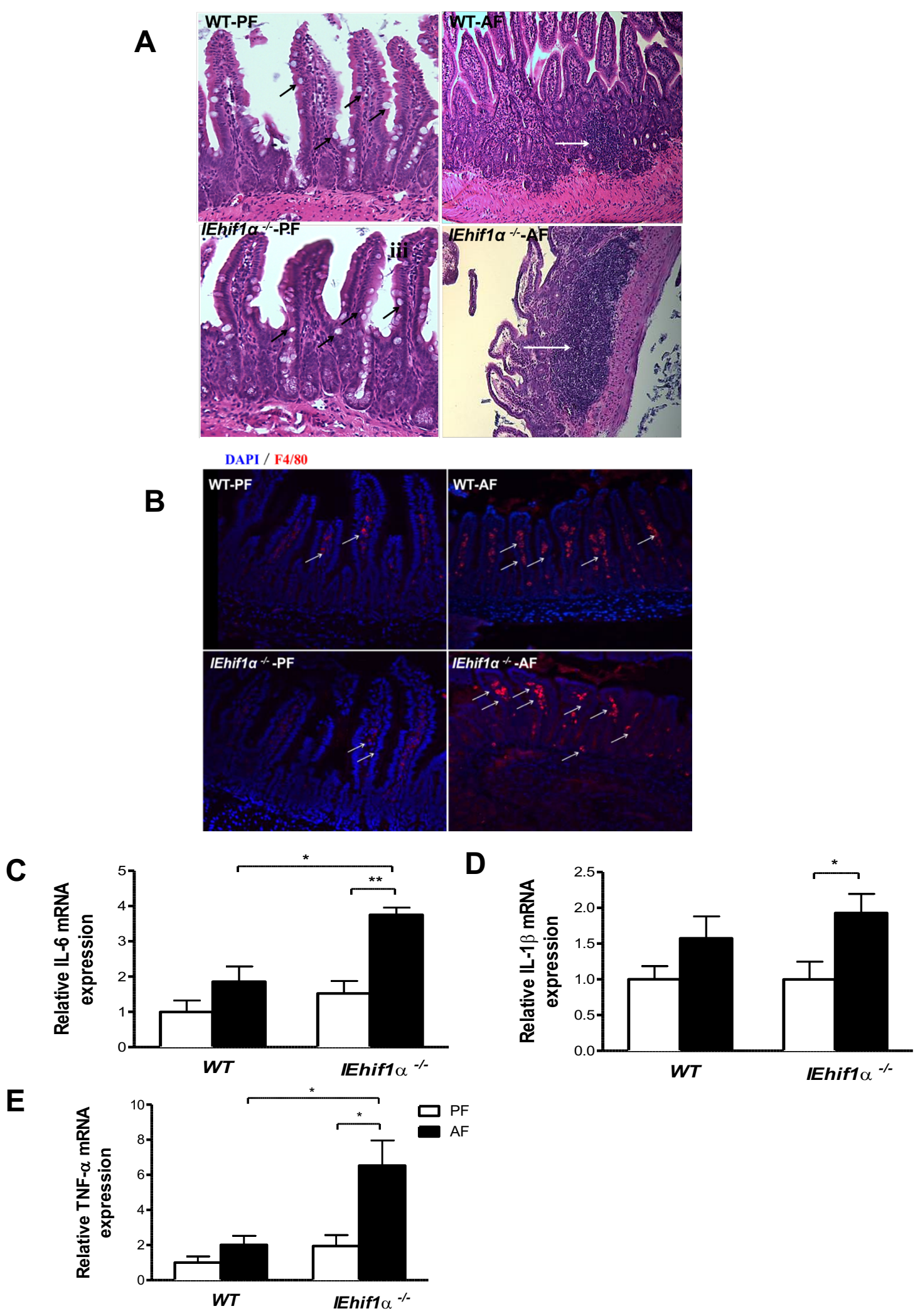
Figure 10. Effect of Hif-1a on intestinal inflammation. (A) HE staining of ileal tissues. Original magnification, $\times 10 . P F-f e d W T$ and IEhif1 $\alpha^{-/-}$mice show normal architecture and rounder, light "hollows" (black arrows) in the epithelium representing the apical cytoplasm of the goblet cells, which is filled with mucincontaining secretory vesicles. Abundant infiltrating cells showed a macrophagelike appearance in Peyer's patches (PPs) (white arrows), Peyer's patches' domes were irregular, and the surrounding villi were sparse and atrophic in ethanoltreated IEhif1 $\alpha^{-/-}$mice. (B) Immunofluorescent staining of F4/80 (red) showed increased macrophages in ileum of AF IEhif1 $\alpha^{--}$mice (arrows). DAPI (blue) was used to visualize nuclei. Original magnification: $\times 10$. (C, D, E) Ileum IL-6, IL-1 $\beta$ and TNF- $\alpha$ mRNA levels. ${ }^{*} P<0.05$. 


\section{Alcohol Increases Intestinal Permeability and Bacterial Translocation}

Increased intestinal barrier damage and inflammation leads to higher intestinal permeability and induces greater bacteria translocation. To further determine the role of epithelial HIF-1 $\alpha$ in alcohol-induced translocation of bacteria/bacterial products to the liver, we analyzed circulating LPS concentration and Escherichia coli (E. coli) protein in the liver. As shown in Fig.11A, serum LPS level was slightly elevated by alcohol feeding in the WT mice, but significantly increased in IEhif1 $1 \alpha^{-/-}$mice. Furthermore, hepatic contents of $E$. coli protein were increased in WT mice following alcohol exposure, and this increase was more

pronounced in IEhif1 $\alpha^{-/}$mice, as evaluated by immunofluorescent staining of hepatic tissues (Fig. 11B). 
A

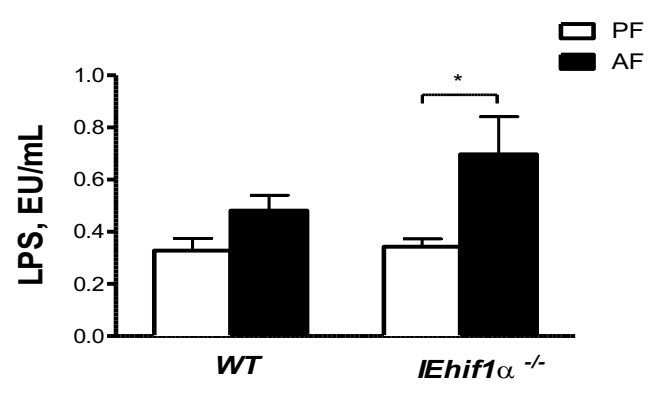

B

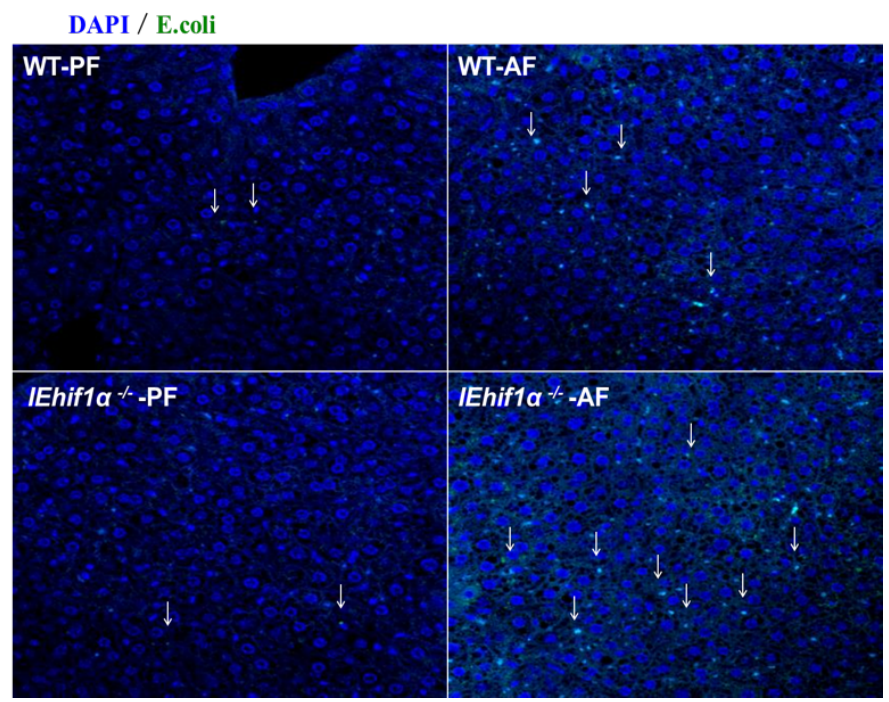

Figure 11. Effect of Hif-1a on gut permeability and bacterial translocation. (A) Serum LPS levels. (B) Hepatic staining of E. coli protein (green staining, arrows,). DAPI (blue) was used to visualize nuclei. Original magnification, $\times 10 .{ }^{*} P<0.05$ 


\section{Antibiotic Sterilization of the Gut Reduces Alcohol-Induced Liver Fat Accumulation and Injury}

To further elucidate the role of gut bacteria in alcohol-induced liver steatosis and injury in IEhif1 $\alpha^{-/-}$mice, non-absorbable antibiotics (ABx; Polymyxin B and Neomycin) were administered to the mice exposed to alcohol for 12 days. $A B x$ treatment decreased hepatic fat accumulation (Fig. 12A), liver triglyceride levels (Fig. 12B) and serum ALT levels (Fig. 12C) in both WT and IEhif1 $1 \alpha^{-/-}$mice. However, these effects were more pronounced in IEhif1 $\alpha^{-/-}$mice. These results support the concept that gut dysbiosis is critical in alcohol-induced hepatic steatosis and injury in the IEhif1 $1 \alpha^{-/-}$mice. 

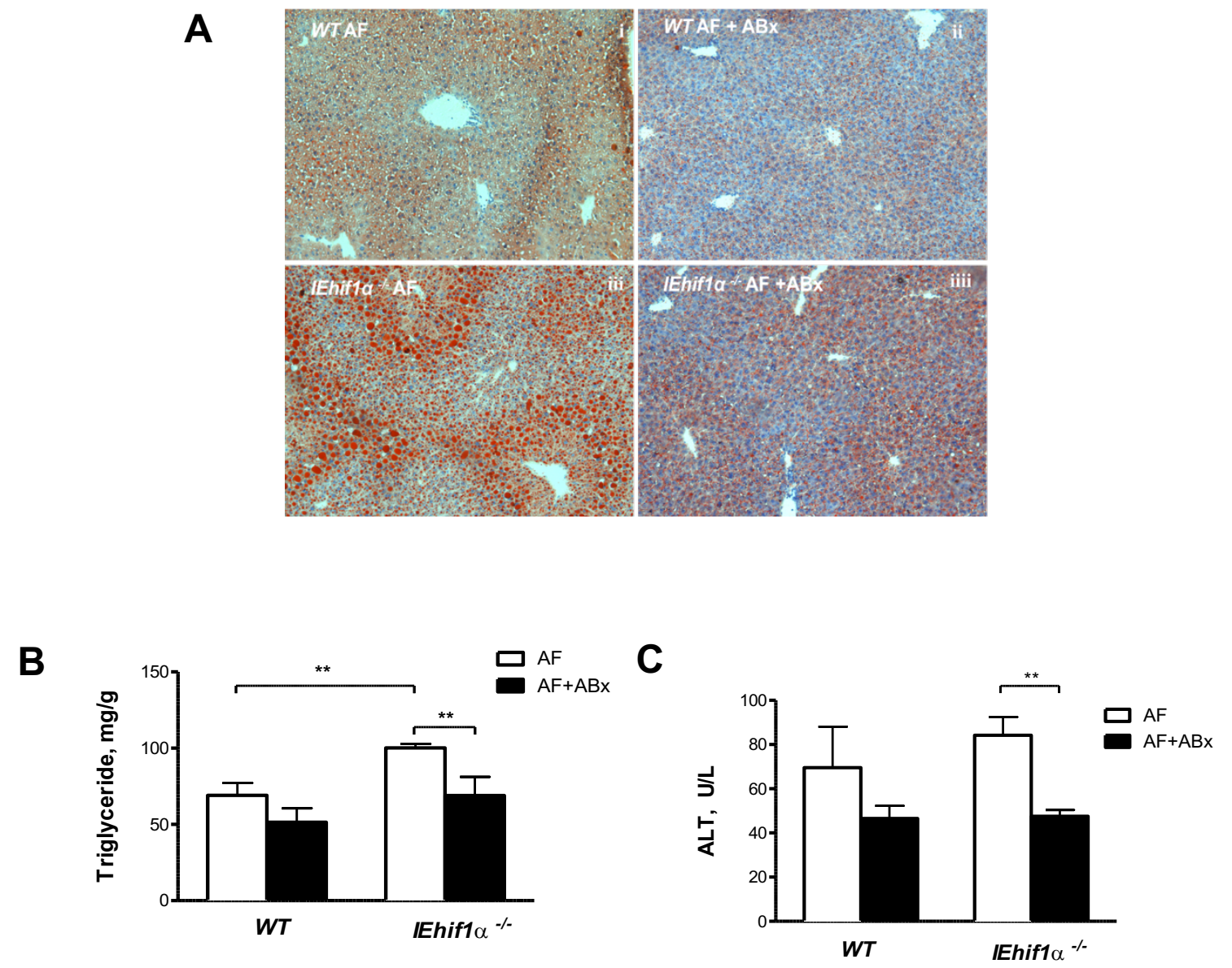

Figure 12. Effects of non-absorbable broad-spectrum antibiotics $(A B x)$ on EtOHinduced liver steatosis and injury. WT and IEhif1 $\alpha^{-/-}$mice were fed $5 \%$ alcohol liquid diets for 24 days. Antibiotics treatment was started at day 12 after alcohol feeding, and mice were gavaged daily until harvesting. (A) Oil red O staining of hepatic tissues. Original magnification, $\times 10$. (B) Quantification of hepatic triglyceride content. (C) Serum alanine aminotransferase (ALT) activities. ${ }^{* *} P<0.01$. 


\section{HIF-1 $\alpha$ is Required for the Protective Effect of Lactobacillus rhamnosus GG in ALD}

Our previous studies have shown that the probiotic, LGG, protects against ALD by increasing intestinal HIF signaling and modifying gut bacterial homeostasis [38]. In this study, we tested whether HIF-1a is required for the protective effects of LGG. IEhif $1 \alpha^{-/-}$and WT mice were fed $5 \%(\mathrm{w} / \mathrm{v})$ alcohol for 10 days and a single dose of alcohol was gavaged in the morning of last day, as described previously [37]. LGG was administered by gavage at a dose of $10^{9}$ CFU/day along with alcohol exposure. Agreeing with previous study, LGG administration significantly reduced hepatic fat accumulation resulting from alcohol exposure in WT mice. However, these protective effects were diminished in IEhif1 $\alpha^{-/}$mice, suggesting that HIF-1 $\alpha$ is required for the beneficial effects of LGG in ALD treatment (Fig. 13A, B). 
A

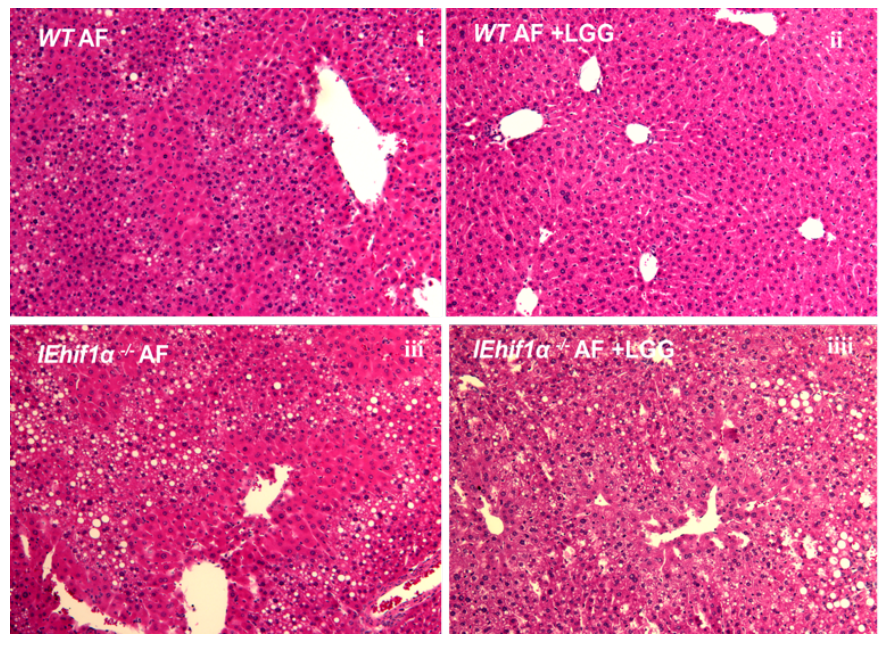

B

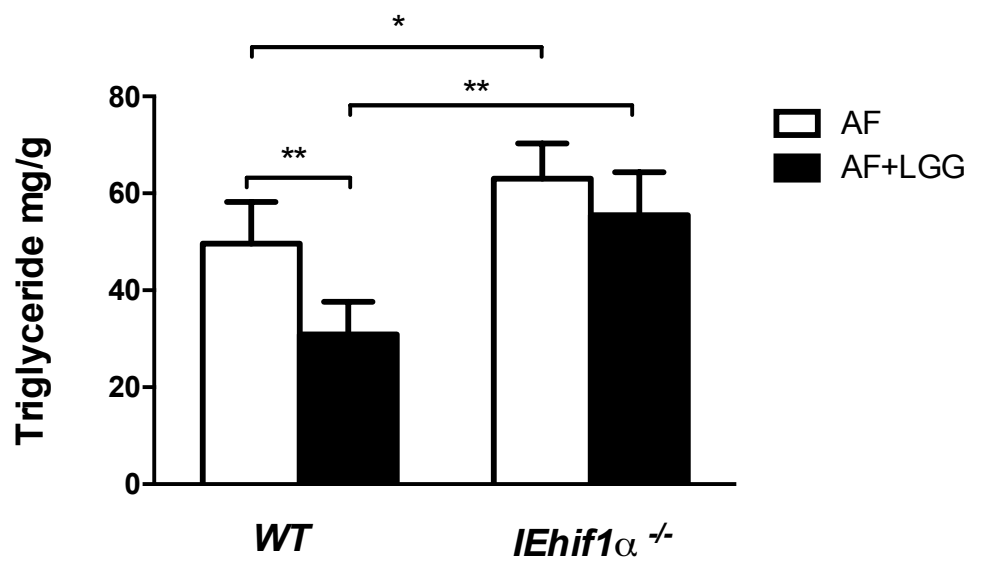

Figure 13. Effects of Hif-1a on Lactobacillus rhamnosus GG treatment in ALD. (A) HE staining revealed LGG administration reduced steatosis by alcohol exposure in WT mice. However, LGG protective effects were diminished in IEhif1 $\alpha^{--/}$mice. (B) Quantification of hepatic triglyceride content. ${ }^{*} P<0.05,{ }^{* *} P<0.01$. 


\section{DISCUSSION}

The gut-liver axis plays an important role in the pathogenesis of chronic liver disease in experimental animals and humans. Intestinal dysbiosis and the disruption of the intestinal barrier integrity by alcohol are prominent features of ALD. Previous studies demonstrated that alcohol exposure-associated changes in gut metabolites and antimicrobial peptide production contribute to ALD [6, 9, 18]. The mechanisms by which alcohol disrupts the antimicrobial peptide response leading to dysbiosis and intestinal barrier dysfunction are not fully understood. In this study, we investigated the role of intestinal HIF-1 $\alpha$ in the gutliver axis in ALD using intestinal epithelial specific HIF-1a deficient mice. In IEhif1 $\alpha^{-1-}$ mice, 24-day alcohol exposure diminished the HIF-1a-mediated adaptive response on intestinal integrity and gut bacterial homeostasis, resulting in an exacerbated liver steatosis, inflammation, fibrosis and injury.

Pathogenic bacteria overgrowth and a reduction of beneficial bacteria constitute gut dysbiosis in ALD. The gut microbiota homeostasis is controlled by bacteria-bacteria and bacteria-host interactions under both healthy and diseased conditions. Alcohol exposure disrupts microbiota homeostasis. However, the gut mucosal response has adaptive mechanisms to restore homeostasis by increasing antimicrobial substances. We postulate that epithelial HIF-1 $\alpha$ represents such an adaptive mechanism. We speculated that disruption of HIF1a signaling in the intestine would cause/exacerbate gut dysbiosis following alcohol exposure. Consistent with our previous research, 24-day alcohol exposure changed gut microbiota homeostasis slightly in WT mice. However, 
depletion of intestinal epithelial HIF-1 1 resulted in a more severe dysbiosis. The IEhif1 $\alpha^{-/-}$mice had reduced Firmicutes and increased Bacteroidetes in their fecal samples. Such a change has been shown in a mouse model of ALD using intragastric feeding [40]. At the bacterial species level, Akkermansia (Akk), gramnegative anaerobic bacteria, were not affected by alcohol in WT mice, but were increased in the IEhif1 $\alpha^{-/-}$mice. The role of Akk in the ALD remains elusive. Supplementation with Akk showed a protective effect in ALD [41], while an endogenous increase of Akk may impact the intestinal innate immune system and facilitate bacterial translocation by degrading the intestinal mucus [42, 43]. The causal relation between an intestinal increase in Akk and intestinal integrity needs further study. Interestingly, Lactobacillus bacteria were markedly depleted by 24-day alcohol exposure in WT mice, and this decrease was even more pronounced in IEhif1 $1{ }^{-/-}$mice. A recent study demonstrated that Lactobacillus utilized saturated long-chain fatty acids, and these saturated fatty acids were beneficial in ALD treatment [44]. A short-chain fatty acid, butyrate, plays an essential role in epithelial cell nutrition and intestinal physiology. Butyrate regulates epigenetic processes through HDAC inhibition. Intestinal consumption of butyrate causes local hypoxia leading to increased HIF-1a expression. Although Lactobacillus itself does not produce butyrate, studies have shown that Lactobacillus promotes eubiosis, thereby resulting increased butyrate production. Butyrate-producing bacteria are mainly in the phylum Firmucutes, which was decreased by alcohol in our study. Furthermore, the decrease of Lactobacillus in ALD is consistent with the beneficial effect of LGG supplementation on ALD as 
shown by several authors $[37,38,45-47]$. Taken together, our results demonstrate that depleting intestinal epithelial HIF-1 $\alpha$ causes gut dysbiosis following a 24-day alcohol feeding regimen in mice.

$\mathrm{HIF-1 \alpha}$ is a master transcription factor regulating a variety of genes in the intestine. Anti-microbial peptides, $\beta$-defensin and CRAMP, are regulated by HIF$1 \alpha[27,30]$. Paneth cell-derived $\beta$-defensins and epithelial cell- and microphagederived CRAMP regulate gut microbiota homeostasis. Our results showed that $\beta$ defensins were adaptively increased and CRAMP was decreased by 24-day alcohol exposure in WT mice. However, depleting HIF-1 $\alpha$ eliminated $\beta$-defensin upregulation and further decreased CRAMP. This, at least partially, explains why IEhif $1 \alpha^{-/-}$mice developed dysbiosis following alcohol exposure. In contrast, activation of HIF-1 $1 \alpha$ in epithelial T84 cells inhibited bacterial growth and increased antimicrobial gene expression. In vivo activation of HIF-1a by DMOG demonstrated a partial prevention of ALD. However, this observation is not conclusive because DOMG treatment is not intestine specific. While intestinal HIF-1 $\alpha$ might be beneficial in ALD, hepatic activation of HIF-1 $\alpha$ showed contradictory results $[48,49]$. The causative role of gut dysbiosis in IEhif $1 a^{-/-}$mice in ALD was further demonstrated by sterilization of the gut using non-absorbable antibiotics. Treatment with $A B x$ reduced $A L D$ regardless the presence or absence of the HIF-1a gene in mice.

Previous studies in inflammatory bowel disease showed that intestinal HIF$1 \alpha$ deficiency causes intestinal leakiness $[28,33]$. The current study showed that IEhif1 $\alpha^{-/-}$mice had an increase in intestinal permeability in ALD [9]. Subsequently, 
bacteria and bacterial products translocated from the intestinal lumen to the systemic circulation and liver. As shown in our results, IEhif1 ${ }^{-/-}$mice displayed a higher LPS level in the serum and an increased $E$. coli protein in the liver after alcohol feeding. LPS binds to TLR4 on hepatocytes and Kupffer cells resulting in hepatic fat accumulation and inflammation in ALD, which is an established and well-studied mechanism in chronic ALD.

How does HIF-1 $\alpha$ impact intestinal barrier function? In addition to the effect of HIF-1 $1 \alpha$ on antimicrobial peptide regulation, HIF-1 $1 \alpha$ also regulates several critical factors that are important in intestinal barrier integrity. P-gp functions as a pump by expelling translocated xenobiotics and bacterial toxins from the enterocytes into the intestinal lumen. ITF is a mucus modifier that helps to maintain a dynamic mucus layer. Claudin-1 is a major tight junction protein in the intestinal epithelial. Previous studies have demonstrated that these proteins are HIF-1 $\alpha$ targets $[19,26,28]$. Reduction in ITF, claudin-1 and P-gp in IEhif1 $\alpha^{-/-}$mice following alcohol exposure destabilizes gut barrier function resulting in elevated LPS concentration in serum and E. coli protein in the liver, as seen in our study. In addition, previous studies also showed that alcohol exposure increased intestinal Cyp2E1 expression [50], which is responsible for the production of ROS in the intestine. Furthermore, alcohol feeding significantly increased intestinal inflammation in IEhif1 $\alpha^{-/-}$mice. Taken together, these multiple mechanisms contribute to the exacerbated gut barrier dysfunction in IEhif1 $1{ }^{-/-}$mice in ALD.

Our previous studies have shown that long-term (8 weeks) alcohol exposure decreased HIF-2 $\alpha$ protein levels in mouse intestine [37]. However, HIF- 
$1 \alpha$ was not evaluated. Given the importance of HIF-1a in the regulation of intestinal homeostasis, we examined the expression of HIF-1a in this study. To our surprise, 24-day alcohol exposure increased HIF-1a mRNA expression in WT mice. However, a decreased HIF-1 $1 \alpha$ expression in the ileum was observed after 48 days alcohol exposure. The HIF-1 $\alpha$ target genes, $\beta$-defensins, $P$-gp and ITF $[19,26,30]$, were also increased in the WT mice by 24 days alcohol exposure.

The increase in HIF-1a signaling resulting from the relatively short alcohol exposure (24 days) likely represents an adaptive upregulation during the initial period. However, this adaptive response is decreased with prolonged alcohol exposure. Depletion of intestinal HIF-1a gene diminished the upregulation of these antimicrobial peptides and barrier protective genes, suggesting a HIF-1 $\alpha$ mediated transcriptional regulation.

Our previous studies demonstrate that the probiotic, LGG, is beneficial in preventing/treating of ALD in mice. However, the beneficial effects were diminished when HIF-1a was deleted in the intestine. LGG is able to increase the luminal concentrations of long-chain fatty acids and short-chain fatty acids in mice exposed to alcohol. Lactobacilli, in turn, metabolize saturated fatty acids to keep their growth. On the other hand, supplementation with tributyrin, a prodrug of butyrate, protects from intestinal tight junction disruption by alcohol [44]. Currently, it is still unclear as to how butyrate protects tight junctions, but other research showed that butyrate metabolism in in the intestine consumes oxygen and stabilizes HIF-1 $\alpha$ [51], which is protective in the intestinal barrier. Thus, it is likely that LGG promotes butyrate-producing bacteria growth, and the resulting 
butyrate production increases HIF-1 $\alpha$ stabilization and protects the intestinal barrier. Intestinal HIF-1a depletion abolishes this protective effect of LGG against alcohol-induced intestinal barrier disruption.

In conclusion, our findings demonstrate that intestinal epithelial HIF-1 $\alpha$ is critically involved in the intestinal pathogenesis of alcohol-induced barrier disruption and subsequent liver injury. HIF-1 $\alpha$ activation regulates gut bacterial homeostasis though increasing anti-microbial peptides and stabilizes barrier function via upregulation of P-gp and tight junction proteins. The probiotic, LGG, exerts its beneficial effects through intestinal HIF-1a-mediated pathways in ALD. Dietary approaches and pharmacological agents that activate intestinal HIF-1 $\alpha$ could be developed to prevent/treat ALD. 


\section{CHAPTER II}

\section{DSS-INDUCED INTESTINAL DAMAGE EXACERBATES LIVER INJURY BY ACUTE ALCOHOL EXPOSURE IN MICE: ROLE OF INTESTINAL HYPOXIA-INDUCIBLE FACTOR 1a}

\section{INTRODUCTION}

An acute form of alcoholic liver disease (ALD), alcoholic hepatitis (AH) is a specific clinical syndrome characterized by hepatocellular necrosis, jaundice, an inflammatory reaction with numerous polymorphonuclear leukocytes and fibrosis in patients with a recent history of heavy alcohol consumption [1-3]. AH has been linked with excessive alcohol drinking over a prolonged period of time. However, it is now recognized that many patients diagnosed with $\mathrm{AH}$ report alcohol use over shorter periods of time before diagnosis. Binge drinking is defined by the National Institute on Alcohol Abuse and Alcoholism as the consumption of 5 or more drinks by a male or 4 or more drinks by a female in about 2 hours, resulting in a blood alcohol concentration of $0.08 \%$ or greater $[4,5]$.

The importance of the gut-liver axis is increasingly recognized in alcoholic liver disease and in decompensation in other chronic liver diseases [6-8]. Animal and human studies have shown that alcohol consumption causes "leaky gut," translocation of bacteria and microbial compounds across the intestinal 
basement membrane into the portal and systemic circulation. Emerging evidence has revealed an acute dose of alcohol increases circulating markers of bacterialproduct translocation across the gut barrier even in healthy individuals[9]. Circulating bacterial products such as lipopolysaccharide (LPS) are one of the hallmarks of ALD. They can activate Toll-like receptor 4 (TLR-4) signaling pathways and initiate an innate immune response[10]. However, the mechanisms for induction of inflammation in ALD have not been clarified completely.

Inflammatory bowel diseases (IBD), chronic intestinal inflammatory process, are characterized by repeated injury of the intestinal mucosa, loss of the intestinal epithelial barrier function and microvascular disturbance [11-13]. Exposure to DSS (dextran sulfate sodium) leads to increased intestinal permeability and mucosal changes in the ileum and colon in experimental animals $[14,15]$. This chronic colitis model results in increased portal LPS concentrations, which may be a clue to the development of ALD in patients with chronic or binge alcohol consumption. However, the involvement of alcohol consumption in IBD-associated ALD has not been explored in previous studies.

Observations from both humans and experimental animals suggest that colonic hypoxia is significantly increased to the gut following both alcohol exposure and colitis $[16,17]$. Interestingly, a number of barrier-protective and anti-microbial peptide genes are critically regulated by hypoxia-inducible factor$1 \alpha$ (HIF-1 $\alpha$ ), including intestinal trefoil factor (ITF), claudin-1, multidrug resistance gene-1 (MDR1), $\beta$-Defensin-1 and CRAMP [18-22]. HIF-1 $\alpha$ is expressed in inflamed mucosa from IBD patients and mouse models of colitis. 
Studies of murine IBD have revealed that loss of epithelial HIF-1 $\alpha$ correlates with more severe clinical symptoms, whereas constitutive activation of HIF-1 is protective [23]. Our previous studies also determined that intestinal epithelial specific HIF-1a knockout worsened alcohol-induced liver injury and resulted in a more severe dysbiosis. Despite this, the role of intestinal HIF-1a in IBD patients and an animal model of colitis with chronic and binge alcohol consumption has rarely been examined. According, the aim of this current study was to determine whether intestinal HIF1a deletion increases intestinal permeability resulting in an elevation of endotoxemia in a dextran sulfate sodium (DSS)-induced colitis murine model, and exacerbates acute alcohol-induced intestinal damage and liver injury.

\section{MATERIALS AND METHODS}

\section{Animal Models of Dextran Sulfate Sodium and Alcohol Feeding}

C57BL/6J, hif1 $\alpha_{-}^{f / / f l}$, Villin-Cre and $C A M P^{-/-}$mice were purchased from Jackson Laboratory (Bar Harbor, ME). IEhif1 $\alpha^{-/-}$mice were generated by crossing hif1 $\alpha_{-}^{\text {fl/fl }}$ and Villin-Cre mice as previous described. Colitis was induced by feeding mice $3 \%$ DSS dissolved in drinking water for 7 days, and the mice were killed by decapitation on the seventh evening. Control mice received water without DSS. A model of binge alcohol was made by the treatment of mice with EtOH gavage at a dose of $6 \mathrm{~g} / \mathrm{kg}$ body weight and the mice were killed $9 \mathrm{~h}$ after the administration. Control mice were gavaged with an iso-caloric amount of dextrose. The DSS plus alcohol model was produced in mice pre-treated DSS 7 days, then given $\mathrm{EtOH}$ 
gavage at a dose of $6 \mathrm{~g} / \mathrm{kg}$. The mice were killed $9 \mathrm{~h}$ after the ethanol administration. All animal protocols were approved by the Institutional Animal Care and Use Committee of the University of Louisville.

\section{Histological analysis}

The liver and small intestine tissues were collected in $4 \%$ paraformaldehyde and then imbedded in paraffin. Tissues were cut into $5 \mu \mathrm{m}$ sections and stained with hematoxylin and eosin (H\&E) and analyzed by light microscopy. Apoptotic cell death in the liver and cell culture was assessed by detection of DNA fragmentation using an ApopTag peroxidase in situ apoptosis detection kit (Millipore, Billerica, MA). Goblet cells were stained with Alcian blue (Sigma, St. Louis, MO) and counterstained with Nuclear Fast Red.

\section{Tissue triglyceride}

Liver tissues were homogenized in distilled water and the homogenate was collected for lipid extraction. Triglyceride content was determined using commercially available colorimetric kits (Thermo Scientific, Waltham, MA).

\section{Serum ALT and AST assay}

Mouse serum was collected by orbital vein bleeding at time of euthanasia. Serum alanine aminotransferase (ALT) and aspartate aminotransferase (AST) were analyzed by an Infinity kit (Thermo Scientific, Waltham, MA). 


\section{ELISA assays}

IL-6 and TNF- $\alpha$ levels in serum were measured with ELISA assay kits (BD, Sparks, MD). Serum CRAMP level was measured by ELISA assay kit (Mybiosource, San Diego, CA).

\section{Endotoxin assay}

All material used for harvesting blood and measuring endotoxin was pyrogen free. An endpoint, chromogenic Limulus amebocyte lysate (LAL) endotoxin kit was used to determine plasma LPS levels according to the manufacturer's protocol (Lonza, Basel, Switzerland).

\section{Immunofluorescent staining of FFPE tissue.}

Formalin-fixed paraffin embedded (FFPE) tissue was processed for staining as described previously with slight modification. Following deparaffinization, antigen retrieval was performed in unmasking solution (Vector Laboratories, Burlingame, CA) for 20 min at $125^{\circ} \mathrm{C}$ in a Decloaking chamber (Biocare Medical, Pacheco, CA). Unreacted aldehydes were quenched for 10 min with $1 \% \mathrm{NaBH}_{4}$. Prior to blocking, ImagelT enhancer (Invitrogen, Carlsbad, CA) was applied to each section. Non-specific antibody binding was blocked with either 1\% IgG-free BSA or 5\% Normal donkey serum (Jackson Immuno, West Grove, PA) in TBS (Trisbuffered saline), depending on the antibodies used. Primary antibodies were incubated overnight at $4^{\circ} \mathrm{C}$. Sections were washed with TBS and AlexaFluorconjugated secondary antibodies (Invitrogen) were applied for 30 min at room 
temperature. DAPI counterstain (Invitrogen) was used to image nuclei, and slides were mounted with ProLong gold (Invitrogen). Primary antibodies used were: TLR-4 (Abcam) and Claudin-1 (Santa Cruz, Dallas, TX).

\section{Western blot analysis}

Liver and ileal tissues were lysed on ice for $30 \mathrm{~min}$ in IPB $(50 \mathrm{mM}$ Tris $\cdot \mathrm{HCl}, \mathrm{pH}$ 7.4, $150 \mathrm{mM} \mathrm{NaCl}, 2 \mathrm{mM}$ EDTA, $4 \mathrm{mM} \mathrm{Na}_{3} \mathrm{VO}_{4}, 40 \mathrm{mM} \mathrm{NaF}, 1 \%$ Triton X-100, 1 $\mathrm{mM}$ PMSF, $1 \%$ protease inhibitor cocktail) and centrifuged at $14,000 \times \mathrm{g}$ for 10 min. The supernatants were collected. An appropriate amount of protein in total tissue lysates was resolved by SDS-polyacrylamide gel electrophoresis and transferred onto a polyvinylidene difluoride membrane (Whatman, Sanford, ME). Membranes were blocked for $1 \mathrm{~h}$ in Tris-buffered saline/Tween 20 (10 mM Tris$\mathrm{HCl}, \mathrm{pH} 8.0,150 \mathrm{mM} \mathrm{NaCl}$, and $0.05 \%$ Tween 20 ) containing $5 \%$ nonfat dry milk and incubated overnight at $4^{\circ} \mathrm{C}$ with the different primary antibodies diluted in blocking buffer. Subsequently, membranes were incubated with peroxidaseconjugated second antibodies. Following treatment with supersignal west HRP substrate (MilliporeSigma, Billerica, MA), protein bands were detected by a ChemiDoc Molecular Imager (Bio-Rad, Hercules, CA). Data were normalized to $\beta$-actin.

\section{Quantification of GFP-E.coli translocation toward mesenteric adipose tissue to liver}


Ampicillin-resistant GFP-E.coli were obtained from R'emy Burcelin's lab (Rangueil Hospital, Department of Therapeutics, Toulouse, France). Five hours after gavage with $10^{9}$ GFP-E.coli, mice were sacrificed. Mesenteric adipose tissue (MAT) and liver were harvested. Tissues were then homogenized in Luria Broth (LB) (BD, Sparks, MD), plated onto ampicillin-supplemented $(100 \mathrm{mg} / \mathrm{ml})$ LB agar, and yellow colonies were enumerated after overnight incubation at $37^{\circ} \mathrm{C}$.

\section{Results}

\section{Intestinal epithelial Hif1a-deficiency exacerbates DSS-induced colitis}

First, the role of intestinal epithelial Hif1 $\alpha$ in inflammatory bowel disease

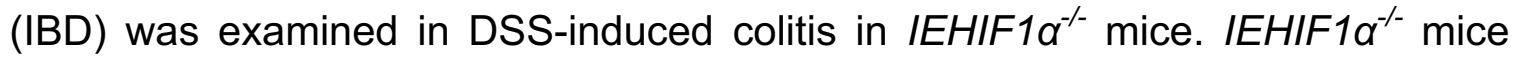
and the control mice were treated with DSS (3\%) in drinking water for seven days. All of mice that received DSS developed typical clinical signs of colitis, including weight loss, diarrhea and rectal bleeding. As shown in Fig 1A, 7-day DSS treatment reduced body weight by about $10 \%$ in WT mice, but by nearly $30 \%$ in

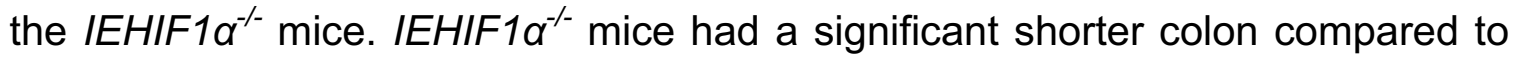
the control mice, which is a symptom of DSS-induced colitis in mice (Fig. 1B). Overall disease scores were higher in the IEHIF1 $\alpha^{-/-}$mice than in the control mice (Fig 1C). As expected, DSS treatment significantly increased spleen size, indicating an increased systemic inflammation. However, there was no difference in spleen/body weight between control and IEHIF1a ${ }^{-/}$mice (Fig. 1D). The liver/body weight ratio was not changed by DSS treatment in either control mice 
or the IEHIF1 $\alpha^{-/-}$mice (Fig. 1E). H\&E staining of liver sections revealed normal liver histology in both control and the IEHIF1 $\alpha^{-/}$mice fed DSS (Fig. 1F). The hepatic triglyceride level and ALT, AST levels confirm the histological observation (Fig. 1G, H). These results indicate that DSS-induced acute colitis did not affect liver fat metabolism and liver injury. 
A

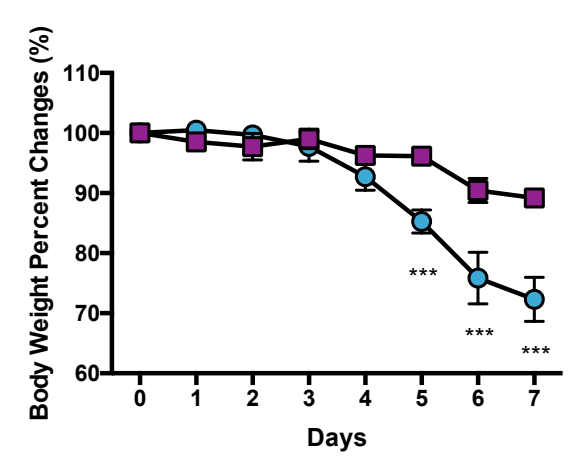

C

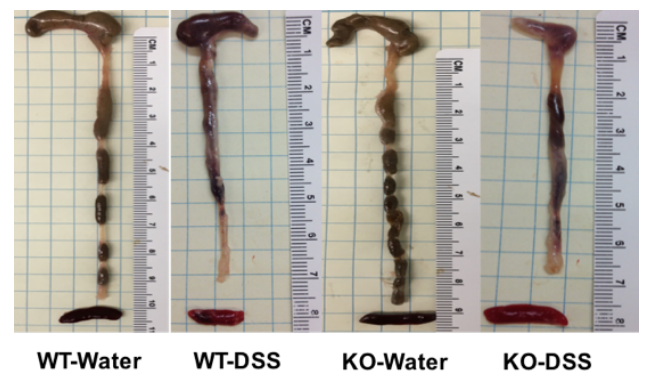

D

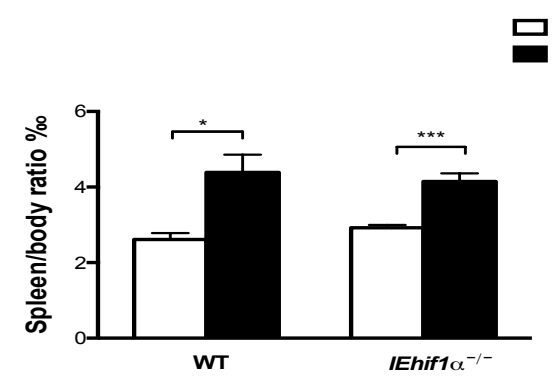

B

마 WT-DSS

- o. KO-DSS
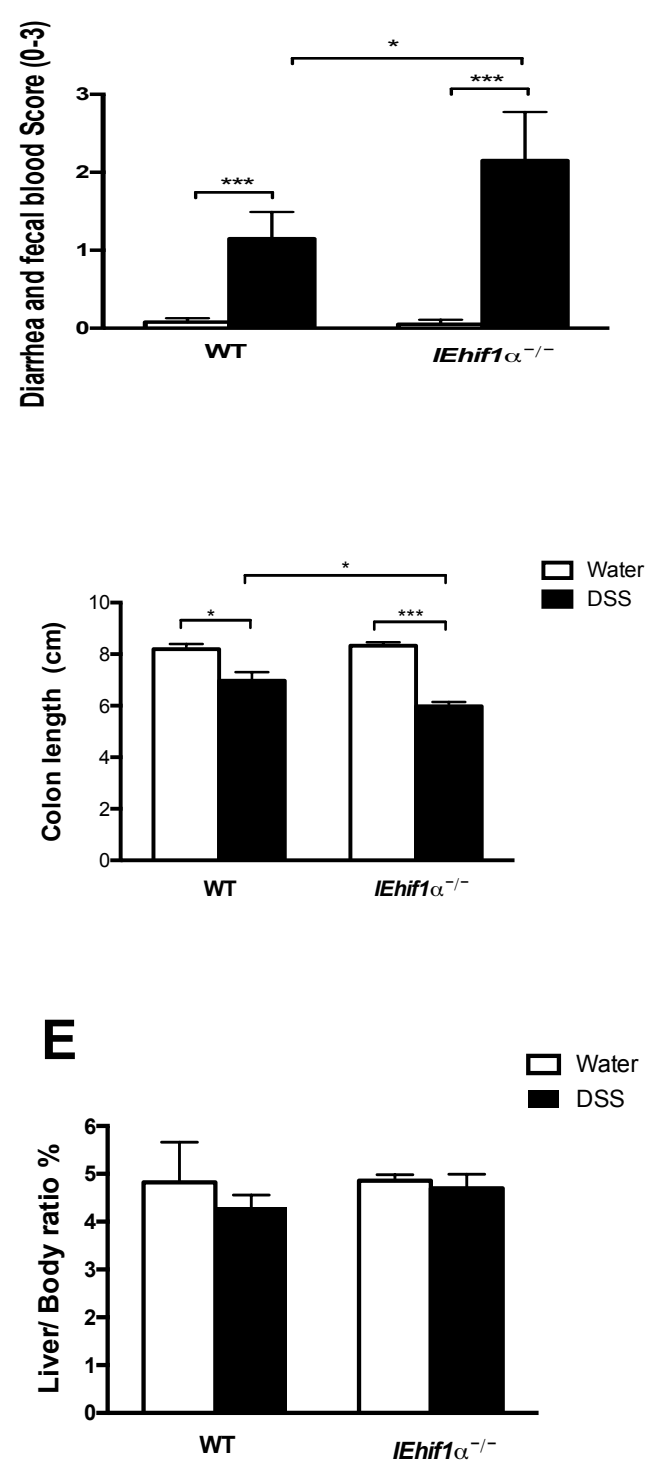
F

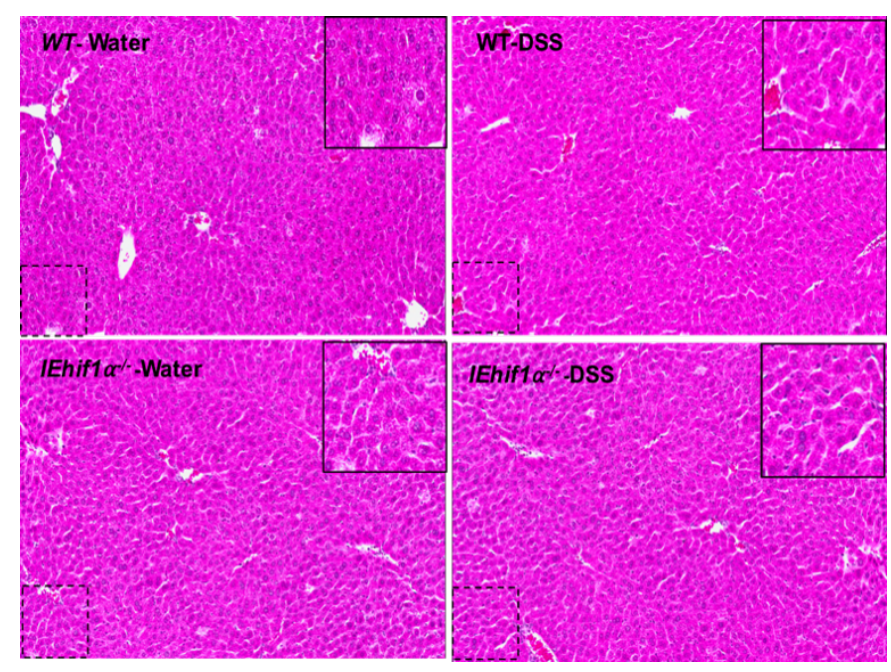

G

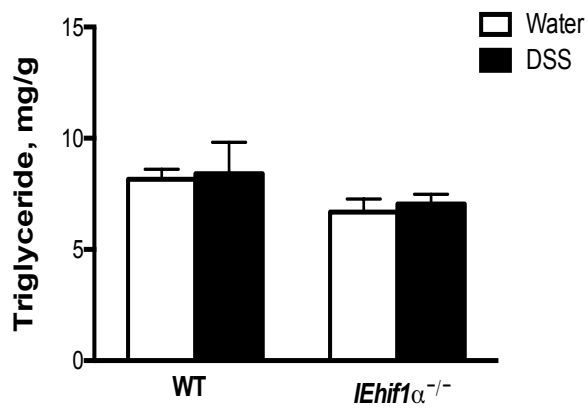

H

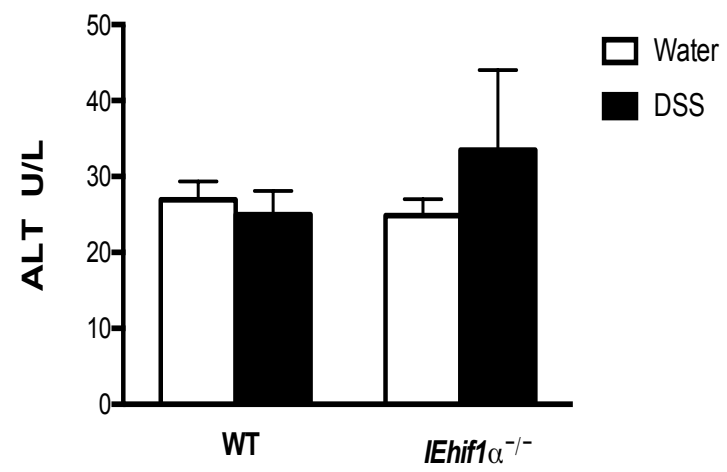

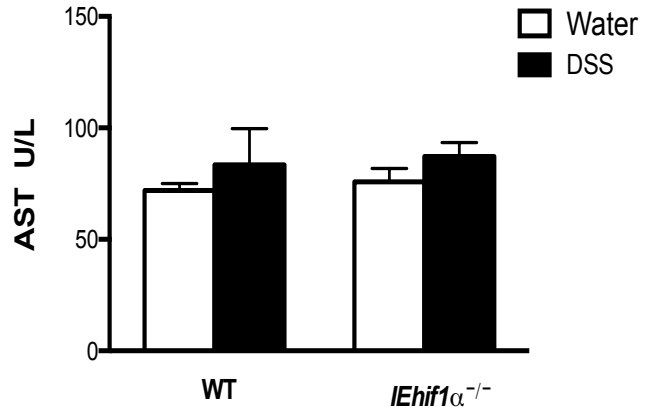


Figure 1. Effect of DSS on clinical symptoms and liver histopathological signs in a mouse colitis model. (A) Changes in body weights and (B) clinical scores of IEHIF1 ${ }^{-/-}$mice and control mice administered 3\% DSS; mice were monitored every day. Body weight values are expressed as a percentage of the starting body weight. (C) Colons were excised from mice and their lengths were measured 7 days after initiating DSS administration. Macroscopic features of the colons. (D, E) Liver/spleen weight to body weight ratio of WT and IEhif1 $1 \alpha^{-/-}$mice fed water or DSS. (F) Hematoxylin and eosin staining of the liver sections of water and DSS WT and IEhif1 $\alpha^{-/-}$mice. Original magnification, $\times 10 .(G)$ Serum alanine aminotransferase (ALT) and aspartate aminotransferase (AST) activities of water and DSS WT and IEhif1 $\alpha^{-/-}$mice. ${ }^{*} P<0.05,{ }^{* * *} P<0.001$. 


\section{Acute EtOH on DSS increases systemic inflammation}

To evaluate the effect of acute alcohol exposure on animals with DSSinduced colitis, we administered $\mathrm{EtOH}(6 \mathrm{~g} / \mathrm{kg})$ by oral gavage 9 hours before sacrifice on the last day. Acute alcohol did not affect body weight or colon length (Fig. 2A, B). However, alcohol on DSS treatment significantly increased spleen/body weight ratio in the IEHIF1 $1 \alpha^{-/-}$mice compared to the WT mice (Fig. 2C). In addition, alcohol on DSS increased serum TNF- $\alpha$ and IL-6 level in

IEHIF1 $\alpha^{-/-}$mice (Fig. 2D, E), suggesting that intestinal epithelial HIF-1 $\alpha$ plays a critical role in alcohol-induced systemic inflammation. 

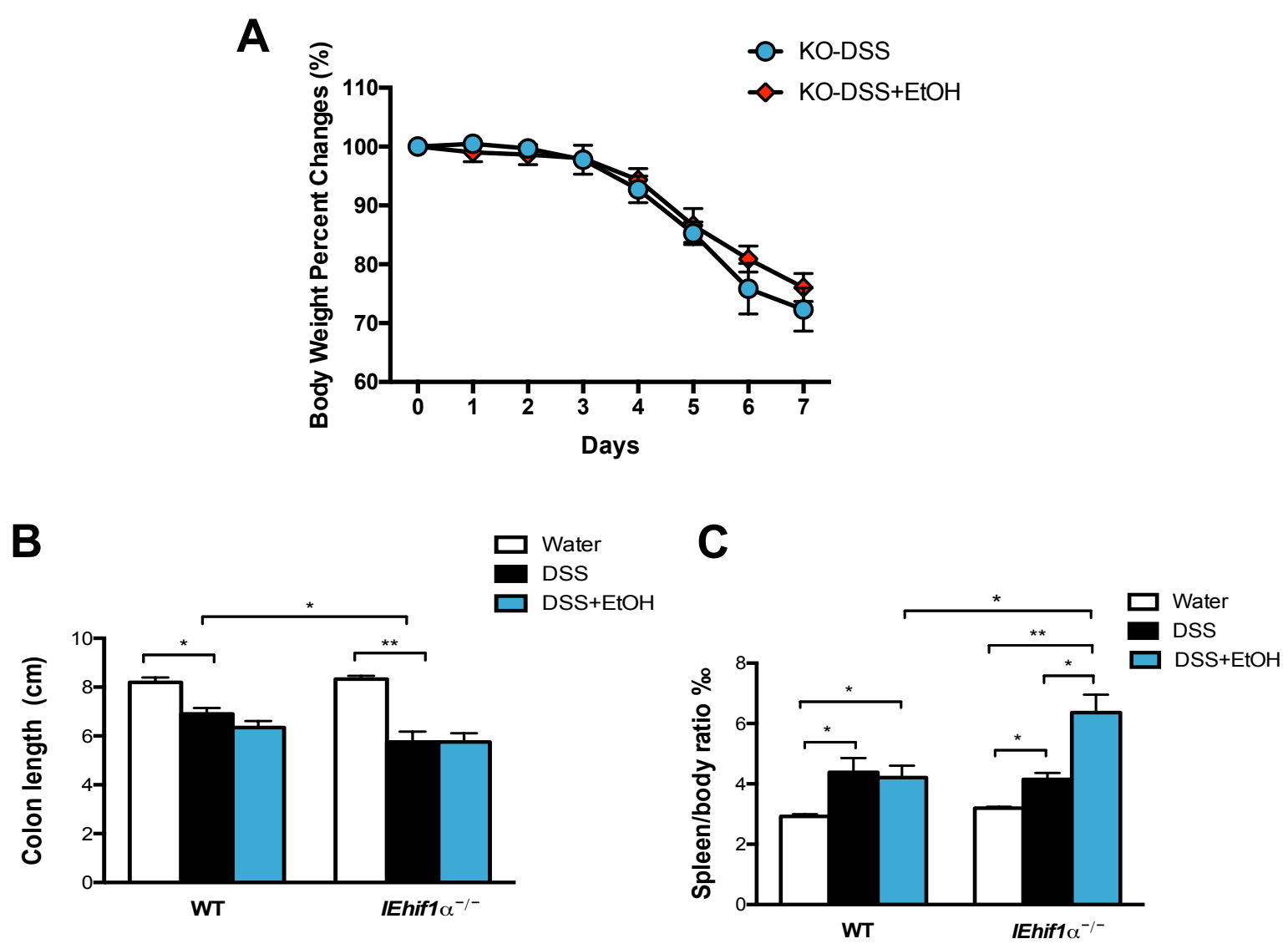

D

E
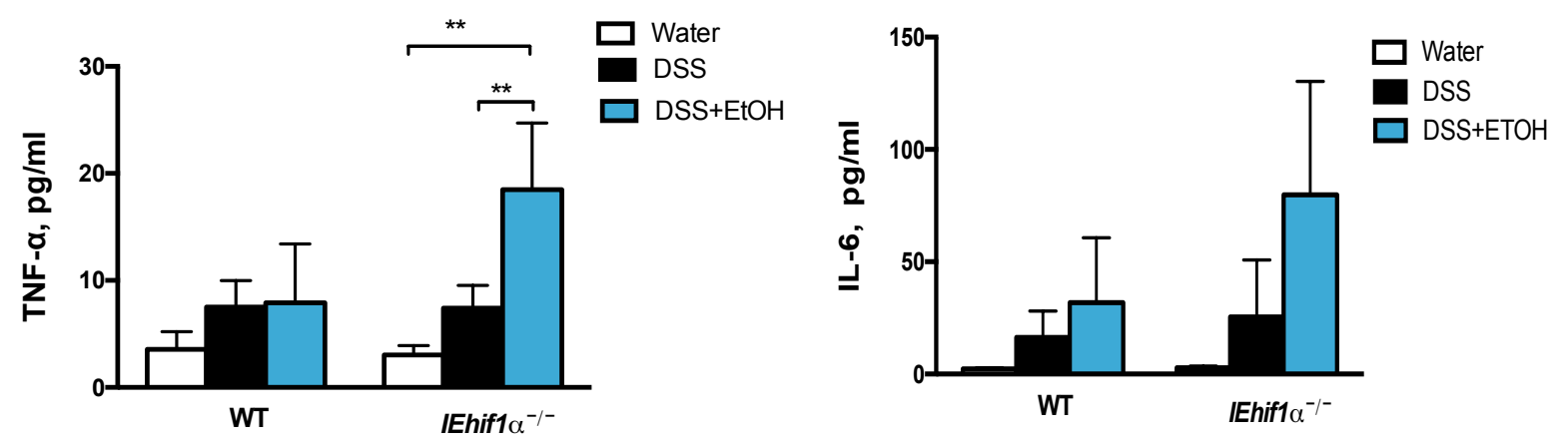
Figure 2. Inflammatory responses in binge $\mathrm{EtOH}$ on DSS-induced colitis. (A) Changes in body weights of IEHIF1a $\alpha^{-/}$mice and control mice administered 3\% DSS plus one binge of $6 \mathrm{~g} / \mathrm{kg} \mathrm{EtOH}$. (B) Colons were excised from mice and their lengths were measured 7 days after initiating 3\% DSS with EtOH administration. (C) Spleen weight to body weight ratio of WT and IEhif1 $\alpha^{-/-}$mice fed $3 \%$ DSS with binge EtOH. (D, E) Systemic expression of proinflammatory cytokines TNF- $\alpha$ and IL-6 in serum. ${ }^{*} P<0.05,{ }^{* *} P<0.01,{ }^{* * *} P<0.001$. 


\section{DSS-induced colitis enhances binge alcohol induced hepatic inflammation}

Plasma ALT levels were significantly enhanced by acute alcohol administration in both WT and IEHIF1a ${ }^{-/-}$mice, while plasma AST showed a marginal increase (Fig. 3A and 3B). Interestingly, when the mice were pretreated with DSS, acute EtOH only marginally increased plasma ALT and AST levels in WT mice, while a significant increase in ALT and AST was observed in the IEHIF $1 \alpha^{-/-}$mice (Fig. 3A and 3B). However, hepatic TG had only a trend of increase in both types of mice when the colitis mice were exposed to EtOH (Fig. 3C). H\&E staining of the liver sections showed an increase in steatosis in both types of mice, but the degree of steatosis was higher in the IEHIF1 ${ }^{-/-}$mice (Fig. 3D).

Next, we measured hepatic apoptosis. TUNEL assay revealed that acute $\mathrm{EtOH}$ administration in DSS-primed mice significantly increased apoptotic cell death in both types of mice. However, the apoptotic cells were significantly greater in number in the IEHIF1 $1 \alpha^{-/}$mice compared to WT mice (Fig. 3E).

TLR4 mediates the inflammatory effects in the liver in response to endotoxin (LPS) derived from the gut lumen. Immunofluorescent staining of TLR4 in liver tissues and hepatic TLR4 immunoblotting showed no differences among groups of WT mice and IEHIF1 $\alpha^{-/-}$mice fed EtOH (Fig. 3F and 3G). However, alcohol on DSS significantly increased hepatic TLR4 expression in both types of mice. Comparing the WT mice and IEHIF1 $\alpha^{-/-}$mice, we observed a significant increase in TLR4 protein level in the livers of IEHIF1a ${ }^{-/-}$mice (Fig. 3F and 3G). Taken together, the data presented above demonstrate that DSS pretreatment 
primed mice for acute alcohol-induced liver injury; intestinal epithelial HIF-1 $\alpha$ depletion exacerbated the outcomes. 
A

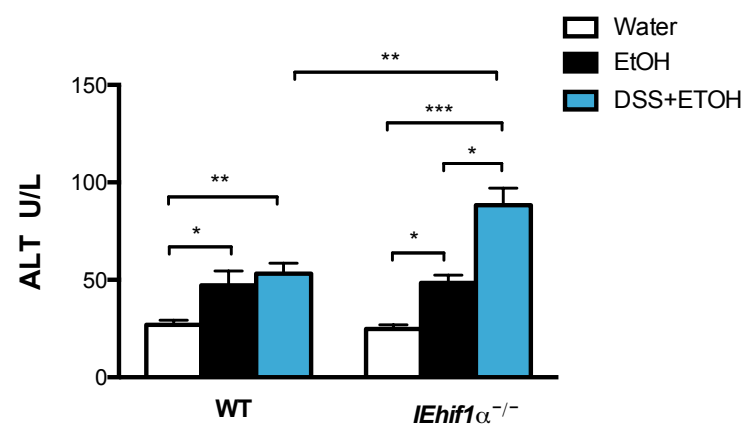

C

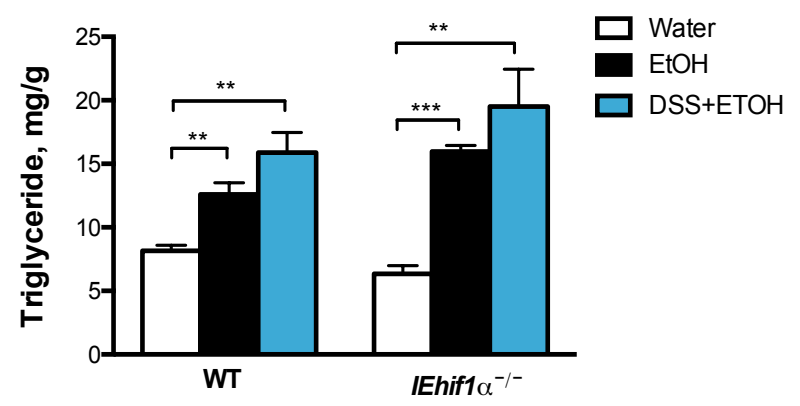

D
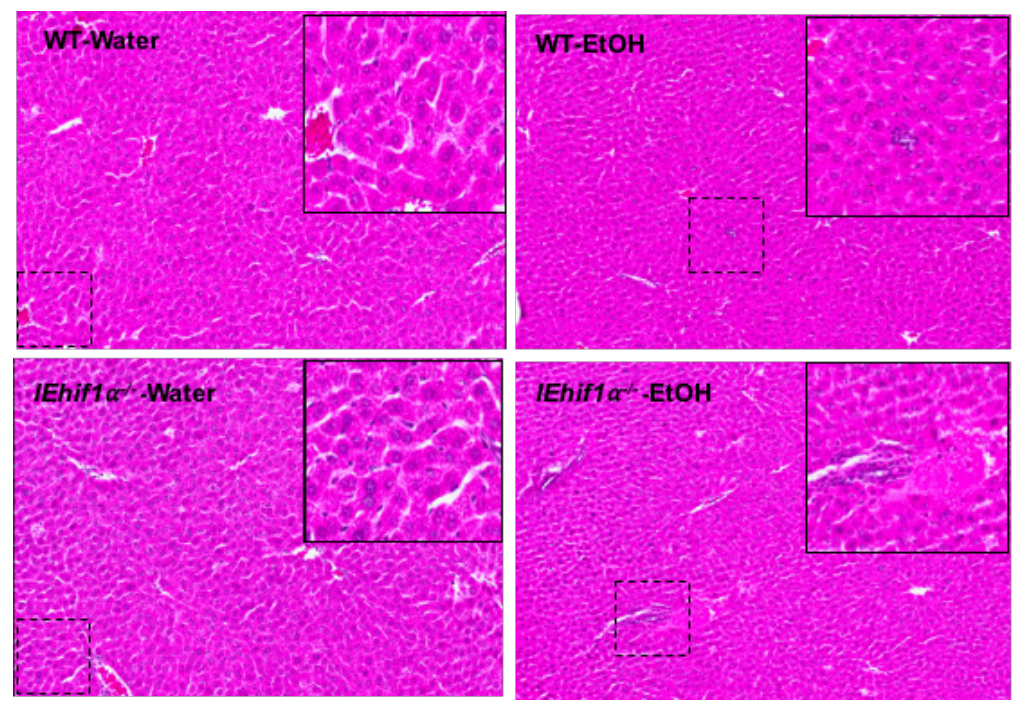

B

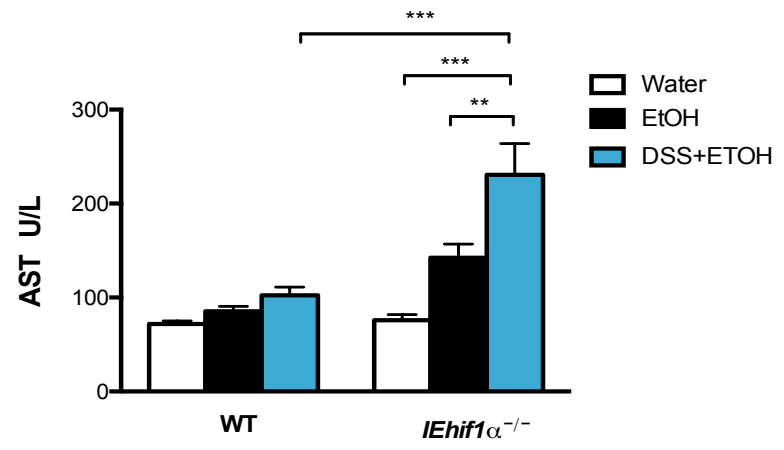


E
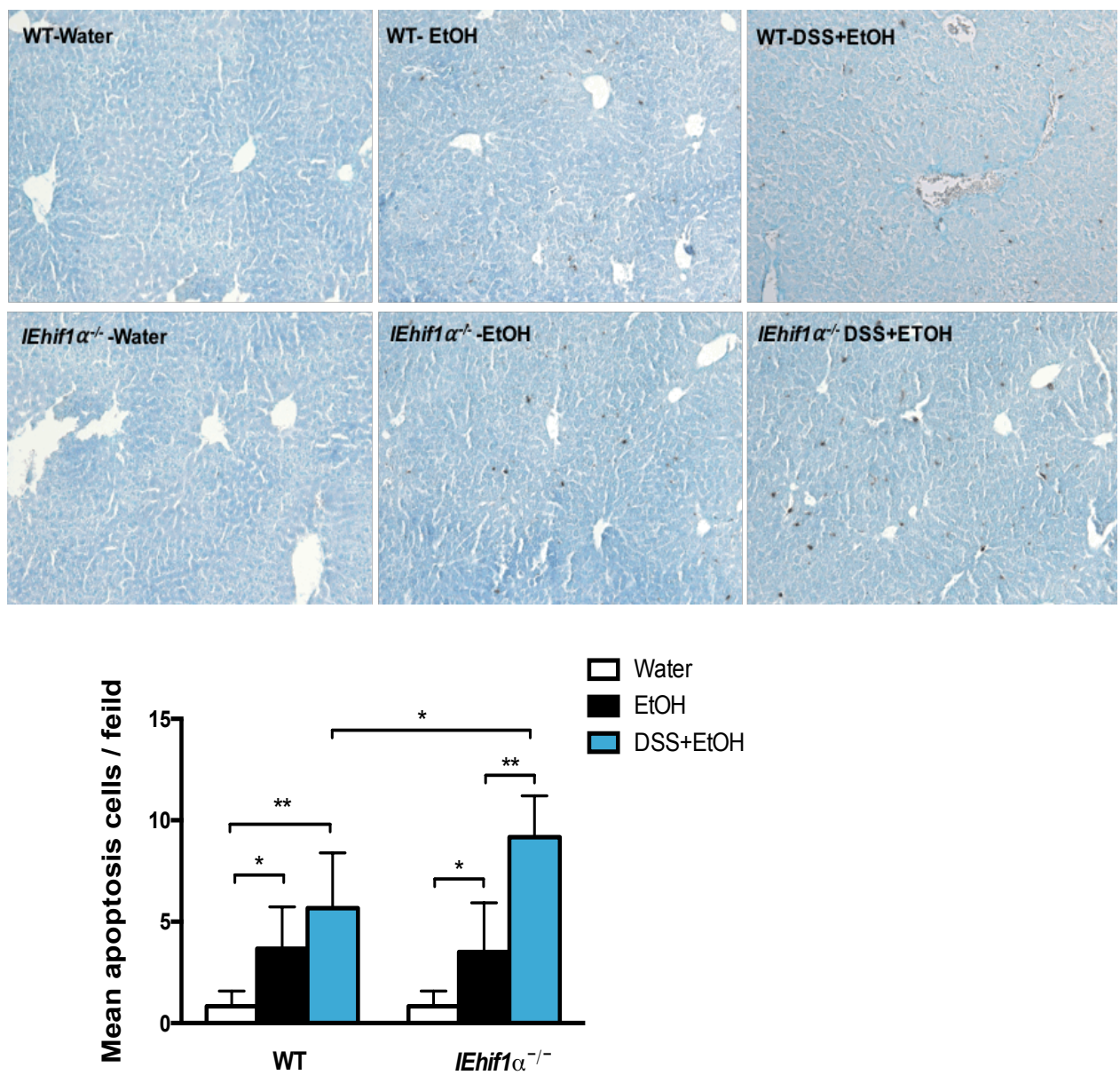

F

DIPA TLR-4

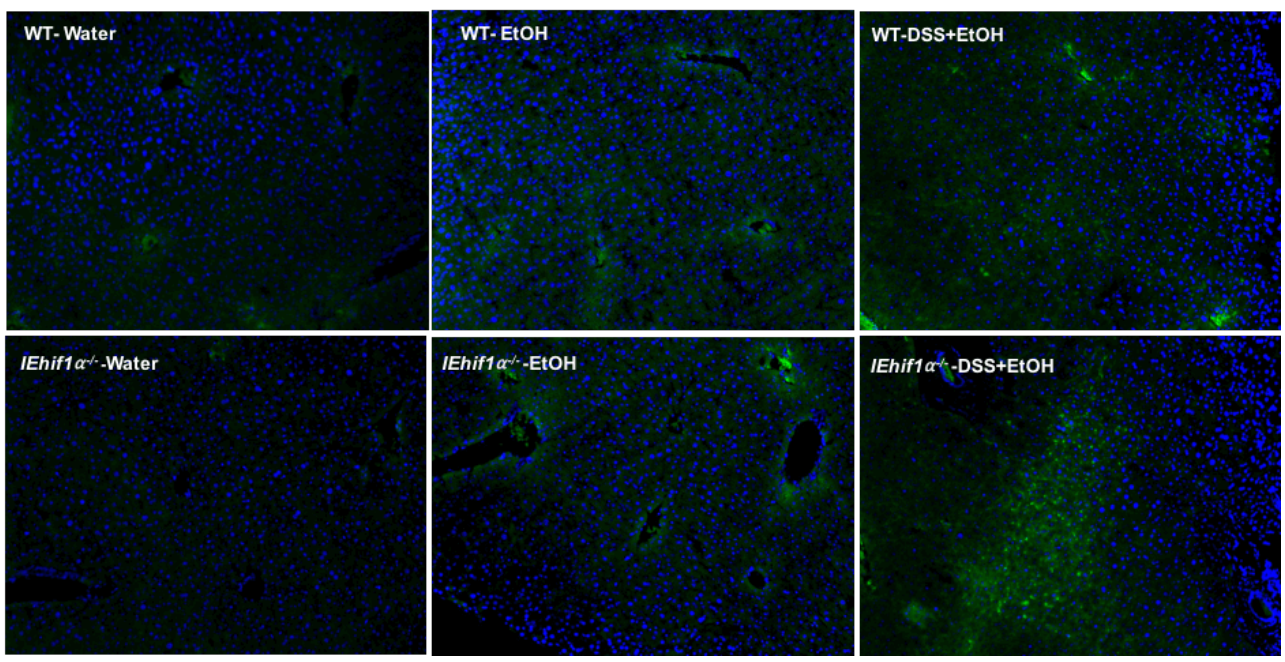




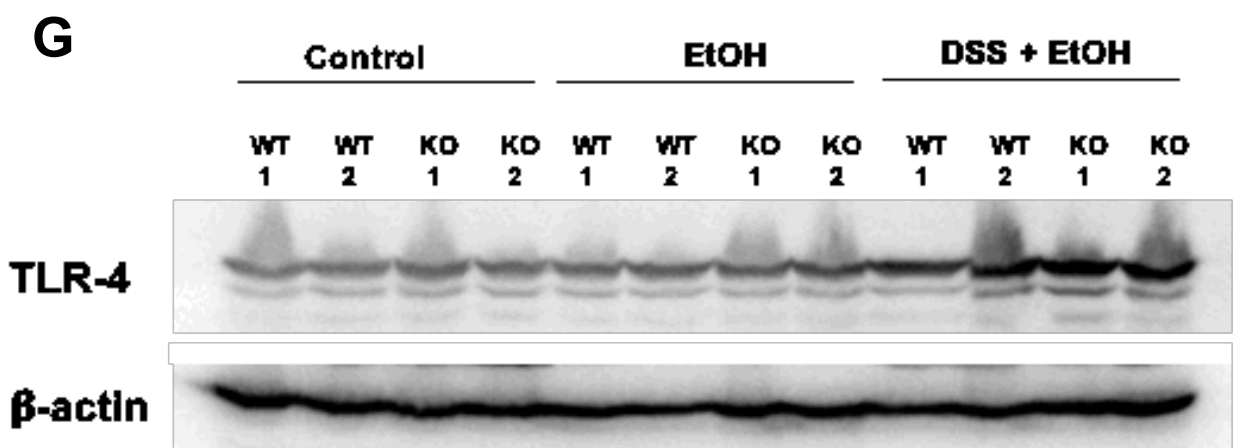

Figure 3. IEhif1 $1 \alpha^{-/-}$mice have exacerbated liver injury by alcohol on DSS treatment. (A, B) Serum alanine aminotransferase (ALT) and aspartate aminotransferase (AST) activities of WT and IEhif1 $\alpha^{-/-}$mice. Control group (without DSS; water), binge alcohol group (6 g/kg) and 3\% DSS+ $6 \mathrm{~g} / \mathrm{kg} \mathrm{EtOH}$ administration group. (C) Quantification of hepatic triglyceride content. (D) Hematoxylin and eosin staining of the liver sections. Original magnification, $\times 10$. (E) Terminal deoxynucleotidyl transferase dUTP nick-end labeling (TUNEL) assay in the liver section, quantitative measurements of TUNEL-positive cells in liver. Original magnification, $\times 10$. (F) Immunoflorescent staining of Toll-like receptor 4 (TLR-4) in the liver section. DAPI (blue) was used to counterstain nuclei. Original magnification, $\times 10$. (G) TLR-4 protein Western blotting and quantification of liver tissues normalized by $\beta$-actin. ${ }^{*} P<0.05, \quad{ }^{* *} P<0.01$, ${ }^{* \star *} P<0.001$. 


\section{IEHIF1a ${ }^{-/-}$mice exhibit enhanced plasma LPS levels and increased translocation of bacteria}

Translocation of enteric bacteria and bacterial products into the liver plays an important role in acute alcoholic liver injury [25]. Treatment of EtOH or DSS alone in either WT mice or IEHIF1 $\alpha^{-/-}$mice caused a marginal increase in plasma LPS concentration. However, EtOH on DSS treatment significantly increased plasma LPS levels in IEHIF1 ${ }^{--}$mice, but not in the control mice (Fig. 4A). To determine the live bacterial translocation, we gavaged mice with ampicillin resistant- and GFP-labeled E. coli and cultured mesenteric adipose tissue (MAT) and liver tissues. As shown in Fig 4B, live E. coli cells were identified in the liver of DSS-primed control mice treated with acute alcohol. Interestingly, the livers of IEHIF1 $\alpha^{-/-}$mice had significantly increased numbers of $E$. coli cells, indicating depletion of intestinal HIF-1 $\alpha$ enhanced bacterial translocation to the liver. As expected, MAT showed a significant numbers of live E. coli upon EtOH treatment in DSS-primed mice. However, there was no difference between WT mice and the IEHIF1 $\alpha^{-/-}$mice (Fig 4B, and 4C). Taken together, our data demonstrate that in the DSS-primed mouse model, acute alcohol enhances the translocation of bacteria and bacterial products from the intestine lumen to extraenteric tissues including MAT and liver; intestinal Hif1 $\alpha$ deletion exacerbates this translocation. 


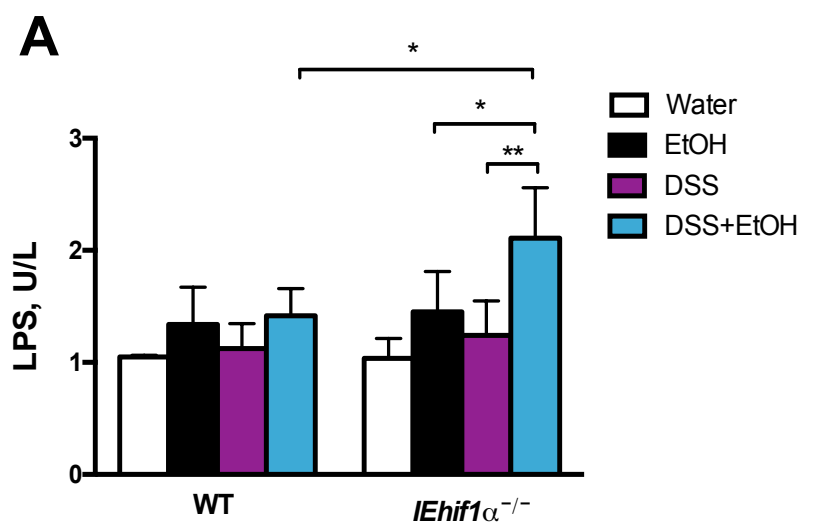

B

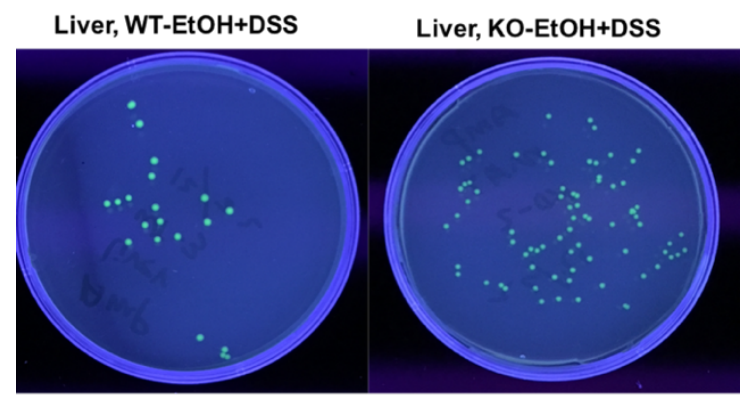

MAT, WT-EtOH+DSS MAT, KO-EtOH+DSS

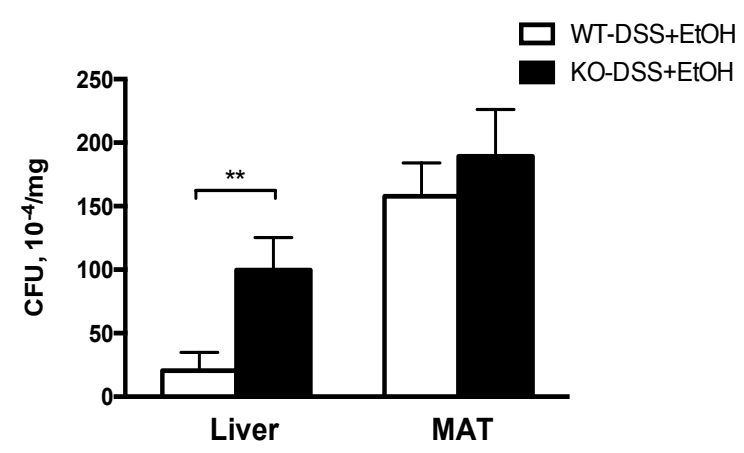

Figure 4. Effect of Hif-1a on gut permeability and bacterial translocation. (A) Serum LPS levels. (B) Macroscopic features of the GFP- E. Coli on the LB agar by UV light exposure. (C) Numbers of GFP-E. coli CFU/g of MAT and liver in IEhif1 $^{-/-}$mice and their corresponding WT controls treated $3 \% D S S+6 \mathrm{~g} / \mathrm{kg}$ EtOH, 5 h post-gavage with $10^{9} \mathrm{CFU}$ of GFP-E.coli. ${ }^{*} P<0.05,{ }^{*} P<0.01$. 


\section{Effect of DSS pretreatment on acute EtOH induced intestinal barrier dysfunction and CRAMP depletion shows exacerbated liver injury}

Goblet cells play a critical role in antimicrobial peptide production and barrier function. Alcian blue staining of colon tissues showed that EtOH on DSS treatment significantly decreased goblet cells in WT mice, and this depletion was more pronounced in IEHIF1a ${ }^{-/-}$mice (Fig.5A). The histological analysis of the distal colon revealed marked mucosal damage, characterized by an intense inflammatory cell infiltrate extending throughout the mucosa and submucosa, and crypt destruction in IEHIF1 $1 \alpha^{-/-}$mice (Fig. 5A). To further define the role of Hif1a in mediating intestinal barrier dysfunction after alcohol administration, we analyzed expression of claudin-1, one of the tight junction (TJ) proteins in the epithelial tissues, and the antimicrobial peptide, CRAMP. Immunofluorescence staining of claudin-1 revealed that IEHIF1a $\alpha^{-/-}$mice showed a lower expression in the ileum after DSS plus ethanol feeding (Fig. 5B). DSS induced a marked increase in CRAMP expression in WT mice. However, this elevation was impaired in the IEHIF1a $\alpha^{-/-}$mice (Fig. 5C). When the DSS-pretreated mice were exposed to EtOH, CRAMP expression was significantly decreased in WT mice, and the decrease was more pronounced in the IEHIF1 $\alpha^{-/-}$mice (Fig. 5C). Circulating CRAMP was increased by DSS pretreatment in WT mice, but not in IEHIF1 $\alpha^{-/}$mice. Interestingly, EtOH exposure eliminated the increased CRAMP produced by DSS in the WT mice (Fig. 5D). Next, we examined the liver injury by EtOH in DSSpretreated CRAMP knockout mice. Acute EtOH on DSS pretreatment significantly increased plasma ALT and AST levels in WT mice, and more so in 
the CRAMP knockouts (Fig. 5E). 


\section{A}
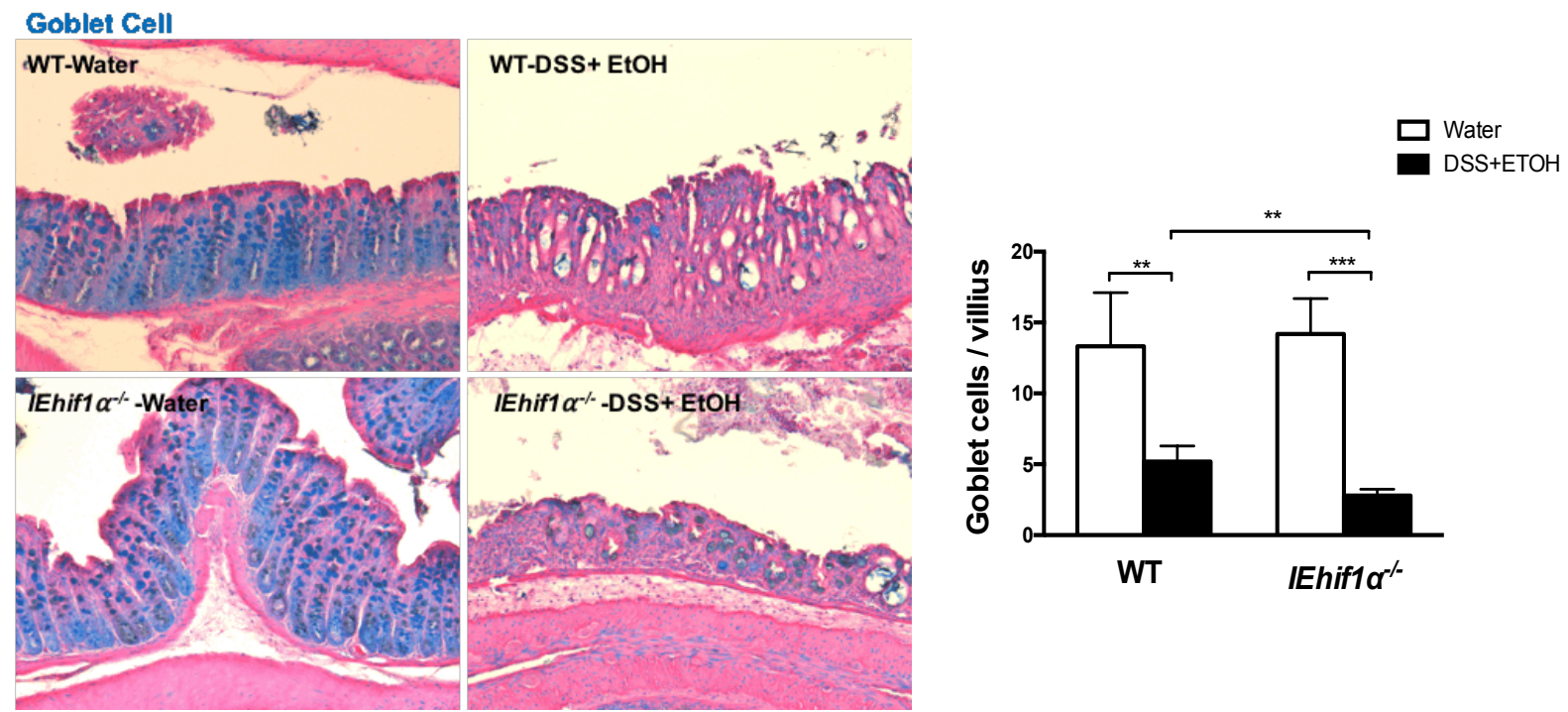

B

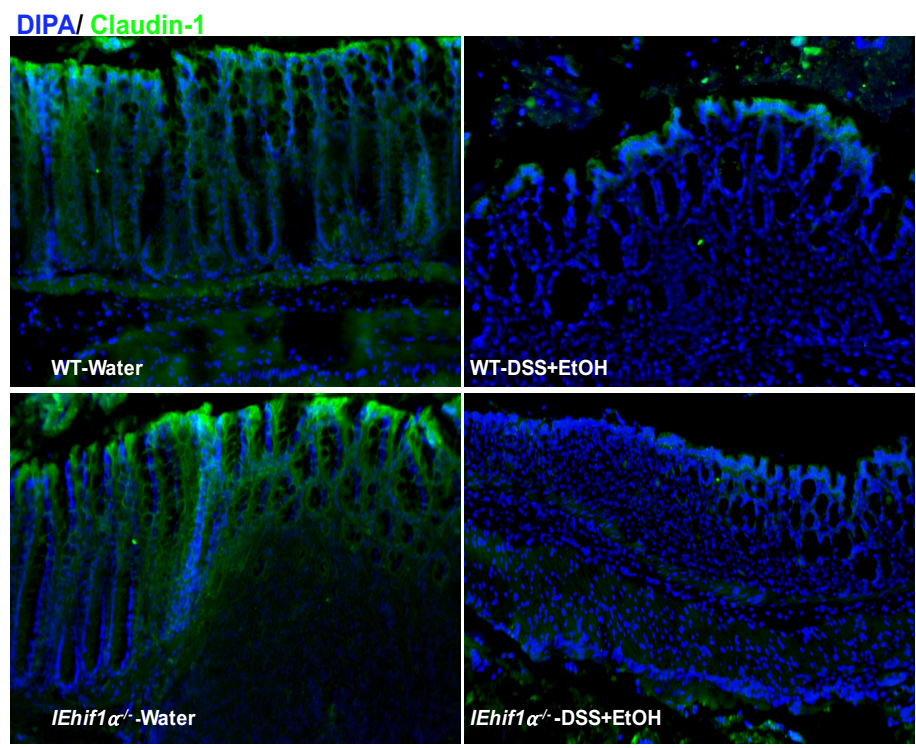




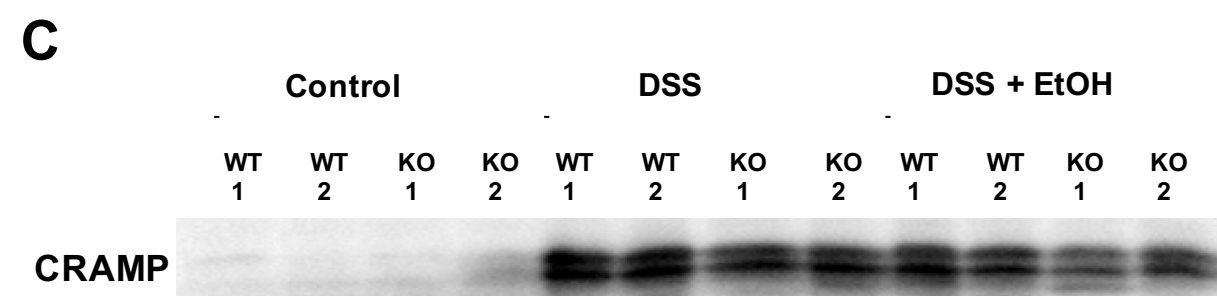

$\beta$-actin

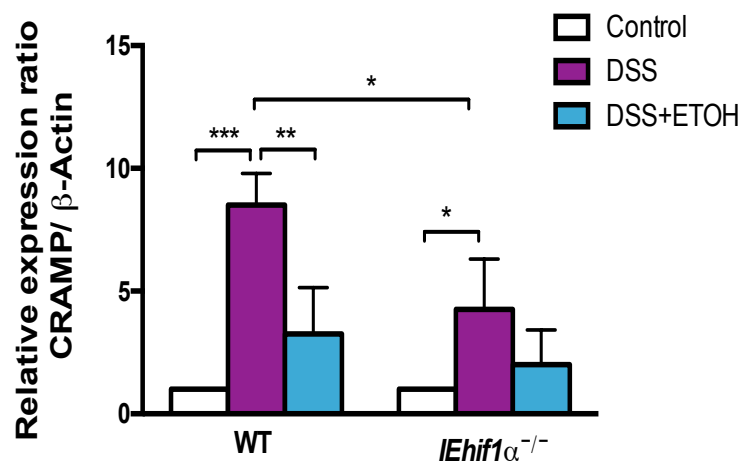

D

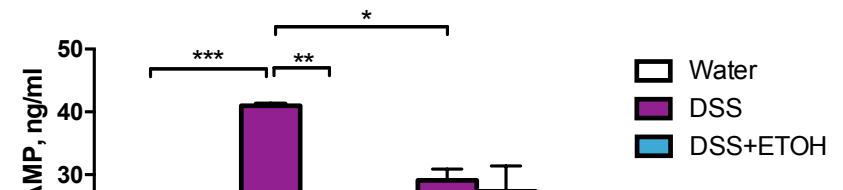

E
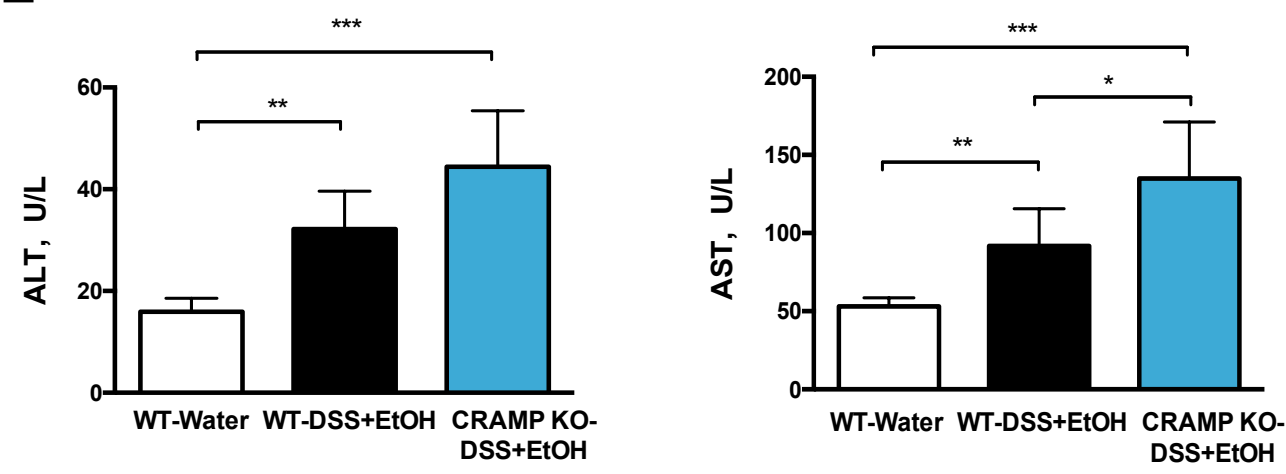
Figure 5. Effect of DSS pretreatment on acute EtOH induced intestinal barrier dysfunction. (A) Alcian blue staining of representative sections from the proximal colon of WT and IEhif1 ${ }^{-/-}$mice treated with $3 \%$ DSS plus $6 \mathrm{~g} / \mathrm{kg} \mathrm{EtOH}$. Quantification of the number of Alcian blue-positive goblet cells per crypt-villus unit was performed. (B) Immunoflorescent staining of Claudin-1 in the colon section. DAPI (blue) was used to counterstain nuclei. (C) CRAMP protein Western blotting and quantification of colon tissues normalized by $\beta$-actin. (D) Serum level of CRAMP was measured by ELISA kit. (E) Serum alanine aminotransferase (ALT) and aspartate aminotransferase (AST) activities of WT and CRAMP ${ }^{-/}$mice treated with $3 \% D S S+6 \mathrm{~g} / \mathrm{kg}$ EtOH. $\quad{ }^{*} P<0.05,{ }^{* *} P<0.01$, ${ }^{* \star *} P<0.001$. 


\section{Discussion}

The association between colitis and liver disease was first described in the late 19th century $[26,27]$. Emerging evidence shows alcohol and high fat diet are increasingly being recognized as a cause of hepatic steatosis among patients with IBD[28-31]. Although there are few clinical reports about ALD with IBD patients, there is no study showing that ulcerative colitis with alcohol exposure enhances liver injury and liver failure. In this study, we first describe a link between the colonic inflammatory response and alcohol induced hepatic injury.

In the present study, data obtained showed that in intestinal HIF-1 $\alpha \mathrm{KO}$ mice, DSS exposure induced clinical symptoms, systemic inflammatory reaction and colonic inflammation characterized by increased local pro-inflammatory mediators and histopathological changes. These observations are similar to those described in either epithelial HIF-1 $\alpha^{-/-}$mice or HIF-1 $\beta^{-1-}$ mice[32,33]. However, liver injury was not observed in DSS-colitis either WT or KO mice, and there were no histopathological changes or up regulation of inflammatory mediators. These results suggest a limited involvement of the liver in the colitis process, which is in agreement with previous animal and human studies[34-37]. Among these studies, one explained this phenomenon is DSS-induced experimental colitis leads to endotoxin tolerance for liver, but did not provide more mechanisms.

The main question in our study was whether colitis can enhance alcohol induced liver injury. Although liver injury was not observed in DSS-colitis mice, we considered that the portal endotoxemia (in colitis model) facilitated the liver 
injury induced by other compounds, because small amounts of LPS are known to enhance susceptibility to various hepatotoxic agents [38]. A recent study showed that the systemic biologic activity of the increased LPS after alcohol binge contributed to the increased inflammatory cytokines in liver[9]. In the present study, contrary to expectation, we observed no change of ALT and AST in the acute alcohol on DSS-colitis mice compared to ALT and AST in mice exposed only to an alcohol binge, indicating that exposure of a single alcohol binge impairs liver to the same extent as does the DSS and alcohol treatment. However, the most surprising finding is that serum ALT and AST levels significantly increased in HIF-1 $\alpha^{-/-}$mice after a single binge alcohol on colitis and this liver injury was confirmed by elevated levels of hepatic pro-inflammatory mediators and histopathological changes.

Intestinal HIF-1 $\alpha$ plays an important role in the colitis model because a number of barrier-protective genes are critically regulated by HIF-1 $\alpha$, including intestinal trefoil factor (ITF), CD73, P-glycoprotein (P-gp), cathelicidin (CRAMP), and claudin-1,muc3 and $\beta$-defensin1 (DEFB1) [19-23]. Based on this, we considered that intestinal HIF-1a deletion might exacerbate gut-permeability and dampen the intestinal innate immunity response; binge alcohol as the second hit induced more inflammation and greater gut permeability in colitis mice. Among these finding, one of the most important results is that the expression of the antimicrobial peptide, CRAMP, was significantly increased in both colon and serum, illustrating the attempt to re-establish the disturbed barrier. However, we did not find the same results in alcohol treatment and in the HIF-1 $\alpha \mathrm{KO}$ mice. 
According to these results and in light of earlier findings, which demonstrated that alcohol has the potential to modulate intestinal CRAMP production. Recent studies have shown that a few antimicrobial peptides (AMPs) also have the potential to neutralize LPS-induced endotoxic effects. Among these AMPs, the list included human LL-37 (mouse CRAMP) [39-41]. Although strong binding of CRAMP to LPS is not sufficient to block LPS biological activity, binding of CRAMP to LPS aggregates accompanied by aggregate dissociation prevents LPS from binding to the carrier protein LBP, or alternatively to its receptor, and hence inhibits cytokine release. Indeed, we showed that CRAMP reduced the level of mRNA expression of the two cytokines which stimulate by LPS in RAW264.7 cells. Therefore, we used global CRAMP knockout mice to investigate our hypothesis. As we expected, binge alcohol on colitis enhanced liver injury in CRAMP KO mice compared with WT mice. All these results show that the intestinal HIF-1 $\alpha$ - CRAMP pathway plays an important role in intestinal damage induced by alcohol-induced liver injury.

In summary, we provide new evidence that a concomitant colonic damage enhances hepatic injury in experimental ALD. Interestingly, the compensatory upregulation of antimicrobial peptides in mice with colitis was not significantly expressed in HIF-1 $1 \alpha \mathrm{KO}$ mice, and alcohol also further reduced its expression. This may facilitate gut-driveled LPS, bacteria and cytokine translocation, as evidenced by increased serum concentration. To our knowledge, this is the first report which provides conclusive evidence that binge alcohol is a "second" hit, which is sufficient to induce hepatic inflammation in colitis without intestinal 
CRAMP expression, regulated by HIF- $1 \alpha$ gene expression. Our findings may also provide another mechanism for DSS induced endotoxin tolerance in the liver. Further studies are necessary to discover the mechanism of decreased intestinal antimicrobial peptide generation and precisely to determine the CRAMP-bind LPS in our model. 


\section{REFERENCES}

Overview

[1] O'Shea RS, Dasarathy S, McCullough AJ, Practice Guideline Committee of the American Association for the Study of Liver Diseases, Practice Parameters Committee of the American College of Gastroenterology. Alcoholic liver disease. Hepatology 2010;51:307-28.

[2] European Association for the Study of Liver. EASL Clinical Practical Guidelines: Management of Alcoholic Liver Disease. J Hepatol 2012;57:399-420.

[3] Lucey MR, Mathurin P, Morgan TR. Alcoholic Hepatitis. N Engl J Med 2009;360:2758-69.

[4] Dominguez M, Rinc?n D, Abraldes JG, Miquel R, Colmenero J, Bellot P, et al. A New Scoring System for Prognostic Stratification of Patients With Alcoholic Hepatitis. Am J Gastroenterol 2008;103:2747-56.

[5] Choudhry MA, Chaudry IH. Alcohol, burn injury, and the intestine. J Emerg Trauma Shock 2008;1:81-7.

[6] Tsukamoto H, Xi XP. Incomplete compensation of enhanced hepatic oxygen consumption in rats with alcoholic centrilobular liver necrosis. Hepatology 1989;9:302-6.

[7] Hamanaka RB, Chandel NS. Mitochondrial reactive oxygen species regulate hypoxic signaling. Curr Opin Cell Biol 2009;21:894-9.

[8] Fan D, Coughlin LA, Neubauer MM, Kim J, Kim MS, Zhan X, et al. Activation of HIF-1 $\alpha$ and LL-37 by commensal bacteria inhibits Candida albicans colonization. Nat Med 2015;21:808-14.

[9] Saeedi BJ, Kao DJ, Kitzenberg DA, Dobrinskikh E, Schwisow KD, Masterson JC, et al. HIF-dependent regulation of claudin-1 is central to intestinal epithelial tight junction integrity. Mol Biol Cell 2015;26:2252-62.

[10] Kietzmann T, Cornesse Y, Brechtel K, Modaressi S, Jungermann K. Perivenous expression of the mRNA of the three hypoxia-inducible factor alpha-subunits, HIF1alpha, HIF2alpha and HIF3alpha, in rat liver. Biochem 
J 2001;354:531-7.

[11] Greijer AE. The role of hypoxia inducible factor 1 (HIF-1) in hypoxia induced apoptosis. J Clin Pathol 2004;57:1009-14.

[12] Jaakkola P, Mole DR, Tian Y-M, Wilson MI, Gielbert J, Gaskell SJ, et al. Targeting of HIF- $\alpha$ to the von Hippel-Lindau Ubiquitylation Complex by O2Regulated Prolyl Hydroxylation. Science (80- ) 2001;292.

[13] Wang X, Wu D, Yang L, Gan L, Cederbaum Al. Cytochrome P450 2E1 potentiates ethanol induction of hypoxia and HIF-1? in vivo. Free Radic Biol Med 2013;63:175-86.

[14] Nishiyama Y, Goda N, Kanai M, Niwa D, Osanai K, Yamamoto Y, et al. HIF-1 1 induction suppresses excessive lipid accumulation in alcoholic fatty liver in mice. J Hepatol 2012;56:441-7.

[15] Nath I.; Csak, T.; Petrasek, J.; Mueller, C.; Kodys, K.; Catalano, D.; Mandrekar, P.; Szabo, G. B. L. Hepatocyte-specific hypoxia-inducible factor-1alpha is a determinant of lipid accumulation and liver injury in alcohol-induced steatosis in mice. Hepatology 2011;53:1526-37.

[16] Li L, Chen S-H, Zhang Y, Yu C-H, Li S-D, Li Y-M. Is the hypoxia-inducible factor-1 alpha mRNA expression activated by ethanol-induced injury, the mechanism underlying alcoholic liver disease? Hepatobiliary Pancreat Dis Int 2006;5:560-3.

[17] Bala S, Marcos M, Gattu A, Catalano D, Szabo G. Acute Binge Drinking Increases Serum Endotoxin and Bacterial DNA Levels in Healthy Individuals. PLoS One 2014;9:e96864.

[18] Yun J-W, Son M-J, Abdelmegeed MA, Banerjee A, Morgan TR, Yoo S-H, et al. Binge alcohol promotes hypoxic liver injury through a CYP2E1-HIF$1 \alpha$-dependent apoptosis pathway in mice and humans. Free Radic Biol Med 2014;77:183-94.

[19] Ni H-M, Bhakta A, Wang S, Li Z, Manley S, Huang H, et al. Role of hypoxia inducing factor- $1 \beta$ in alcohol-induced autophagy, steatosis and liver injury in mice. PLoS One 2014;9:e115849.

[20] Ambade A, Satishchandran A, Szabo G. Alcoholic hepatitis accelerates early hepatobiliary cancer by increasing stemness and miR-122-mediated HIF-1a activation. Sci Rep 2016;6:21340.

[21] Stewart S, Jones D, Day CP. Alcoholic liver disease: new insights into mechanisms and preventative strategies. Trends Mol Med 2001;7:408-13. 
[22] Lieber CS. Metabolism of Alcohol. Clin Liver Dis 2005;9:1-35.

[23] Morimoto M, Hagbj?rk A-L, Wan Y-JY, Fu PC, Clot P, Albano E, et al. Modulation of experimental alcohol-induced liver disease by cytochrome P450 2E1 inhibitors. Hepatology 1995;21:1610-7.

[24] Lu Y, Zhuge J, Wang X, Bai J, Cederbaum Al. Cytochrome P450 2E1 contributes to ethanol-induced fatty liver in mice. Hepatology 2008;47:1483-94.

[25] Callegari E, Gramantieri L, Domenicali M, D'Abundo L, Sabbioni S, Negrini M. MicroRNAs in liver cancer: a model for investigating pathogenesis and novel therapeutic approaches. Cell Death Differ 2015;22:46-57.

[26] Coulouarn C, Factor VM, Andersen JB, Durkin ME, Thorgeirsson SS. Loss of miR-122 expression in liver cancer correlates with suppression of the hepatic phenotype and gain of metastatic properties. Oncogene 2009;28:3526-36.

[27] McCrae JC, Sharkey N, Webb DJ, Vliegenthart ADB, Dear JW. Ethanol consumption produces a small increase in circulating miR-122 in healthy individuals. Clin Toxicol 2016;54:53-5.

[28] Csak T, Bala S, Lippai D, Satishchandran A, Catalano D, Kodys K, et al. microRNA-122 regulates hypoxia-inducible factor-1 and vimentin in hepatocytes and correlates with fibrosis in diet-induced steatohepatitis. Liver Int 2015;35:532-41.

[29] Adachi Y, Moore LE, Bradford BU, Gao W, Thurman RG. Antibiotics prevent liver injury in rats following long-term exposure to ethanol. Gastroenterology 1995;108:218-24.

[30] Duryee MJ, Klassen LW, Freeman TL, Willis MS, Tuma DJ, Thiele GM. Lipopolysaccharide is a cofactor for malondialdehyde-acetaldehyde adduct-mediated cytokine/chemokine release by rat sinusoidal liver endothelial and Kupffer cells. Alcohol Clin Exp Res 2004;28:1931-8.

[31] Haziot A, Chen S, Ferrero E, Low MG, Silber R, Goyert SM. The monocyte differentiation antigen, CD14, is anchored to the cell membrane by a phosphatidylinositol linkage. J Immunol 1988;141:547-52.

[32] Albano E. Oxidative mechanisms in the pathogenesis of alcoholic liver disease. Mol Aspects Med 2008;29:9-16. doi:10.1016/j.mam.2007.09.004. 
[33] Colgan SP, Taylor CT. Hypoxia: an alarm signal during intestinal inflammation. Nat Rev Gastroenterol Hepatol 2010;7:281-7.

[34] Cummins EP, Berra E, Comerford KM, Ginouves A, Fitzgerald KT, Seeballuck $F$, et al. Prolyl hydroxylase-1 negatively regulates IkappaB kinase-beta, giving insight into hypoxia-induced NFkappaB activity. Proc Natl Acad Sci U S A 2006;103:18154-9.

[35] Taylor CT. Interdependent roles for hypoxia inducible factor and nuclear factor-kappaB in hypoxic inflammation. J Physiol 2008;586:4055-9.

[36] Sitkovsky M, Lukashev D. Regulation of immune cells by local-tissue oxygen tension: HIF1 alpha and adenosine receptors. Nat Rev Immunol 2005;5:712-21.

[37] Sitkovsky M V, Lukashev D, Apasov S, Kojima H, Koshiba M, Caldwell C, et al. Physiological control of immune response and inflammatory tissue damage by hypoxia-inducible factors and adenosine A2A receptors. Annu Rev Immunol 2004;22:657-82.

[38] Eckle T, Köhler D, Lehmann R, El Kasmi K, Eltzschig HK. Hypoxiainducible factor- 1 is central to cardioprotection: a new paradigm for ischemic preconditioning. Circulation 2008;118:166-75.

[39] Eltzschig HK, Abdulla P, Hoffman E, Hamilton KE, Daniels D, Schönfeld C, et al. HIF-1-dependent repression of equilibrative nucleoside transporter (ENT) in hypoxia. J Exp Med 2005;202:1493-505.

[40] Frede S, Stockmann C, Winning S, Freitag P, Fandrey J. Hypoxia-inducible factor (HIF) 1alpha accumulation and HIF target gene expression are impaired after induction of endotoxin tolerance. J Immunol 2009;182:64706.

[41] Wang Y, Kirpich I, Liu Y, Ma Z, Barve S, McClain CJ, et al. Lactobacillus rhamnosus GG treatment potentiates intestinal hypoxia-inducible factor, promotes intestinal integrity and ameliorates alcohol-induced liver injury. Am J Pathol 2011;179:2866-75.

Chapter I

[1] Gao B, Bataller R. Alcoholic Liver Disease: Pathogenesis and New Therapeutic Targets. Gastroenterology 2011;141:1572-1585. 
[2] Adachi Y, Moore LE, Bradford BU, Gao W, Thurman RG. Antibiotics prevent liver injury in rats following long-term exposure to ethanol. Gastroenterology 1995;108:218-224.

[3] Parlesak A, Schafer C, Schutz T, Bode JC, Bode C. Increased intestinal permeability to macromolecules and endotoxemia in patients with chronic alcohol abuse in different stages of alcohol-induced liver disease. J Hepatol 2000;32:742-747.

[4] Chen P, Miyamoto Y, Mazagova M, Lee KC, Eckmann L, Schnabl B. Microbiota Protects Mice Against Acute Alcohol-Induced Liver Injury. Alcohol Clin Exp Res 2015;39:2313-2323.

[5] Keshavarzian A, Farhadi A, Forsyth CB, Rangan J, Jakate S, Shaikh M, et al. Evidence that chronic alcohol exposure promotes intestinal oxidative stress, intestinal hyperpermeability and endotoxemia prior to development of alcoholic steatohepatitis in rats. J Hepatol 2009;50:538-547.

[6] Szabo G, Bala S. Alcoholic liver disease and the gut-liver axis. World J Gastroenterol 2010;16:1321-1329.

[7] Uesugi T, Froh M, Arteel GE, Bradford BU, Thurman RG. Toll-like receptor 4 is involved in the mechanism of early alcohol-induced liver injury in mice. Hepatology 2001;34:101-108.

[8] Petrasek J, Mandrekar P, Szabo G. Toll-like receptors in the pathogenesis of alcoholic liver disease. Gastroenterology research and practice 2010;2010.

[9] Keshavarzian A, Holmes EW, Patel M, Iber F, Fields JZ, Pethkar S. Leaky gut in alcoholic cirrhosis: a possible mechanism for alcohol-induced liver damage. The American journal of gastroenterology 1999;94:200-207.

[10] Wang Y, Tong J, Chang B, Wang B, Zhang D. Effects of alcohol on intestinal epithelial barrier permeability and expression of tight junctionassociated proteins. Molecular medicine reports 2014;9:2352-2356.

[11] Cheng $\mathrm{H}$, Leblond $\mathrm{CP}$. Origin, differentiation and renewal of the four main epithelial cell types in the mouse small intestine. V. Unitarian Theory of the origin of the four epithelial cell types. The American journal of anatomy 1974;141:537561.

[12] Zhao F, Edwards R, Dizon D, Afrasiabi K, Mastroianni JR, Geyfman M, et al. Disruption of Paneth and goblet cell homeostasis and increased endoplasmic reticulum stress in Agr2-/- mice. Dev Biol 2010;338:270-279. 
[13] Johansson ME, Phillipson M, Petersson J, Velcich A, Holm L, Hansson GC. The inner of the two Muc2 mucin-dependent mucus layers in colon is devoid of bacteria. Proc Natl Acad Sci U S A 2008;105:15064-15069.

[14] Van der Sluis M, De Koning BA, De Bruijn AC, Velcich A, Meijerink JP, Van Goudoever JB, et al. Muc2-deficient mice spontaneously develop colitis, indicating that MUC2 is critical for colonic protection. Gastroenterology 2006;131:117-129.

[15] Taupin D, Podolsky DK. Trefoil factors: initiators of mucosal healing. Nature Reviews Molecular Cell Biology 2003;4:721-732.

[16] Forster C. Tight junctions and the modulation of barrier function in disease. Histochemistry and cell biology 2008;130:55-70.

[17] Hapfelmeier S, Lawson MA, Slack E, Kirundi JK, Stoel M, Heikenwalder $M$, et al. Reversible microbial colonization of germ-free mice reveals the dynamics of IgA immune responses. Science (New York, NY) 2010;328:17051709.

[18] Szabo G. Gut-liver axis in alcoholic liver disease. Gastroenterology 2015;148:30-36.

[19] Furuta GT, Turner JR, Taylor CT, Hershberg RM, Comerford K, Narravula $\mathrm{S}$, et al. Hypoxia-inducible factor 1-dependent induction of intestinal trefoil factor protects barrier function during hypoxia. The Journal of experimental medicine 2001;193:1027-1034.

[20] Taylor CT, Colgan SP. Therapeutic targets for hypoxia-elicited pathways. Pharmaceutical research 1999;16:1498-1505.

[21] Cramer T, Yamanishi Y, Clausen BE, Forster I, Pawlinski R, Mackman N, et al. HIF-1alpha is essential for myeloid cell-mediated inflammation. Cell 2003;112:645-657.

[22] Sitkovsky M, Lukashev D. Regulation of immune cells by local-tissue oxygen tension: HIF1 alpha and adenosine receptors. Nature reviews Immunology 2005;5:712-721.

[23] Morote-Garcia JC, Rosenberger P, Kuhlicke J, Eltzschig HK. HIF-1dependent repression of adenosine kinase attenuates hypoxia-induced vascular leak. Blood 2008;111:5571-5580.

[24] Glover LE, Bowers BE, Saeedi B, Ehrentraut SF, Campbell EL, Bayless AJ, et al. Control of creatine metabolism by HIF is an endogenous mechanism of barrier regulation in colitis. Proc Natl Acad Sci U S A 2013;110:19820-19825. 
[25] Synnestvedt K, Furuta GT, Comerford KM, Louis N, Karhausen J, Eltzschig HK, et al. Ecto-5'-nucleotidase (CD73) regulation by hypoxia-inducible factor-1 mediates permeability changes in intestinal epithelia. J Clin Invest 2002;110:993-1002.

[26] Comerford KM, Wallace TJ, Karhausen J, Louis NA, Montalto MC, Colgan SP. Hypoxia-inducible factor-1-dependent regulation of the multidrug resistance (MDR1) gene. Cancer Res 2002;62:3387-3394.

[27] Fan D, Coughlin LA, Neubauer MM, Kim J, Kim MS, Zhan X, et al. Activation of HIF-1alpha and LL-37 by commensal bacteria inhibits Candida albicans colonization. Nat Med 2015;21:808-814.

[28] Saeedi BJ, Kao DJ, Kitzenberg DA, Dobrinskikh E, Schwisow KD, Masterson JC, et al. HIF-dependent regulation of claudin-1 is central to intestinal epithelial tight junction integrity. Molecular biology of the cell 2015;26:2252-2262.

[29] Louis NA, Hamilton KE, Canny G, Shekels LL, Ho SB, Colgan SP. Selective induction of mucin-3 by hypoxia in intestinal epithelia. J Cell Biochem 2006;99:1616-1627.

[30] Kelly CJ, Glover LE, Campbell EL, Kominsky DJ, Ehrentraut SF, Bowers $\mathrm{BE}$, et al. Fundamental role for HIF-1alpha in constitutive expression of human beta defensin-1. Mucosal Immunol 2013;6:1110-1118.

[31] Siegert I, Schodel J, Nairz M, Schatz V, Dettmer K, Dick C, et al. FerritinMediated Iron Sequestration Stabilizes Hypoxia-Inducible Factor-1alpha upon LPS Activation in the Presence of Ample Oxygen. Cell reports 2015;13:20482055.

[32] Frede S, Stockmann C, Winning S, Freitag P, Fandrey J. Hypoxiainducible factor (HIF) 1alpha accumulation and HIF target gene expression are impaired after induction of endotoxin tolerance. J Immunol 2009;182:6470-6476. [33] Karhausen J, Furuta GT, Tomaszewski JE, Johnson RS, Colgan SP, Haase VH. Epithelial hypoxia-inducible factor-1 is protective in murine experimental colitis. J Clin Invest 2004;114:1098-1106.

[34] Campbell EL, Bruyninckx WJ, Kelly CJ, Glover LE, McNamee EN, Bowers $\mathrm{BE}$, et al. Transmigrating neutrophils shape the mucosal microenvironment through localized oxygen depletion to influence resolution of inflammation. Immunity 2014;40:66-77.

[35] Curtis VF, Ehrentraut SF, Campbell EL, Glover LE, Bayless A, Kelly CJ, et al. Stabilization of HIF through inhibition of Cullin-2 neddylation is protective in mucosal inflammatory responses. Faseb j 2015;29:208-215. 
[36] Keely S, Campbell EL, Baird AW, Hansbro PM, Shalwitz RA, Kotsakis A, et al. Contribution of epithelial innate immunity to systemic protection afforded by prolyl hydroxylase inhibition in murine colitis. Mucosal Immunol 2014;7:114-123.

[37] Wang Y, Liu Y, Sidhu A, Ma Z, McClain C, Feng W. Lactobacillus rhamnosus GG culture supernatant ameliorates acute alcohol-induced intestinal permeability and liver injury. Am J Physiol Gastrointest Liver Physiol 2012;303:G32-41.

[38] Wang Y, Kirpich I, Liu Y, Ma Z, Barve S, McClain CJ, et al. Lactobacillus rhamnosus GG treatment potentiates intestinal hypoxia-inducible factor, promotes intestinal integrity and ameliorates alcohol-induced liver injury. Am J Pathol 2011;179:2866-2875.

[39] Mastrogiannaki M, Matak P, Keith B, Simon MC, Vaulont S, Peyssonnaux C. HIF-2alpha, but not HIF-1alpha, promotes iron absorption in mice. J Clin Invest 2009;119:1159-1166.

[40] Yan AW, Fouts DE, Brandl J, Starkel P, Torralba M, Schott E, et al. Enteric Dysbiosis Associated with a Mouse Model of Alcoholic Liver Disease. Hepatology 2011;53:96-105.

[41] Grander C, Wieser V, Gerner RR, Grabherr F, Pfister A, Lichtmannegger L, Enrich B, et al. Akkermansia Muciniphila Protects from Alcoholic Liver Disease. Journal of Hepatology 2016;64.

[42] Derrien M, Collado MC, Ben-Amor K, Salminen S, de Vos WM. The Mucin degrader Akkermansia muciniphila is an abundant resident of the human intestinal tract. Appl Environ Microbiol 2008;74:1646-1648.

[43] Everard A, Belzer C, Geurts L, Ouwerkerk JP, Druart C, Bindels LB, et al. Cross-talk between Akkermansia muciniphila and intestinal epithelium controls diet-induced obesity. Proc Natl Acad Sci U S A 2013;110:9066-9071.

[44] Chen P, Torralba M, Tan J, Embree M, Zengler K, Starkel P, et al. Supplementation of Saturated Long-Chain Fatty Acids Maintains Intestinal Eubiosis and Reduces Ethanol-induced Liver Injury in Mice. Gastroenterology 2015;148:203-U345.

[45] Bull-Otterson L, Feng W, Kirpich I, Wang Y, Qin X, Liu Y, et al. Metagenomic analyses of alcohol induced pathogenic alterations in the intestinal microbiome and the effect of Lactobacillus rhamnosus GG treatment. PLoS One 2013;8:e53028.

[46] Zhao H, Zhao C, Dong Y, Zhang M, Wang Y, Li F, et al. Inhibition of miR122a by Lactobacillus rhamnosus GG culture supernatant increases 
intestinal occludin expression and protects mice from alcoholic liver disease. Toxicol Lett 2015;234:194-200.

[47] Probiotics (Lactobacillus rhamnosus R0011 and acidophilus R0052) Reduce the Expression of Toll-Like Receptor 4 in Mice with Alcoholic Liver Disease. 2017.

[48] Nath B, Levin I, Csak T, Petrasek J, Mueller C, Kodys K, et al. Hepatocytespecific hypoxia-inducible factor-1alpha is a determinant of lipid accumulation and liver injury in alcohol-induced steatosis in mice. Hepatology 2011;53:15261537.

[49] Nishiyama Y, Goda N, Kanai M, Niwa D, Osanai K, Yamamoto Y, et al. HIF-1alpha induction suppresses excessive lipid accumulation in alcoholic fatty liver in mice. J Hepatol 2012;56:441-447.

[50]. Forsyth CB, Voigt RM, Shaikh M, Tang Y, Cederbaum Al, Turek FW, Keshavarzian A: Role for intestinal CYP2E1 in alcohol-induced circadian genemediated intestinal hyperpermeability. In: Am J Physiol Gastrointest Liver Physiol. Volume 305, 2013; G185-195.

[51]. Kelly CJ, Zheng L, Campbell EL, Saeedi B, Scholz CC, Bayless AJ, Wilson KE, et al. Crosstalk between Microbiota-Derived Short-Chain Fatty Acids and Intestinal Epithelial HIF Augments Tissue Barrier Function. Cell Host Microbe 2015;17:662-671.

Chapter II

[1] Mezey E. Treatment of alcoholic liver disease. Semin Liver Dis 1993;13:210-6.

[2] Alcoholic liver disease: morphological manifestations. Review by an international group. Lancet (London, England) 1981;1:707-11.

[3] Lucey MR, Mathurin P, Morgan TR. Alcoholic Hepatitis. N Engl J Med 2009;360:2758-69.

[4] Dugum MF, McCullough AJ. Acute Alcoholic Hepatitis, the Clinical Aspects. Clin Liver Dis 2016;20:499-508.

[5] Zakhari S, Li T-K. Determinants of alcohol use and abuse: Impact of quantity and frequency patterns on liver disease. Hepatology 2007;46:2032-9. 
[6] Wang Y, Liu Y, Sidhu A, Ma Z, McClain C, Feng W. Lactobacillus rhamnosus GG culture supernatant ameliorates acute alcohol-induced intestinal permeability and liver injury. Am J Physiol Gastrointest Liver Physiol 2012;303:G32-41.

[7] Bull-Otterson L, Feng W, Kirpich I, Wang Y, Qin X, Liu Y, et al. Metagenomic analyses of alcohol induced pathogenic alterations in the intestinal microbiome and the effect of Lactobacillus rhamnosus GG treatment. PLoS One 2013;8:e53028.

[8] Wang Y, Kirpich I, Liu Y, Ma Z, Barve S, McClain CJ, et al. Lactobacillus rhamnosus GG treatment potentiates intestinal hypoxia-inducible factor, promotes intestinal integrity and ameliorates alcohol-induced liver injury. Am J Pathol 2011;179:2866-75.

[9] Bala S, Marcos M, Gattu A, Catalano D, Szabo G. Acute binge drinking increases serum endotoxin and bacterial DNA levels in healthy individuals. PLoS One 2014;9:e96864.

[10] Saikia P, Bellos D, McMullen MR, Pollard KA, de la Motte C, Nagy LE. miR181b-3p and its target importin a5 regulate TLR4 signaling in Kupffer cells and liver injury in mice in response to ethanol. Hepatology 2017.

[11] Thornton M, Solomon MJ. Crohn's disease: in defense of a microvascular aetiology. Int J Colorectal Dis 2002;17:287-97.

[12] Hatoum OA, Binion DG, Otterson MF, Gutterman DD. Acquired microvascular dysfunction in inflammatory bowel disease: Loss of nitric oxide-mediated vasodilation. Gastroenterology 2003;125:58-69.

[13] Sands BE. From symptom to diagnosis: clinical distinctions among various forms of intestinal inflammation. Gastroenterology 2004;126:1518-32.

[14] Melgar S, Karlsson A, Michaëlsson E. Acute colitis induced by dextran sulfate sodium progresses to chronicity in C57BL/6 but not in BALB/c mice: correlation between symptoms and inflammation. AJP Gastrointest Liver Physiol 2005;288:G1328-38.

[15] Dawson PA, Huxley S, Gardiner B, Tran T, McAuley JL, Grimmond S, et al. Reduced mucin sulfonation and impaired intestinal barrier function in the hyposulfataemic NaS1 null mouse. Gut 2009;58:910-9.

[16] Choudhry MA, Chaudry IH. Alcohol, burn injury, and the intestine. J Emerg Trauma Shock 2008;1:81-7. 
[17] Hauser CJ, Locke RR, Kao HW, Patterson J, Zipser RD. Visceral surface oxygen tension in experimental colitis in the rabbit. J Lab Clin Med 1988;112:68-71.

[18] Comerford KM, Wallace TJ, Karhausen J, Louis NA, Montalto MC, Colgan SP. Hypoxia-inducible factor-1-dependent regulation of the multidrug resistance (MDR1) gene. Cancer Res 2002;62:3387-94.

[19] Furuta GT, Turner JR, Taylor CT, Hershberg RM, Comerford K, Narravula $\mathrm{S}$, et al. Hypoxia-inducible factor 1-dependent induction of intestinal trefoil factor protects barrier function during hypoxia. J Exp Med 2001;193:102734.

[20] Saeedi BJ, Kao DJ, Kitzenberg DA, Dobrinskikh E, Schwisow KD, Masterson JC, et al. HIF-dependent regulation of claudin-1 is central to intestinal epithelial tight junction integrity. Mol Biol Cell 2015;26:2252-62.

[21] Kelly CJ, Glover LE, Campbell EL, Kominsky DJ, Ehrentraut SF, Bowers $\mathrm{BE}$, et al. Fundamental role for HIF-1 $\alpha$ in constitutive expression of human $\beta$ defensin-1. Mucosal Immunol 2013;6:1110-8.

[22] Fan D, Coughlin LA, Neubauer MM, Kim J, Kim MS, Zhan X, et al. Activation of HIF-1 $\alpha$ and LL-37 by commensal bacteria inhibits Candida albicans colonization. Nat Med 2015;21:808-14.

[23] Karhausen J, Furuta GT, Tomaszewski JE, Johnson RS, Colgan SP, Haase VH. Epithelial hypoxia-inducible factor-1 is protective in murine experimental colitis. J Clin Invest 2004;114:1098-106.

[24] Morteau O, Morham SG, Sellon R, Dieleman LA, Langenbach R, Smithies $O$, et al. Impaired mucosal defense to acute colonic injury in mice lacking cyclooxygenase-1 or cyclooxygenase-2. J Clin Invest 2000;105:469-78.

[25] Lowe PP, Gyongyosi B, Satishchandran A, Iracheta-Vellve A, Ambade A, Kodys $\mathrm{K}$, et al. Alcohol-related changes in the intestinal microbiome influence neutrophil infiltration, inflammation and steatosis in early alcoholic hepatitis in mice. PLoS One 2017;12:e0174544.

[26] Thomas GH. Ulceration of the colon with enlarged fatty liver. Trans Pathol Soc Philadelphia 1874:4:87.

[27] Lister TD. A specimen of diffuse ulcerative colitis with secondary diffuse hepatitis. Trans Pathol Six London 1899:50:130.

[28] Elsing C. Alcohol binging causes peliosis hepatis during azathioprine therapy in Crohn's disease. World J Gastroenterol 2007;13:4646. 
[29] Gäbele E, Dostert K, Hofmann C, Wiest R, Schölmerich J, Hellerbrand C, et al. DSS induced colitis increases portal LPS levels and enhances hepatic inflammation and fibrogenesis in experimental NASH. J Hepatol 2011;55:1391-9.

[30] Glassner K, Malaty HM, Abraham BP. Epidemiology and Risk Factors of Nonalcoholic Fatty Liver Disease Among Patients with Inflammatory Bowel Disease. Inflamm Bowel Dis 2017;23:998-1003.

[31] Sourianarayanane A, Garg G, Smith TH, Butt MI, Mccullough AJ, Shen B. Risk factors of non-alcoholic fatty liver disease in patients with inflammatory bowel disease $\{2013 ; 7: 279-85$.

[32] Keely S, Campbell EL, Baird AW, Hansbro PM, Shalwitz RA, Kotsakis A, et al. Contribution of epithelial innate immunity to systemic protection afforded by prolyl hydroxylase inhibition in murine colitis. Mucosal Immunol 2014;7:114-23.

[33] Glover LE, Bowers BE, Saeedi B, Ehrentraut SF, Campbell EL, Bayless AJ, et al. Control of creatine metabolism by HIF is an endogenous mechanism of barrier regulation in colitis. Proc Natl Acad Sci U S A 2013;110:19820-5.

[34] Karlsson A, Jägervall A, Pettersson M, Andersson A-K, Gillberg P-G, Melgar S. Dextran sulphate sodium induces acute colitis and alters hepatic function in hamsters. Int Immunopharmacol 2008;8:20-7.

[35] Masubuchi Y, Horie T. ENDOTOXIN-MEDIATED DISTURBANCE OF HEPATIC CYTOCHROME P450 FUNCTION AND DEVELOPMENT OF ENDOTOXIN TOLERANCE IN THE RAT MODEL OF DEXTRAN SULFATE SODIUM-INDUCED EXPERIMENTAL COLITIS. Drug Metab Dispos 2004;32:437-41.

[36] Scott JR, Fox-Robichaud AE. Hepatic leukocyte recruitment in a model of acute colitis. Am J Physiol Gastrointest Liver Physiol 2002;283:G561-6.

[37] Adams DH, Eksteen B. Aberrant homing of mucosal T cells and extraintestinal manifestations of inflammatory bowel disease. Nat Rev Immunol 2006.

[38] ROTH R, HARKEMA J, PESTKA J, GANEY P. Is Exposure to Bacterial Endotoxin a Determinant of Susceptibility to Intoxication from Xenobiotic Agents? Toxicol Appl Pharmacol 1997;147:300-11.

[39] Pulido D, Nogu?s MV, Boix E, Torrent M. Lipopolysaccharide Neutralization by Antimicrobial Peptides: A Gambit in the Innate Host 
Defense Strategy. J Innate Immun 2012;4:327-36.

[40] Larrick JW, Hirata M, Balint RF, Lee J, Zhong J, Wright SC. Human CAP18: a novel antimicrobial lipopolysaccharide-binding protein. Infect Immun 1995;63:1291-7.

[41] Ciornei CD, Sigurdardóttir T, Schmidtchen A, Bodelsson M. Antimicrobial and chemoattractant activity, lipopolysaccharide neutralization, cytotoxicity, and inhibition by serum of analogs of human cathelicidin LL-37. Antimicrob Agents Chemother 2005;49:2845-50. 


\section{LIST OF ABBREVIATIONS}

\begin{tabular}{ll} 
AAH & $\begin{array}{l}\text { acute alcoholic hepatitis } \\
\text { ABx }\end{array}$ \\
AF & alcohol-fed \\
ALD & alcoholic liver disease \\
ALT & alanine aminotransferase \\
AMPs & antimicrobial peptides \\
AST & aspartate aminotransferase \\
CAE & chloracetate esterase \\
CRAMP & Cathelicidin related antimicrobial peptide \\
DMOG & dimethyloxalylglycine \\
DSS & dextran sulfate sodium \\
E. coli & Escherichia coli \\
FFPE & formalin-fixed paraffin embedded \\
GFP & green fluorescent protein \\
hBD-1, 2 & human $\beta$-defensin-1, 2 \\
HDL & high-density lipoprotein cholesterol \\
HIF-1 $\alpha$ & hypoxia inducible factor-1 $\alpha$ \\
IBD & inflammatory bowel diseases \\
ITF & intestinal trefoil factor \\
\hline
\end{tabular}




$\begin{array}{ll}\text { LAL } & \text { Limulus amebocyte lysate } \\ \text { LDL } & \text { low-density lipoprotein cholesterol } \\ \text { LGG } & \text { Lactobacillus rhamnosus GG } \\ \text { LPS } & \text { lipopolysaccharide } \\ \text { MAT } & \text { mesenteric adipose tissue } \\ \text { MDR1 } & \text { multidrug resistance protein-1 } \\ \text { P-gp } & \text { P-glycoprotein } \\ \text { PF } & \text { pair-fed } \\ \text { TJ } & \text { tight junction } \\ \text { TLR4 } & \text { Toll-like receptor 4 } \\ \text { VLDL } & \text { very low-density lipoprotein cholesterol }\end{array}$




\title{
CURRICULUM VITAE
}

\author{
NAME Tuo (Tom) Shao
}

CONTACT 617-981-1009 (cell phone) E-mail tuoshao89@gmail.com

DOB P.R. China----September 23, 1988

EDUCATION

2006-2010 Wuhan Bioengineering Institute

B.S. Pharmacy (2010)

2011-2014 Wenzhou Medical University School of Pharmacy

M.S. Pharmacology (2014)

2014-2017 University of Louisville School of Medicine

Department of pharmacology and Toxicology

Ph.D. Pharmacology and Toxicology (2017)

PROFESSIONAL SOCIETY

Society of Toxicology (SOT)

American Society for Pharmacology and Experimental Therapeutics (ASPET)

Research Society of Alcoholism (RSA)

American Association for the Study of Liver Diseases (AASLD)

HONORS AND AWARDS: 
2013 Outstanding publication of the year, China Licensed Pharmacist Journal

2015 Presidential Poster of Distinction in American Association for the Study of Liver Diseases (AASLD)

2015 Trainee Travel Award for the 18th International Symposium on Cells of the Hepatic Sinusoid (ISCHS)

2017 ASPET Graduate Student Travel Award in Experimental Biology (EB)

2017 Student Merit Award to Research Society on Alcoholism (RSA) annual meeting

\section{NATIONAL MEETING PRESENTATIONS}

Shao T, Craig James McClain, Wenke Feng. DSS-induced intestinal damage exacerbates liver injury by acute alcohol exposure in mice: role of intestinal hypoxia-inducible factor 1 $\alpha$. Research Society of Alcohol (RSA) 2017, Student Merit Award. (Denver, CO, USA, 2017)

Shao T, Craig James McClain, Wenke Feng. DSS-induced intestinal damage exacerbates liver injury by acute alcohol exposure in mice: role of intestinal hypoxia-inducible factor 1a. Experimental Biology (EB) 2017, ASPET Graduate Student Travel Award. (Chicago, IL, USA, 2017)

Shao T, Craig James McClain, Wenke Feng. Intestinal HIF-1a Deletion Exacerbates Alcohol-induced Hepatic Steatosis Mediated by Intestinal Dysbiosis and Barrier Dysfunction. Research Society of Alcohol (RSA) 2016. (New Orleans, LA, USA, 2016)

Shao T, Craig James McClain, Wenke Feng. Intestinal HIF-1a Deletion Exacerbates Alcohol-induced Hepatic Steatosis Mediated by Intestinal Dysbiosis and Barrier Dysfunction. American Association for the Study of Liver Diseases (AASLD), Presidential Poster of Distinction. (San Francisco, CA, USA, 2015)

Shao T, Craig James McClain, Wenke Feng. Intestinal HIF-1a Deletion Exacerbates Alcohol-induced Hepatic Steatosis Mediated by Intestinal Dysbiosis and Barrier Dysfunction. International Symposium on Cells of the Hepatic Sinusoid (ISCHS), Trainee Travel Award. (Asilomar, CA, USA, 2015)

Shao T, Xu Y, O'Donnell JM. Ferulic acid increases pain threshold and ameliorates depression-like behaviors in Reserpine-treated mice: behavioral and neurobiological analyses. Neuroscience Retreat. (Morgantown, WVU, SA, 2013) 
Zhang C, Shao T, Xu Y, O'Donnell JM. Stress induced anxiety- and depressivelike behaviors are associated with the imbalance of redox state: the protective effect of PDE2 inhibitor. Neuroscience 2012. (New Orleans, LA, USA, 2012)

\section{PUBLICATIONS}

Shao T, Craig James McClain, Wenke Feng. DSS-induced intestinal damage exacerbates liver injury by acute alcohol exposure in mice: role of intestinal hypoxia-inducible factor $1 \alpha$. In progress.

Shao T, Liming Liu, Craig James McClain, Wenke Feng. Intestinal HIF-1a Deletion Exacerbates Alcohol-induced Hepatic Steatosis Mediated by Intestinal Dysbiosis and Barrier Dysfunction. Journal of Hepatology. Submitted.

Shao $T^{*}$, Luria V, Ruan $L^{*}$, Pan J, O’Donnell JM, Ying Xu. Cognitive abnormalities and hippocampal alterations in EphB2 knockout mice. Scientific Report. Submitted. ( ${ }^{*} \mathrm{co}-$ first author)

X kong, Y Yang, L Ren, T Shao, F Li, C Zhao, L Liu, H Zhang, C McClain, W Feng. Activation of autophagy attenuates EtOH-LPS-induced hepatic steatosis and injury through MD2 associated TLR4 signaling. Scientific Report. Submitted.

Liu, L.; Zhao, C.; Yang, Y.; Kong, X.; Shao, T.; Ren, L.; Zhuang, X. Fibroblast Growth Factor 21 Deficiency Attenuates Experimental Colitis-Induced Adipose Tissue Lipolysis. Gastroenterol Res Pract. 10.1155/2017/3089378.

Shao T*, Xu ying*, Zhang $L^{*}$, Wang L, Sun J, Li J, Zhu X, O'Donnell JM, Pan J. Ferulic acid increases pain threshold and ameliorates depression-like behaviors in reserpine-treated mice: behavioral and neurobiological analyses. Metab Brain Dis. $2013\left({ }^{*}\right.$ Co-first author)

Ma X, Wang R, Zhao X, Zhang C, Sun J, Li J, Zhang L, Shao T, Ruan L, Chen L, $\mathrm{Xu} \mathrm{Y,} \mathrm{Pan} \mathrm{J.} \mathrm{Antidepressant-like} \mathrm{effect} \mathrm{of} \mathrm{flaxseed} \mathrm{secoisolariciresinol}$ diglycoside in ovariectomized mice subjected to unpredictable chronic stress. Metab Brain Dis. 2013; 28:77-84.

Zhao L, Lin M, Shao T, Pan J. Antidepressant like effect of acute administration with trans-Resveratrol combined with Piperine and the possible mechanism. Chin. J. Pharmacol. Toxicol. 2012; 26: 610-617. 